\title{
Metaphysical detectives and postmodern spaces, or the case of the missing boundaries
}

\author{
Richard A. Swope \\ West Virginia University
}

Follow this and additional works at: https://researchrepository.wvu.edu/etd

\section{Recommended Citation}

Swope, Richard A., "Metaphysical detectives and postmodern spaces, or the case of the missing boundaries" (2001). Graduate Theses, Dissertations, and Problem Reports. 1359.

https://researchrepository.wvu.edu/etd/1359

This Dissertation is protected by copyright and/or related rights. It has been brought to you by the The Research Repository @ WVU with permission from the rights-holder(s). You are free to use this Dissertation in any way that is permitted by the copyright and related rights legislation that applies to your use. For other uses you must obtain permission from the rights-holder(s) directly, unless additional rights are indicated by a Creative Commons license in the record and/ or on the work itself. This Dissertation has been accepted for inclusion in WVU Graduate Theses, Dissertations, and Problem Reports collection by an authorized administrator of The Research Repository @ WVU.

For more information, please contact researchrepository@mail.wvu.edu. 


\title{
Metaphysical Detectives and Postmodern Spaces, or the Case of the Missing Boundaries
}

\author{
Richard A. Swope \\ Dissertation submitted to the \\ College of Arts and Sciences \\ at West Virginia University \\ in Partial Fulfillment of the requirements \\ for the degree of
}

Doctor of Philosophy

in

English/Literature

\author{
Brian McHale, Ph.D., Chair \\ John Lamb, Ph.D. \\ Robert Markley, Ph.D. \\ Susan Shaw Sailor, Ph.D. \\ Paul Krainak, M.F.A. \\ Department of English
}

\author{
Morgantown, West Virginia \\ 2001
}

Keywords: Postmodern American Fiction, Social Space, Theories of Space, Detective Fiction, Postmodern Culture

Copyright 2001 Richard A. Swope 


\section{ABSTRACT \\ Metaphysical Detectives and Postmodern Spaces, or the Case of the Missing Boundaries}

\section{Richard Swope}

Taking as its point of departure Henri Lefebvre's contention that "(Social) space is a (social) product," my dissertation explores the contemporary American novels of Pynchon, Acker, Reed, Auster, DeLillo, and McElroy as well as the two recent films Dark City and The Thirteenth Floor and their dramatization of the production of twentieth-century social space. I approach these works as metaphysical detective stories which evoke the classic detective figure only to frustrate his impulse to solve and contain. Following Foucault's contention that "space is fundamental to any exercise of power," I suggest that the detective figure is significant to an understanding of the history of spatial production in that the detective both relies upon the striating logic of Western science as well as - particularly in his surveillance of the city — perpetuates that logic by rationally ordering the spaces he observes. The metaphysical detective, however, confronts the reconstituted space of postmodern culture, resulting largely from the globalization of capitalism and expanding technologies, which resists former logic-driven methods of delimiting social spaces and subjects in space. Through their appropriation of the classic detective, these metaphysical detective stories embody, then, a competing history of spatial logic that once exposed causes us to rethink the ideology of social space(s) in the West, while also shedding light on the ways in which gender, race, and class are both constructed within and act as formants in the production of space. 


\section{CONTENTS}

Introduction

Chapter 1

Into the Space of Postmodernism: Navigating the Zone in Pynchon's

Gravity's Rainbow

Chapter 2

Supposing an Urban Space: Paul Auster's The New York Trilogy

Chapter 3

In-Between Subjects and In-Between Spaces: The Out of Place Detective in Don DeLillo's The Names and Joseph McElroy's Lookout Cartridge

\section{Chapter 4}

Returning to the Scene of the Crime: The History of Social Space

by Kathy Acker

Chapter 5

Crossing Western Space: Ishmael Reed's Mumbo Jumbo

\section{Chapter 6}

Cinema and the Crime of Social (Spatial) Reality 


\section{Acknowledgments}

This project would not have been possible without the help of those who served on my committee. I am especially thankful to Brian McHale, the committee Chair, for his always useful suggestions as well as his editorial eye. The other members, John Lamb, Susan Sailer, Robert Markley, and Paul Krainak, also contributed greatly. I have benefitted immeasurably from both their positive feedback, which inspired me to continue on with my work, and their critical insights, which pushed my thinking to new limits. I also wish to acknowledge the inspiration and unconditional support I received from my wife Andrea and our son Gavin. They, as much as anyone, made this project happen. 


\section{Introduction}

Prior to his death in 1984, Michel Foucault's "Des Espaces Autres," appearing in English as "Of Other Spaces," made the announcement that the "present epoch will perhaps be above all else the epoch of space" (22). Around the same time, Fredric Jameson similarly suggested that following a "spatial turn" postmodern culture was now "dominated by categories of space rather than by categories of time, as in the preceding period of modernism" (16). Jameson and Foucault are not alone in their attention to space. Almost without exception, those who have attempted to theorize late-twentiethcentury culture-including Foucault and Jameson as well as David Harvey, Michel de Certeau, Edward Soja, and jointly Gilles Deleuze and Felix Guattari— have recognized the need to put space squarely on the agenda.

Despite such widely recognized dialogues on postmodern space, however, scant criticism addresses the contribution of postmodern fiction to this larger discourse on space and spatial practices, at least not at length. ${ }^{1}$ The smattering of critical work that does address this subject generally does not go beyond identifying a spatial dominant within postmodern works. That is to say, while there exists a fair amount of criticism that employs spatial analysis to illuminate individual works of fiction, not much of this work has emphasized the ways in which the fiction itself adds to our understanding of the spaces we imagine, construct, and experience. To fill in this critical gap so to speak, the following study places several examples of postmodernist fiction in dialogue with a variety of theoretical works addressing space and spatial practices, my objective being to explore the history of the production—intellectual as well as material—of Western space(s) through postmodern fiction. To begin this discussion, I have narrowed the playing field by selecting samples from a specific sub-genre within the larger body of what has been labeled postmodern fiction, namely the metaphysical detective story. The metaphysical 
detective story readily lends itself to a discussion of space in postmodern culture for two primary reasons. First, critics have recognized the metaphysical detective as a significant figure within postmodern fiction. Michael Holquist has gone so far as to suggest that what the "presuppositions of myth and depth psychology were to Modernism . . . the detective story is to Post-modernism” (135). Equally important, detective fiction has for some time now been recognized as a genre that is inherently preoccupied with the space(s) inside and around which its characters live and move. One of the fundamental rules of the classic detective story is its strict spatial limitation; the murder generally takes place within an isolated or sealed environment: a hotel, a train, or even a locked room. Tightly restricting the space of the crime serves a dual purpose. First, by limiting the space in which the crime is committed, the classic detective story from its outset narrows the number of possible suspects to those already in or near the scene of the crime, giving both the detective and the reader a legitimate opportunity to solve the mystery. And secondly, the "impossible" space of the locked room, or sealed environment itself provides a mystery that the detective and reader must solve before learning the identity of the murderer or criminal. ${ }^{2}$

The importance of space in the classic detective novel is not confined to sealed environments alone. As both Robin Woods and D.A. Miller have shown, the ideological function of the classic detective was to maintain the separation of ghetto or criminal space(s) and bourgeois space(s). As in the case of such master sleuths as Holmes and Poirot, the detective possesses the rare ability to traverse both worlds, with the sole purpose of protecting the latter, the decriminalized space of the middle class, from the contagion of the former. It is also clear that hard-boiled detective fiction, such as the work of Raymond Chandler and Dashiell Hammet, places equal emphasis on the modernist urban 
spaces its characters inhabit. Ralph Willet argues that the hard-boiled private eye has played a crucial role in our notions of twentieth-century urban space because of his unique construction as the (male) subject who "sees and deciphers the signifiers of that labyrinth of populated spaces and buildings which forms the modern metropolis" (3). In short, the hard-boiled detective shows us the modernist city as we have never seen it before, its criminal element and alienating effects laid bare.

The point that I wish to emphasize here is that in both its nineteenth and twentieth-century versions the detective figure, roaming and observing, dramatizes the quintessential (thinking) subject who both participates in the production of space(s) at the cultural moment in which he lives and is in turn produced by those spaces. As Henri Lefebvre argues, subjects are not constructed through or in language alone; additionally, "all 'subjects' are situated in a space in which they must either recognize themselves or lose themselves" (35). Since becoming a subject involves accepting "a role and a function" which "implies a location, a place in society, a position" (Lefebvre 182-3), subjectivity must be recognized as at least in part spatial in nature. The significance of the detective figure is that his function is to delineate both his own position (space) within the state as well as the position (space) of all subjects since his primary task, accomplished through surveillance, is to restore order, to put everything and everyone back in his, her, or its ideologically designated space. In other words, the detective is the spatial subject par excellence, both in the constitution of his own position as well as that of others, which explains why literary criticism has long connected discussions of space with those of detection. Nonetheless, despite the critical attention to space in both the classic and hard-boiled versions of detective fiction and despite the abundance of recent criticism that attempts to theorize postmodern space, little has been written regarding the function of space in the postmodern version of 
the detective story, ${ }^{3}$ a genre that places the detective figure in spaces that behave radically differently from those Enlightenment or modernist spaces that earlier detectives imagined, investigated, and subsequently solved. My intention is, then, twofold: to extend the spatial analysis of detective fiction to its postmodern version and in the process to illustrate the ways in which the metaphysical detective story writes, or re-writes the history of spatial production in the West and in the process adds to or revises our understanding of how we both imagine, produce, and experience the space of postmodern culture.

\section{The Metaphysical Detective}

Like much of postmodern fiction, metaphysical detective stories appropriate, use and abuse, narratives of the literary past, in this case the conventional detective story. Generally speaking, critics of detective fiction, Holquist among them, trace its origins to Edgar Allan Poe's Chevalier Dupin. Dupin is the original armchair detective, a bastion of logic who during the late nineteenth and early twentieth century becomes popularized in the form of such well-known detectives as Sherlock Holmes or Hercule Poirot. The conventional detective, of course, always solves the crime, restoring order by piecing together a trail of clues. The reason for the detective's success is simple. "The detective, the instrument of pure logic" is always "able to triumph" because he holds to "the belief that the mind, given enough time, can understand everything" (Holquist 141), an assumption the classic detective novel itself reenforces. Roger Caillois explains, "The value of a detective novel can be quite neatly defined by the affront to reason and experience contained in its point of departure, and the more or less complete and believable way that both reason and experience are satisfied by its conclusion" (3). Ultimately, the crime is not so important as "the reduction of the impossible to the possible, of the inexplicable to the 
explained, of the supernatural to the natural" (Caillois 3). The classic detective story, by the close of its pages, leaves no room for mystery.

William Spanos points out that the constitutive logic of the classic detective novel coincides with the ideological presuppositions within which these novels originate: the "problem-solution perspective" so much a part of science and other systems of logic long valued in both Europe and America. This "problem-solution perspective" bases itself on the assumption that the world is knowable, "on a monolithic certainty that immediate psychic or historical experience is part of a comforting, even exciting and suspenseful well-made cosmic drama or novel—more particularly, a detective story" (Spanos 167). Although science conceives of the world as a mystery, it also provides the "comforting certainty that the scientist/psychoanalyst/ social scientist can solve the immediate problem by the inductive method," leading "to an explanation of the 'mystery'" (Spanos 167). Thus, the detective story solves not only the "affront to reason" that emerges within its pages but also functions as a site of ideological containment, reinscribing the positivistic notion that the world-including the spaces that we produce and inhabit—and the self are known or at least knowable.

Spanos recognizes, however, that in the second half of the twentieth century ${ }^{4}$ several postmodernist authors, whose fictions question the very tenets of "knowledge," construct works of detective fiction that no longer insist on solutions but, rather, emphasize a variety of unsolvable mysteries. Appropriating classic detection, such works "evoke the impulse to 'detect' and/or to psychoanalyze in order to violently frustrate it by refusing to solve the crime" (Spanos 171). As Holquist further explains, "the new metaphysical detective story . . . is non-teleological, is not concerned to have a neat ending in which all the questions are answered, and which can therefore be forgotten" 
(153). The questions remain at the end; clues lead not to solutions but rather to other disseminating clues, and finally the "end" fails to create closure. Thus, "instead of familiarity," metaphysical detective stories give "strangeness." "Instead of reassurance, they disturb" (Holquist 153).

While the metaphysical detective story has been contrasted with and differentiated from primarily the classic detective story, it also differs in significant ways from hard-boiled detective fiction, despite the fact that the hard-boiled detective in many ways already disrupts the tidiness of the classic detective story. The hard-boiled detective, such as Chandler's Philip Marlowe, clearly does not embody pure logic in the same way as Dupin. As Willet suggests, the primary difference between the classic detective (Dupin, Poirot, Holmes) and the hard-boiled detective is that while the former is an "aesthete" who observes from a safe distance, the latter "is immersed in events and plays a part in the contingent world of the narrative which writes him as much as, in many instances, he writes it" (10). That is to say, as opposed to the classic detective, the hard-boiled gumshoe is far more likely to physically engage the city space he wanders in search of clues. As a result, the hard-boiled detective often finds it impossible to remove himself from the "corruptive" space of the city and, as a result, is often infected by the contagion himself, meaning the hard-boiled novel does not so fully contain the criminal element as do earlier works of detection. Still, conventional hard-boiled fiction has its generic rules; the initial crime is both solved and solvable by the end of the story—we get the satisfaction of knowing who the murderer is - and the hard-boiled detective maintains the belief in his own ability to solve mysterious crimes at least enough to move on to the next case (hence the serialization of hardboiled fiction). Thus, while works of hard-boiled detection often, at least cryptically, offer a critique of the obsessively tidy logic of classic detection, they still stop short of the truly metaphysical detective 
story which seeks to explode that logic.

Umberto Eco's The Name of the Rose offers one of the best examples of metaphysical detective fiction. In the novel a monk detective, William of Baskerville, along with his sidekick Adso - parodies of Holmes and Watson - attempt to solve a rash of murders taking place within a medieval monastery. Although William does eventually find the murderer, or $a$ murderer, Jorge, this discovery not only fails to provide the epistemological certainty it ought to restore, but actually creates, or more accurately exposes, only more uncertainty. As William himself laments,

I arrived at Jorge through an apocalyptic pattern that seemed to underlie all the crimes and yet it was accidental. I arrived at Jorge seeking one criminal for all the crimes and we discovered that each crime was committed by a different person, or by no one ... Where is my wisdom, then? I behaved stubbornly, pursuing a semblance of order, when I should have known well that there is no order in the universe. (599) Epitomizing the postmodern loss of ontological and epistemological security, William's final showdown of wits with the murderer does not restore order as it would in the classic detective novel, but actually leads to the fiery destruction of the abbey's library, and eventually the entire abbey. McHale points out that in so far as the library's structure is mapped according to the world's geography, William's "solving" the case actually equals the destruction of the world itself (161). Knowing the murderer's identity solves nothing because meanwhile the "world" has essentially fallen out from under the detective, his ontological certainties evaporating. Like all metaphysical detectives, William "finds himself confronting the insoluble mysteries of his own interpretation and his own identity" (Merivale and Sweeney 2). William cannot content himself with knowing who committed the murder, or even why, when meanwhile 
the world, life, grows only more perplexing, when the real crime is now "contingent existence" (Spanos 167).

As will most likely not have gone unnoticed in this example, metaphysical detective stories explore many issues that currently occupy literary theorists, including Eco himself. Patricia Merivale and Susan Sweeney suggest, in fact, that metaphysical detective stories are "inherently linked to literary theory" in that they "explicitly speculate about the workings of language, the structure of narrative, the limitations of genre, the meanings of prior texts, and the nature of reading" (7). I would add to this that they also explicitly speculate on the nature and production of social space.

To understand the significance of the detective story for an attempt to theorize space, we need first to recognize that the detective-like reliance upon ratiocination and the impulse toward totalities manifest themselves concretely in the rationally constructed metropolises of industrial capitalism, the ultimate products of modernity. Facing population growth and unprecedented mobility, resulting largely from the onset of the automobile and other technological advances, modernist planners, still suffering from the impulse to "solve" the world, designed their cities based on the assumption that they might organize space so as to impose order on the growing chaos of social relations and, to use Joyce's words, the "nightmare of history." Thus, the classic detective, armed with his ability to map and contain the scene or space of the crime, (pre)figures the aspirations of the modernist city planner whose belief in the detective-like ability to solve the world produces — or at least imagines — a securely delineated space inside which the social can be placed and controlled. In the metaphysical detective story, however, both the ideology of positivism and the neatly packaged spaces it produces are invoked only to be called into question. That is to say, in the process of launching a full-scale assault on 
Enlightenment consciousness, the metaphysical detective novel re-conceives our notions of premodernist, modernist, and postmodernist spatial logic. The question my project attempts to answer is how exactly does metaphysical detective fiction reconstruct spatial history and logic. In other words, how do works of metaphysical detection theorize, or re-theorize, space as produced in the West? Before answering such questions, we must first clarify what we mean when we speak of "space."

\section{Theorizing Space}

In his seminal work The Production of Space Lefebvre argues, "(Social) space is a (social) product" (26), in the sense that space, or more precisely spaces plural, are produced by a complex set of modes of production, social relations, intellectual or critical practices, and geographical alterations that intersect, overlap, and conflict to form what we know as social space. Social space is produced both by "spatial practices" - the material changes that produce and reproduce specific "places"- as well as by "representations of space"- the knowledge, signs, and codes through which we conceive and perceive space (33). Consequently, one can understand the production of space only within the larger context of the mode or modes of production at a particular cultural moment. As Jameson notes, “for Lefebvre all modes of production are not merely organized spatially but also constitute distinctive modes of the "production of space"" (365). Space itself, then, must be recognized as having a history, which raises the following question: what exactly is the history of spatial production-its manifestations as well as their cultural underpinnings — in the West?

Along with Lefebvre himself, several recent theorists have attempted to answer this question by providing a history of spatial logic and practices. David Harvey, for instance, traces the history of contemporary social space_-which, much indebted to Foucault, he conceives as a social container that 
reenforces power structures through surveillance and incarceration— - to the same Enlightenment consciousness that gave birth to the detective. Harvey explains that because the Enlightenment project, which he calls the "first great surge of modernist thinking" (249), "took the domination of nature as a necessary condition of human emancipation" and because "space is a 'fact' of nature, this meant that the conquest and rational ordering of space became an integral part of the modernizing project" (249). Thus, the Enlightenment created a "new organization of space dedicated to the techniques of social control, surveillance, and repression of the self and the world of desire" (Harvey 213). Delineating a similar spatial history, Lefebvre himself contends that the spatial logic that we are still responding to in the late twentieth century arises out of western science, specifically the fields of mathematics and geography. These disciplines, he claims, have traditionally conceived space as a static, geometric object, separate from time or history, a universal and homogeneous container that precedes and passively receives the social.

In similar fashion, Derek Gregory documents the contribution of geography as a specialized field of science to general conceptions of space. He suggests that the discipline of geography, also a product of the Enlightenment, has traditionally privileged sight as the means through which a distanced observer might gain empirical certainty and control of a given object of enquiry. The geographer operates as the ultimate autonomous subject, a specifically male subject, assuming the ability to intellectually master space and bodies in space, those "objects" around which the geographer constructs clearly marked boundaries. Through what Lefebvre calls the "logic of visualization," geography—along with the other sciences—in this respect perceives space as a rationalizable object. That is to say, space is represented as the stable container inside which the forces of history can be 
played out and even controlled by carefully mapping and, to use the terminology of Deleuze and Guattari, striating space. This, then, is the spatial tradition that modernist planners inherited and used to construct the twentieth-century city, which de Certeau suggests has served "as a totalizing and almost mythical landmark for socioeconomic and political strategies" (95). The modernists were able to believe in their ability to rationally plan and unify space because they both privileged sight and conceived of space as an object over which they had control; from these assumptions it would appear only logical to deduce that built spaces could impose order on the chaos of social relations. ${ }^{5}$ Again, operating under the "logic of visualization," the tradition of spatial practice as it descends from the Enlightenment to the modernists imagines the geographer/planner as a distantiated male subject, capable of gaining a totalizing view of a given space, which means that the conventional geographer as well as the city planner operate under virtually the same assumptions as those of the classic detective, who also seeks a distanced position from which he can survey the case at hand and from which he will enforce the mapping of boundaries and positions in a temporarily disrupted social order.

These traditional conceptions and representations of space have presented a number of inconsistencies or contradictions to which postmodern artists and theorists have reacted, and to which metaphysical detective fiction directly responds. A variety of contemporary critics provide correctives to prior constructions of space by taking as their starting point Lefebvre's contention that space is indeed produced by a network of socio-economic relations, intellectual practices, and critical discourses. One of the ways that space has been made to appear as a rationalizable, controllable object is by portraying it as time or history's polar opposite. Doreen Massey explains, however, that space should not be thought of as separate from time in that space does not actually equal stasis, or the 
absence of time, but, rather, is itself dynamic. Again, we are not speaking here of a singular, universal space, but of spaces plural, including "places" or specific locales. Though places are commonly conceived as stable, bounded areas from or toward which subjects orient themselves, Massey contends that while they are constituted by unique articulations within a larger network of social relations and understandings, places are not bound nor static, nor do they possess a single identity. They are, rather, "porous networks of social relations ... constructed through the specificity of their interaction with other places" (121). Thus, both space as globally conceived as well as places as specifically imagined are produced and reproduced according to the material conditions and modes of production—economic, intellectual, aesthetic, etc...—as they unfold and change form throughout history.

In a second corrective to conventional spatial logic, de Certeau critiques the logic of visualization, particularly its conception of space as a readable (knowable) text. De Certeau theorizes space and spatial logic by first accepting the premise that space is in fact a fully accessible text. He, therefore, starts atop the World Trade Center— “"the most monumental figure of Western urban development" (93)—-looking down upon New York City, figuratively placing himself in the position of the planner or "reader" of urban space. De Certeau's narrative of city space, however, suggests that such a position is not fully tenable in that it overlooks the "migrational city" that "slips into the clear text of the planned city" (93). This is the space of the walker, the pedestrian who both experiences and "enunciates" urban spaces. While the planner organizes an "ensemble of possibilities" which the walker actualizes, the pedestrian will invent other possibilities along the way, paths for which neither the planner's nor the geographer's gaze can account. That is to say, space is neither merely imagined nor 
read, but is also experienced. The textualization of space, therefore, both ignores as well as masks that experienced or lived space, the space of the everyday practices that actually produce a given space. Lefebvre, in fact, argues that "social space can in no way be compared to a blank page upon which a specific message has been inscribed ... Both natural and urban spaces are, if anything, 'overinscribed': everything therein resembles a rough draft, jumbled and self-contradictory" (142). Here again we confront a striking intersection between the classic detective and the planner of urban space, for the detective also, as the metaphysical detective story makes explicit, operates under the assumption that he can read or know the city in full. The classic detective constructs space as a container of clues, a readable text that inevitably leads this master reader to the solution to the crime. The metaphysical detective, however, more in line with Lefebvre's or de Certeau's accounts, finds it impossible to read the city as his predecessors once did; the urban text no longer gives him access to resolutions because if the postmodern city is a text at all, it is a palimpsest, a multilayered site of spatial logic and social relations as they have evolved over time. Inside this urban matrix, the metaphysical detective can no longer locate a spatial or historical position from which to read or rationally organize the scene or space of the crime.

\section{Theorizing Postmodern Space}

As the specific textual examples will show, the detective's confusion is only aggravated by advances in technology since, roughly, World War II, when space began to be "recast: in response to the growth of air transport ...; in response to various new industries . . ; and in response to the expanding role of multinationals" (Lefebvre 351). As Harvey contends, such recent technologicaleconomical shifts have brought us into "an intense phase of time-space compression that has had a 
disorienting and disruptive impact upon political-economic practices, the balance of class power, as well as upon cultural and social life" (284). Disruptive first because technological "advancement," particularly in the area of computers, has according to Lefebvre created the "fetishism of an abstract economics" which "is being transformed into the fetishism of an abstract economic space" (351). And disruptive secondly because while, on the one hand, globally networked technologies promise to insure the homogeneity, or totalization of social space, placing us all inside a vast "world city," on the other hand, they annihilate former spatial boundaries, fragmenting what was once thought of as "place," and in the process expose the constructed nature of those spatial boundaries. These developments have left us with a contradictory space that is both "whole and broken, global and fractured, at one and the same time" (Lefebvre 356).

Furthermore, as Paul Virilio explains, possibly foremost among postmodern technologies, the all-pervasive "screen"- - television, movie, computer-has radically adjusted our concept of space. In our media culture, the simulacrum reigns, making "real-world" space virtually indistinguishable from the pixilated space of the media. Virilio further suggests that there now exists a direct feedback loop between spaces as imagined on the screen and the production of "real-world" built spaces; Hollywood has become a disneyfied, spectral city, reflecting its movies as much as its movies reflect it (390). What this technological influence means for readers of postmodern fiction is that we must remain aware at all times that the texts we engage can have as their referent, simultaneously, both "real-world" spaces — though these are neither stable nor determinate—as well as those same spaces as viewed through one or more screens (keep in mind detective fiction has a long history in film which itself provides a “referent" for postmodern writers and readers). Thomas Pynchon's Gravity's Rainbow 
makes this point explicitly when we as readers discover at the end of the novel that we have been watching a movie all along; we are not in post-war Europe but in a California theater watching the movie of post-war Europe, or we occupy both spaces at once. In short, we must recognize that the spaces we engage in postmodern culture as well as in postmodern fiction are multi-layered and multimediated.

These recent alterations/disruptions to the production of both global and local space have left us scrambling to make sense of space(s) that no longer obey the rules once established by mathematicians and geographers, resulting in the extensive re-conceptualization of space and spatial theory that has now taken a central role in attempts to theorize the postmodern condition in general. Lefebvre's attempt has been instructive because it calls for "a new kind of spatial imagination capable of confronting the past in a new way and reading its less tangible secrets off the template of its spatial structures - body, cosmos, city, as all those marked the more intangible organization of cultural and libidinal economies and linguistic forms" (Jameson 365). Similarly, Foucault has argued that "space is fundamental in any exercise of power"(my emphasis 252), which suggests that theorizing space and its production promises to provide crucial insights into a variety of socio-symbolic registers. Thus, an analysis of spatial practices and representations of space usefully crosses over into current discourses on economics, identity, gender, and race. Most obviously, theories of space provide us with a greater understanding of the cultural logic of capitalism. In fact, Lefebvre suggests that we cannot fully grasp the logic through which capitalism reproduces the conditions of its own production until we come to recognize that capitalism produces very specific spaces, or representations of space in order to insure its own survival. For instance, capitalism mobilizes and segments space to make it exchangeable, as in 
the creation of private property (336-37). Again, in the process, capitalism produces an increasingly abstract space, a space readily malleable and available to capitalism's own needs. Thus, space itself becomes like a commodity in Marx's terms, both concrete and abstract simultaneously. Fittingly, the production of an increasingly abstract space under late capitalism works to mask the material space or the "real geography" that might testify to the consequences of abstraction, such as the uneven development that simultaneously produces both economic centers and poverty stricken ghettos — the fragmented city space through which the detective wanders. Significantly, part of the project to mask "real geography" under late capitalism involves eliding the very connection between the exercise of power and the spaces it produces (abstract spaces have no history), a connection that both postmodern theories of space and postmodern fictions attempt to expose.

Recent feminist critics have also shown the importance of theorizing space to understanding and countering the exercise of patriarchal power. In an attempt to demystify representations of space under patriarchal hegemony, Elizabeth Grosz argues that space as historically conceived has "functioned either to contain women or to obliterate them" (55). Similarly, Massey suggests that limits placed on the mobility of space, the confinement of particular places as bounded and static, has played a role in the limitations placed on the mobility of identity. She contends that while time and history as dynamic, as becoming, has been coded masculine, space has been viewed as static, as being, as absence or lack, all of which are coded feminine (6). Thus, the conception of space as static works to contain both space itself as well as women - most obviously in domestic space. For Massey, then, the deconstruction of notions of place as limited has very real consequences; revealing the mobile quality of spaces/places, her work undermines the boundaries that a patriarchal social structure has attempted to impose upon 
both space and identity.

What this brief discussion of the cross-currents between cultural materialist/feminist theory and spatial analysis ultimately reveals is that since space is crucial to any hegemonic project, attempts to analyze a given system of power must at some point address the production of space under that system. I intend to show that theorizing space in postmodern culture also creates a highly productive discussion involving a variety of topics of theoretical import: economics, gender, race, class, etc ... I offer the metaphysical detective story as a useful springboard for these discussions because it dramatizes, and subverts, the classic detective figure who, as we have seen, so clearly embodies the cultural assumptions that produce the geographer as well as the city planner, that is, a positivistic belief in the ability of the mind to read, interpret, and order the world — spatially and otherwise — through the exercise of pure logic. But while his classic predecessor rationally mastered the space he encountered, the metaphysical detective, try as he might, cannot maintain the distantiated point of observation within an increasingly abstract and complex set of social relations; rather, more like his hard-boiled cousin, he is a street-level walker, reminiscent of de Certeau's pedestrians, who becomes so immersed in urban and other spaces that he can no longer claim knowledge of even his own relative position in the world. Within the figure of the metaphysical detective, then, we discover a competing history of spatial logic within western metaphysics: from the certain logic of Dupin, to the wandering gaze of the modernist private eye, to the decentered subject adrift in the postmodern city.

\section{Stories of Spatial Production}

In the way of specific case studies of metaphysical detection fiction, I devote chapters respectively to Thomas Pynchon's Gravity's Rainbow, Kathy Acker's The Adult Life of Toulouse 
Lautrec by Henri Toulouse Lautrec, Ishmael Reed's Mumbo Jumbo, a joint chapter to Don DeLillo's The Names and Joseph McElroy's Lookout Cartridge, as well as a concluding chapter to two recent films that can be seen roughly as tales of metaphysical detection: Dark City and The Thirteenth Floor. I have chosen these texts not only because they are representative of metaphysical detection fiction but also because each tells its own, unique story ${ }^{6}$-none of which should be taken as the definitive story — of the history of spatial production in the West and cumulatively help us to rethink both the production of space as well as the socio-symbolic registers that both produce that space and are produced within it. I consciously couple these works of fiction with the works of a variety of theorists who address space, or tell their own story, so as to provide a broad understanding of the multiple ways in which we might enter and understand current discourses on the nature of postmodern space.

I begin with Pynchon's Gravity’s Rainbow, in which an amateur detective, Tyrone Slothrop obsessively searches the European countryside at the close of World War II looking for a V-2 missile — the embodiment of among other things the compulsion toward technological "progress" under late capitalism. I argue that by setting the bulk of his novel within the ambiguously defined space, "The Zone," that is produced by the aftermath of World War II, Pynchon dramatizes a crucial historical shift in the our conception and production of space in the West, a shift that propels the characters into the space of postmodern culture. To explicate Pynchon's account of postmodern space, I place his novel in dialogue with both Jameson's now-famous analysis of "postmodern hyperspace” and Deleuze's own tale of postmodern spatial production, which suggests that we have moved from earlier (modernist) "spaces of enclosure" into a "space of control." Gravity's Rainbow adds significantly to these 
theorizations of postmodern space both because it dramatizes the shift from the modernist notion of clearly defined and differentiated spaces to the hyperspace that characterizes postmodernism and more importantly because the novel illuminates both the factors that produce this postmodern space and the social consequences that postmodern space in turn produces.

My second chapter focuses on Paul Auster's The New York Trilogy, which allows us to establish more concretely the relationship between the operating assumptions of the detective and those of the classic mapper of spaces or modernist city planner. In each of Auster's three novels the detective sets out to solve a case that ultimately may not even exist and is eventually replaced by a quest for identity and stability in the postmodern city. Finding themselves navigating ontologically unstable spaces, Auster's detectives not only fail to resolve their respective cases, but lose themselves, their "place" in the world, along the way. While all three detectives begin with the assumption that they inhabit a modernist space that promises to protect, or "home" them, their attempts, reminiscent of de Certeau, to read the cityscape and construct a unified narrative of their respective cases fail, leading these detectives to the stark realization that the spaces inside which they live and move are not the unified wholes nor the transparently readable templates they had presumed. As the title of the first novel, City of Glass, suggests, the postmodern city is characterized by the illusion of transparency but turns out to be a city of reflectivity, of mirrors. Furthermore, Auster's version of New York City also provides a glimpse into the world of those who suffer from the effects of uneven development under late capitalism. Specifically, Auster calls our attention to the homeless, those who perpetually wander the city without a "place." Ironically, at some point in each of the three novels Auster's detectives find themselves literally homeless. Lacking a stable anchoring point in their urban environment, they are 
compelled to continue their attempts to navigate and enunciate a bewildering postmodern city.

DeLillo's The Names and McElroy's Lookout Cartridge jointly further dramatize the loss of "place" in the postmodern world, only at a global scale. The two works call our attention to both city spaces and spaces outside the city, desert or sacred spaces that appear to elude the rational control and logic of the detective, or the geographer. Deprived of homes, the amateur detectives in these two novels, while attempting to solve mysteries involving espionage and global conspiracy, find themselves caught "in-between," inside the transient or perpetually liminal spaces produced by, among other things, high-tech travel.

In chapter four I turn to Kathy Acker's The Adult Life of Henri Toulouse Lautrec by Henri Toulouse Lautrec, which is instructive in that, more so than my other examples, it returns us to the "scene of the crime," so to speak, by setting portions of its repeatedly shifting narrative in the very city in which the classic detective was born, nineteenth-century Paris, and in so doing re-visits the ideological presuppositions out of which the history of Western space has been formed. For her metaphysical detective story, Acker pirates Agatha Christie's Poirot, a figure through whom Acker provides a compelling critique of the classic detective's ideological, male-centered assumptions, and his need to control space to ensure a solution to the crime. Acker's fiction is particularly thought provoking because it interweaves discourses on capitalism, patriarchy, and sexuality within the space of nineteenth-century Paris, a city upon which Acker superimposes various postmodern cities. In the process, her fiction tests the limits of our social spaces, exploring the ruptures, the contested and contradictory sites within social space that patriarchal capitalism prefers to ignore or at best contain.

Ishmael Reed's Mumbo Jumbo inserts issues of race and cultural specificity into our discussion 
of space in ways that the previous texts do not. Placing Reed's work in dialogue with that of Deleuze and Guattari, I explore the ways in which his "HooDoo-detective" novel challenges the "striating" logic of Western science, or the "striated space" that has been conducive to the development of multinational capitalism. Reed accomplishes this in large part by introducing nonWestern intellectual and aesthetic forms and spatial notions into the world of 1930's Harlem, which in his novel symbolizes a contested site marking the "war" between Western empiricism and what Reed has called Neo-Hoo-Doo thought. Or more to the point, Reed's Harlem is a site of contestation between striated space and the "smooth" or "nomadic" space that Western science attempts either to erase or bring under its control.

My final chapter addresses two recent films, Dark City and The Thirteenth Floor, which by borrowing from science-fiction, provide compelling visions of futuristic or virtually mediated spaces within the context of the metaphysical detective story. In both films, the detective protagonist in the process of investigating a murder is forced to confront the limits, both physical and metaphysical, of the space(s) he inhabits as well as the results of attempting to extend spatial limits through technology. These two films contribute to our story of spatial production by exploring, more fully than the novels, both recent technological "advances" through which late capitalism has sought to extend its reign over space as well as the role that futuristic or virtual spaces have played within the "ideological fantasy" that constitutes our present social (spatial) reality.

As we will see, in each of these stories the detective fails because, among other things, he clings to a positivistic world view which would rationalize all space. While scholarship has shown that metaphysical detectives make similar mistakes in their assumptions regarding language and 
identity_erroneously seeing each as fundamentally stable—it has not been nearly as effective in explicating the role that space plays both in the metaphysical detective story as well as in Western social formation. I offer these stories, then, both fictive and theoretical in nature, as something like entry points into a larger discourse on the history of spatial production that begins roughly with the birth of the detective and carries us into postmodernism, or, as Jameson has it, the cultural logic of late capitalism. 


\section{NOTES}

1. There is one exception, that being Brian Jarvis' recently published Postmodern Cartographies. Jarvis claims that the "intention" of his "study is to examine a range of contemporary responses to the [American] land to establish whether there is an essential continuity in the geographical imagination, or, whether postmodern mappings of space constitute a decisive break with previous traditions" (6). However, his readings of specific texts - among them the works of Pynchon and Auster on whom I also focus - arrive at the rather simplistic conclusion that indeed the seeds of geographical imaginings from earlier cultural moments continue to emerge in American postmodern fiction, specifically the tendency to gravitate "towards utopian and dystopian antipodes" (6), an intellectual trend he traces to the puritans. While postmodernism no doubt continues to respond to its literary and cultural predecessors, Jarvis's book fails to recognize the full complexity of the postmodern response to the American tradition of spatial imagination. His reading of Pynchon, for instance, makes it appear that just because Pynchon regularly appropriates Puritan history and logic, this makes Pynchon a prisoner, or even an advocate of that logic. In short, Jarvis fails to recognize the full range of postmodern responses to the western history of spatial logic. As for Jameson and Harvey, though they more thoroughly theorize space, their case studies concentrate primarily on architecture and visual art.

2. Elizabeth Sweeney contends that the locked room or sealed environment is "the device that embodies the very essence of detective fiction" in that its "imagery of enclosure and entrapment, and its reference only to elements within its own finite space ... provides a perfect metaphor for the inherent self-reflexivity of the genre" (1-2). See Sweeney, Elizabeth. "Locked Rooms: Detective Fiction, Narrative Theory, and Self-Reflexivity." The Cunning Craft: Original Essays on Detective Fiction and Contemporary Theory. Eds. Ronald G. Walker and June M. Frazer. Macomb: Western Illinois UP, 1990. 1-14.

3. Given the polysemous nature of the term postmodernism, it is worth noting how exactly I define postmodernism. First, it is important to recognize, as Brian McHale points out, that there "is no postmodernism 'out there' in the world any more than there ever was a Renaissance or a romanticism 'out there.' These are literary-historical fictions, discursive artifacts constructed either by contemporary readers and writers or retrospectively by literary historians" (4). Nonetheless, McHale suggests that these constructions do collectively produce a set of "dominants" for each literary/cultural moment. By "postmodernism," then, I mean roughly the literary/cultural phenomena that rises to the level of a "dominant" in America/Europe during the latter half of the twentieth century. Given that Holquist ascribes such literary significance to the metaphysical detective story and that Jameson has already declared space a dominant of postmodern culture, the following study gets at one dominant through the other so to speak; by focusing on a set of literary artefacts, specifically works of metaphysical detection, I am asking both how these works comment on space, and in turn how they construct postmodern culture. My goal is not simply to establish space or detective fiction as a dominant of postmodernism. Rather, agreeing with Linda Hutcheon that "postmodernism is . . inescapably political" (4). I turn to metaphysical detective fiction as a dramatization of the ideological and political 
assumptions and consequences that underlie and result from postmodern spatial logic.

4. By limiting the discussion to the latter half of the twentieth century, I do not mean to suggest that we cannot locate earlier literary works that qualify as metaphysical detective stories preoccupied with spatial phenomena. In fact, Patricia Merivale argues that Poe's detective stories, the first of their kind, already showed the seeds of metaphysical detective fiction, and certainly his works challenge spatial boundaries in a "postmodern" fashion. Nonetheless, it is only after World War II that literary historians begin to notice the metaphysical detective story rising to the level of a literary dominant, and it is around the same time that cultural theorist recognize (construct) space as crucial to understanding postmodern culture.

5. According to Lefebvre, modernist architects dreamed of "mastering global space by bringing forms, functions, and structures together in accordance with a unitary conception" (125).

6. I take this notion of story telling specifically from Brian McHale who in Constructing Postmodernism suggests that we might "think in terms of 'telling stories' rather than 'doing theory", (4). In this respect, I place these novels, and the stories they tell, in dialogue with what we more commonly think of as theoretical works, and the stories they tell. 


\section{CHAPTER 1}

\section{Into the Space of Postmodernism: Navigating the Zone in Pynchon's Gravity's Rainbow}

My discussion of metaphysical detective narratives begins with Thomas Pynchon's Gravity’s

Rainbow, a novel that dramatizes the transition (which is in effect never complete) in Western spatial logic away from earlier rationalized spaces, the spaces of the detective, to the thoroughly "irrational" hyperspace of postmodernism. As with the other texts I will address, Gravity's Rainbow dramatizes the history of Western space within the context of a metaphysical detective story, a genre which as Douglas Keesey notes becomes in Pynchon's hands a "critique of dominant ideologies ... world politics and the military-industrial complex" (50). The primary narrative revolves around an American soldier, Tyrone Slothrop, who at the close of World War II is transformed into "a hardboiled private eye" who imagines he is "gonna go out all alone and beat the odds" (561). ${ }^{1}$ While the conventional detective's motivation is fairly straightforward, to solve the crime, and generally originates from a single event such as a murder, Slothrop's conversion from GI to amateur P.I. stems from a highly complicated set of circumstances and transactions. Slothrop spends the bulk of the novel searching the war-torn European countryside for an elusive V-2 rocket, Rocket 00000, which is armed with the Schwarzgerat assembly, but it is difficult to say why.

If we wish to fit Slothrop into the paradigm of the classic detective, we might assume that he, like a good detective, is attempting to reestablish order by solving "the murder" so to speak, that is by tracking down and unraveling the mysteries of this piece of military hardware that symbolizes death on a global scale, Slothrop might somehow mend the social fabric that is so clearly torn. The novel, however, does not support our desire for this kind of simple cause-and-effect relationship between the detective and his investigation but, rather, offers other possible motivations, none of which can be fully 
verified as the sole reason that Slothrop remains on the case. For instance, during his search for the Rocket, Slothrop uncovers evidence, itself not fully verifiable, that as a child he underwent conditioning at the hands of chemist Laszlo Jamf which causes him to experience sexual arousal in the presence of a "Mystery Stimulus" named Imipolex G, a polymer that is later used as an "insulation device" in the V-2 rocket. This information might explain why Slothrop, still in London, allegedly experiences erections that directly coordinate with the arrival of incoming rockets (though this does not quite work since only one Rocket, 00000, has actually been outfitted with Imipolex G). It also explains the interest Slothrop attracts from "The White Visitation," a group comprised of scientists and psychoanalysts as well as psychics and psychic researchers who wish to track Slothrop's response to the rockets. More importantly, this information casts new light on Slothrop's role as a detective, indicating that his search for the Rocket, or Imipolex G, is little more than a conditioned response. If true, this means that unlike the classic detective, who appears to operate independently, Slothrop has virtually no control over his search for a resolution —resolution to what we are never quite certain. It also means that we cannot say whether Slothrop operates as a free agent or merely an agent of the system, or even if these are the only two possibilities.

Ultimately, Slothrop's motivations are of little importance because as with other metaphysical detectives, his search comes to nothing. While at times Slothrop does appear to make progress, piecing together "clues" that point to a global conspiracy he seems on the verge of cracking, by the end of the novel he still has "not recorded, tagged, discovered, or liberated a single scrap of A4 hardware" (391). That is to say, he never locates Rocket 00000 , that seminal clue which promises to lead him to some "truth." Even if he were to track down the elusive Rocket, such a discovery would not 
necessarily grant him what he desires, whatever that may be, nor would it necessarily create the closure we as readers may desire, for the text itself surmises that the "the Schwarzgerät is no Grail" (364). Yet Slothrop continues his search, finding himself engaged in a mystery in which "the search will rule" not the solution (525), that is until the case eventually breaks down entirely and Slothrop becomes a "Scuffling" nomad unable to concentrate on even the initial purpose for his movement.

In the same passage in which Slothrop dubs himself a "hardboiled private eye," we find that while one minute Slothrop is piecing together clues, "if I can find the S-Gerat 'n' how Jamf was hooked in, if I can find that out, yeah yeah Imipolex now" (561), the next minute, unable to maintain his focus, Slothrop is breaking into song, trading in serious detective work for "mindless pleasures" (the novel's original title). Lacking a clear objective, Slothrop's entropic quest loses steam before it even gets started, making him a wanderer more than a quester. In part, Slothrop's failure to concentrate stems from the fact that "the case" keeps multiplying, ramifying in new directions, so much so that attempts on Slothrop's part to use detective logic reveal only that the case itself has grown beyond the reaches of ratiocination. And it is not only the case that disperses in all directions, the detective himself also begins "to thin, to scatter" (509). For this postmodern detective it is not only impossible to join those "bits and pieces" together to form a harmonious picture; it is not even possible to remain intact as a subject.

In this respect Pynchon's appropriation of the detective genre turns into a critique of classic detective logic. As Douglas Keesey suggests, by creating a detective whose "sleuthing after Imipolex G is not self-determined," Pynchon "exposes the traditional detective as an agent of the System" as one who is “ideologically motivated" (50-51). Pynchon's novel makes this critique explicit by suggesting 
that "capitalist expression" takes the form of "pornographies." Notably, these pornographies include "pornographies of deduction—ahh, that sigh when we guess the murderer —all these novels, these films and songs that lull us with, they're approaches, more comfortable and less so, to that Absolute Comfort .. . The self-induced orgasm" (155). Gravity's Rainbow, thus, likens the detective's mastery of logic, that which maintains ideological comfort, to mere masturbation. While as Ralph Willett suggests, the classic detective figure works "to control . . unrestrained desire — through objective techniques of surveillance, tracking (mapping the city) and deduction" (134), Slothrop cannot even control his own desires: "Looks like there are sub-Slothrop needs They know about . . . but now there's also the even more annoying question, What do I need that badly?" (490). As a metaphysical detective, Slothrop comes to the disturbing realization that he cannot even cognitively apprehend —control, maintain, etc... - the driving forces behind his quest for truth, making him little more than the agent of a system that also eludes his attempts to rationally map or order it.

\section{Transitions in Space}

Slothrop's inability to solve the case, to locate the Rocket or map a conspiratorial pattern, results in part from a failure to contain, cognitively as well as physically, the rationalized space upon which the classic detective depends. This loss of spatial control signals more than Slothrop's, or the detective's undoing; rather, through Slothrop, Pynchon alerts us to a transitional phase in spatial production - in how space is imagined, represented, and practiced — in the West following World War II, a transition that Gilles Deleuze attributes to "a generalized crisis in relation to all the environments of enclosure" ( 309). Deleuze explains,

Foucault located the disciplinary societies in the eighteenth and nineteenth centuries; they reach 
their height at the outset of the twentieth. They initiate the organization of vast spaces of enclosure. The individual never ceases passing from one closed environment to another, each having its own laws: first, the family; then the school ... then the factory; from time to time the hospital; possibly the prison, the pre-eminent instance of the enclosed environment. (309) What Deleuze does not point out explicitly here is that these disciplinary societies, and the enclosed spaces they produce, result directly from the science-based disciplines, including geography, that enjoy an ideologically privileged position at the time. As I point out in my introduction, these are the same disciplines out of which the detective figure is born. Since the classic detective figure emerges at the height of the reign of the disciplinary society, we can conclude that the detective is both a producer of and is produced by the closed systems Deleuze aligns with earlier historic periods. In fact, without enclosures, as Slothrop's failure indicates, it becomes increasingly difficult for the detective to control the crime(s) he labors to solve. From Deleuze we can assert, then, that the crisis in detective logic as seen in postmodern fiction arises in part from a larger "crisis in relation to all the environments of enclosure."

According to Deleuze, this general crisis regarding enclosure has helped bring about a "mutation of capitalism" which has in turn produced "societies of control" $(311,309)$. He explains, "Enclosures are moulds, distinct castings, but controls are a modulation, like a self-deforming cast that will continuously change from one moment to the other, or like a sieve whose mesh will transmute from point to point" (310). Because of their lack of permanent boundaries or chains of command, societies of control are striking in part because it is no longer clear who or what is in control. Deleuze suggests that the difference between the two forms can be summed up within the shift from factories to 
corporations. He explains that "nineteenth-century capitalism is a capitalism of concentration, for production and for property. It therefore erects the factory as a space of enclosure, the capitalist being the owner of the means of production but also, progressively, the owner of other spaces conceived through analogy (the worker's familial house, the school)" (311). But while the factory imagined itself as "a body that contained its internal forces ... the corporation is a spirit, a gas" (310), a seemingly boundless institution characterized by ongoing "erosions of frontiers" (312). Inside this newly arising space, the individual is placed "in orbit, in a continuous network" (311), to which there is neither center nor outside. Again, the controlling forces remain shrouded in mystery or at least too multifarious to locate.

It is important to note that while Deleuze suggests that we have moved from the domination of one cultural form to another, this should not be taken as an assertion of a definitive separating moment between two distinct spatial regimes. Rather, like Lefebvre who argues that we ought to think of spatial production in terms of "transition[s]" rather than "well-defined period[s]" (408), Deleuze stresses that just as earlier shifts in cultural production "took place over time," we have not so much experienced once and for all a shift out of spaces of enclosure but "are [still] in a generalized crisis" (309). This is an important distinction because to suggest otherwise, to enforce well-defined periodization, is to work against Gravity's Rainbow's own rejection of such compartmentalized versions of history. In Pynchon's novel, the characters who opt for strict temporal categories are generally associated with The White Visitation. One of its scientist members explicitly argues that history can be broken down into "nodes, critical points" that can be precisely located and separated out from the everyday moments that precede and follow (451). Here the novel implicitly invites to the reader to accept the primary 
historical moment upon which the book itself focuses, the days following the war, as one of those "critical points." The narrator, however, counters this "critical points" theory by suggesting that history is "at best a conspiracy ... to defraud" (164), not an extraction and compilation of crucial moments that once existed in "real" time and space, but rather an after-the-fact, ideologically inflected construction. History's “critical points” are not so much recuperated as they are invented. Consequently, attempts to locate a single, profound moment in the shift from a spatial regime of enclosure to one of vague control are apt to culminate in the re-assertion of one of those well-mapped constructions designed both to simplify history and to use it to ideological ends. The question is how do we discuss a transition between dominant spatial forms without falling into the trap of strict periodization.

I would suggest that we ought to follow Pynchon's lead. To avoid compartmentalizing history, Gravity's Rainbow continually interweaves its presumed present moment, the close of WWII, with multiple other moments, both past and future, so much so as to seriously impair the notion of defining the beginning or end of any "period" - the novel provides not too few originating or dividing points but too many. In this spirit, in referencing Deleuze's delineation of two separate spatial regimes, I do so with the understanding that these forms and their cultural logic are not exclusive to a singular moment in time. We can certainly locate traces of "control" prior to World War II, just as we can still locate the residue of enclosure within the time of the corporation's dominance (some have even suggested that the highly-complex corporate network distracts us from the existence of sites of production, those factories that continue to run on clockwork). To read Gravity's Rainbow as an account of a transitional phase in spatial production, from enclosure to control, is not then to ignore the complex set of (multi-causal) 
relations that both construct cultural dominants and produce transitions or crises in cultural production, nor is it to attempt to construct strictly defined beginnings and endings to these modes of production of space. Rather than as fixed forms, we ought to conceive of the ideologically dominant spaces we confront in Pynchon's novel as spaces in transit, in the process of becoming both physically as well as in the way they are imagined and represented.

\section{Enclosed Encounters}

It strikes me that Deleuze's spatial analysis provides a vocabulary that fittingly describes the kind of spatial mutations we confront in Gravity's Rainbow, a novel that begins clearly inside spaces of enclosure which lie on the verge of mutation. In the early portions of the text, Slothrop and the other characters move within labyrinth-like spaces of confinement. The primary physical space connected to Slothrop is his work cubicle, where he spends most of his time. Not only do cubicles attach together to form maze-like structures, but London itself has become a cubicle city of sorts: "There must be cubicles like this [Slothrop's] all over the ETO [European Theater of Operations]" (18), creating an interlinking maze that extends across the city and beyond. For Slothrop, this boxed-in space "begins to feel more and more like a trap" (114), and, unfortunately, greater London offers him little relief, with its "narrow street[s]" and "ancient brick walls" (114) that also form a labyrinth of sorts.

While the labyrinth is often invoked as a symbol of postmodernism, suggesting something other than strict enclosure, Umberto Eco has defined three distinct types of labyrinths, the first two of which are representative of spatial practices that pre-date the postmodern era: "The first, the classical one, was linear." This is the labyrinth with a center, where the Minotaur lurks, and a way out. Eco argues that in "this kind of labyrinth ... one cannot get lost" (80). The second type is a maze. "A maze 
displays choices between alternative paths, and some of the paths are dead ends. In a maze one can make mistakes" (81). In the maze, an Ariadne's thread may be necessary to find one's way "out," but there is still at least the potential for an exit. This is not the case with the third type of labyrinth, which Eco suggests is a "net." He explains, "The main feature of a net is that every point can be connected with every other point, and, where the connections are not yet designed, they are, however, conceivable and designable. A net is an unlimited territory" (81). To help us imagine this net Eco borrows Deleuze and Guattari's metaphor of the rhizome, "a tangle of bulbs and tubers" (81). Radically different from its predecessors, the rhizomatic net has neither borders, centers, nor exits. These distinctions are important because while Slothrop will eventually work his way into the space of the postmodern net, this is not necessarily the space inside of which he begins. At the very least he imagines that he is still inside a maze, which despite its tricks does provide an exit. As the opening page of the novel tells us, this is a "progressive knotting into" (3), meaning that while Slothrop, an allegorical figure for the postmodern subject, does eventually become fully entangled in a postmodern network and its forces of control, his search for the rocket starts inside a modernist space, a space of enclosure, which however alienating still operates under the assumption that a unified subject might follow its paths to freedom or to some central truth.

Consistent with a regime of enclosure, Slothrop does actually move "outside" the initial confined space of his cubicle or his barracks, but only to be ushered into another enclosed environment. From his workplace Slothrop is taken to St. Veronica's hospital, where he falls into the hands of Ned Pointsman of The White Visitation. To Pointsman, Slothrop is useful only as a lab rat running the maze to find the cheese, or the Rocket in this case. Pointsman even suggests that one might see the "war 
itself as a laboratory"(49), as an observable maze in which Slothrop can be loosed and examined. In an ironic twist, the work space of The White Visitation also turns out to be labyrinthine in nature. As Webley Silvernail realizes, from a "German camera-angle," "this lab here is also a maze, i'n't it now . . behaviorists run these aisles of tables and consoles just like rats 'n' mice" (49). The question remains, though, "who watches from above, and notes their response" (49). The image of The White Visitation's offices as a maze is further evoked by Brigadier Pudding's nightly masochistic journeys to Katje. To reach her, "Old Pudding must negotiate half a dozen offices or anterooms before reaching his destination" (231). The hospital, then, is characterized by "interiors," spaces in which these scientists, men of discipline, contain and study their subjects. In the minds of these cause-and-effect men, all spaces are either already enclosed or readily enclosable, an assumption that fails to account for the fact that the "War has been reconfiguring time and space" (257), placing spaces of enclosure in crisis along with the disciplines that produce such spaces.

While the early portions of the narrative highlight spaces of enclosure, as Brigadier Pudding's disorientation reflects, those spaces and their underlying logic are indeed under attack. An aging soldier, Pudding "was brought up to believe in a literal Chain of Command, as clergymen of earlier centuries believed in the Chain of Being" (77). Pudding believes in a linear structure in which orders move down through clearly defined spaces, just as individuals (potentially) move up through those same strictly ranked spaces. At the close of the WWII, however, Pudding finds that he has been "set down in a new space ... of the War-state itself, its very structure" (76 my emphasis). Pudding is especially troubled by the growing number of departments or "areas of the War": "Who can find his way about this lush maze of initials, arrows solid and dotted, boxes big and small, names printed and memorized?" 
(76). These "newer geometries confuse" Pudding to the point of despair (77). Of course, Pudding's crisis is not his alone, but rather symbolizes the crisis of the modernist subject crossing the threshold that leads from the space of enclosures to that more thoroughly postmodernist space of netted control in which clearly marked boundaries begin to collapse.

The crisis regarding spaces of enclosure is further indicated by the map of London that hangs beside Slothrop's desk, a map he uses to chart his sexual escapades. In a striking mixture of the desire for conquest and cartography, for each woman, Slothrop places a star on his map at the location where the encounter supposedly took place. And it just so happens that each star coordinates exactly with the London sites on which the rockets have fallen, each of Slothrop's dates directly preceding each rocket strike. At first glance, the congruence between Slothrop's map and the incoming rockets seems to suggest the ability, however uncanny, on Slothrop's part, as well as on the part of the scientists studying Slothrop, to establish a pattern which in turn could help them unravel the mysteries of the Rocket. In this case, Slothrop's map would reenforce the conception of space under which the classic and hardboiled detective operates, where the detective can "map" criminal activities or clues in order to "close in" on the guilty party. Slothrop's map, however, ultimately provides a critique of such assumptions, not only because it aligns "pornographies of deduction" with the act of cartography, but moreover because, as we later discover Slothrop's map is based more in the fantastic than in the "real." Thanks to the sleuthing of a pair of professional "gumshoes," Speed and Perdoo-who while the novel's only "official" detectives, are almost as easily distracted as is their amateur counterpart Slothrop—Pointsman and the other scientists learn that the "names on Slothrop's map do not appear to have counterparts in the body" (272). Of course, if the women do not physically exist then Slothrop's map, and the space it 
assumes, that is the linear, rationally structured space of enclosure, undergo serious ontological destabilization. Once the map is thrown into question, the spaces it purportedly marks, or, at least in terms of perception, encloses, become themselves destabilized, or ripe for reconfiguration. What better metaphor for this reconfiguration than the result of the rockets themselves, those holes left in the once ordered and "enclosed" cityscape which is being physically deconstructed.

Gravity's Rainbow records a crisis not only for the modernist space of enclosure, but also for the disciplines that produce an enclosed space. Pynchon suggests this in part by highlighting several disagreements among the scientists of The White Visitation, whose attempts to empirically verify causeand-effect fail time and again. The severity of the crisis regarding the disciplines is made even more apparent by the decision of the scientists to set Slothrop loose from the restrictive space of their laboratory. If they were not feeling the pressure of new forces, there is no reason that they could not continue to rely on old means — analyzing Slothrop inside the tightly regulated space of the hospital—yet they do not keep him inside this space, but rather release him into the very space that is being most radically reconstructed by the war, that being “The Zone.” Rózsavölgyi suggests that giving Slothrop the illusion of freedom will allow them to perform a new kind of test, a " projective' test." "The ba-sic theory is, that when given an unstruc-tured stimulus, some shape-less blob of exper-ience, the subject, will seek to impose, struc-ture on it" (81). More specifically, they will allow Slothrop to experience the unstructured European countryside in order to observe just what kind of structure he will impose on that experience. In their minds, however, they will still be "in control" (82), war-torn Europe acting simply as a larger laboratory/maze inside which they can inspect the behavior of their rat. But while Pointsman and the others assume that even after his "release" Slothrop will remain under their watchful 
eye, this move on their part places their study of Slothrop at great risk, a risk that reflects an attempt to reestablish the hegemony of the disciplines which are facing a significant crisis that comes hand-in-hand with the war's reconfiguration of space and time.

While the decision to loose Slothrop is undoubtedly, at least in part, the product of a larger crisis regarding spaces of enclosure, The White Visitation's men of science, along with the majority of the characters in the novel including Slothrop, should not be seen as fully cognizant of this spatial transition. Again, in the minds of the scientists, all spaces are either already enclosed or readily enclosable. Furthermore, Slothrop himself, thinking like a good detective, begins his surveillance of the European countryside with a similarly rationalized notion of spatial structures, namely that they are readily containable both cognitively and physically. Such assumptions, however, fail to account for the war's effect on spatial production. That is to say, they fail to recognize the nature of the "The Zone," the demilitarized and uniquely deterritorialized space of post-war Germany. It is inside the Zone that we witness a full-fledged reconfiguration of spaces of enclosure as they give way to a far more nebulous spatiality, the modulating space of control.

\section{Enter The Zone}

After a brief stay at the Casino Hermann Goering, where Slothrop begins to undergo significant alterations to his identity, he escapes (or is purposefully let loose) to Nice, where he suddenly realizes "that this is his first day Outside"(256), freed from the clinical enclosure that previously dictated his movements. For this instant, it appears that Slothrop will finally enjoy a space of true freedom, but as he muses further-“"His first free morning. . Free? What's Free?" — it becomes apparent that he has not so much found freedom as he has wandered into a different kind of spatial structure than that with 
which he has previously been familiar, a predicament heightened by Slothrop's arrival in the confounding space of the Zone. Slothrop first learns of the anomalous nature of the Zone from an Argentine anarchist by the name of Francisco Squalidozzi who narrates the history of Argentina in terms of closed and opened spaces. He explains to Slothrop, in "the days of the gauchos, my country was a blank piece of paper" (264). Argentinians had since become "obsessed with building labyrinths, where before there was open plain and sky. To draw ever more complex patterns on the blank sheet. We cannot abide that openness: it is terror to us" (264). In an attempt to counter this reflex, Squalidozzi has been seeking a truly open space, which explains his fascination with the Zone. As he explains, "In ordinary times ... the center always wins ... Decentralizing, back toward anarchism, needs extraordinary times ... this war-this incredible War-just for the moment has wiped out the proliferation of little states that's prevailed in Germany for a thousand years. Wiped it clean. Opened it” (264-65). This small window in history offers Squalidozzi, and Pynchon, an open space that potentially counters the enclosures that we see earlier in the novel. Despite the attractiveness of Squalidozzi's political vision, as far as Slothrop (a product of spaces of enclosure) is concerned, the idea of openness creates a good deal of discomfort. He suggests to Squalidozzi that "bobwire" is somehow "progress," and he assumes that the only thing the anarchists could do with the land is "try to hold it" (264-65). Squalidozzi corrects Slothrop, "No. Taking land is building more fences. We want to leave it open. We want it to grow, to change. In the openness of the German Zone, our hope is limitless" (265); to this he adds, "So is our danger" (265).

Through Squalidozzi's vision of the Zone, then, Pynchon allows us to imagine a space that transcends societies of enclosure, a space that finally breaks the "mold" so to speak. But while 
Squalidozzi suggests that this new space will collapse boundaries, he certainly does not imagine this as a space of control, even of vague control as Deleuze indicates, nor does the Zone appear as such when we first confront it along with Slothrop. Once in the Zone, Slothrop discovers that indeed "the borders fall away" as the "Zone envelops him" (281). As Rózsavölgyi seems to have predicted, Slothrop cannot fully conceive that such a space actually exists and, therefore, does continue to "impose structure on it." Envisioning the Zone as already compartmentalized, Slothrop asks Geli Tripping if Swinemünde is not in the Soviet zone. She instructs him, "Forget frontiers now. Forget subdivisions. There aren't any" (294), implying that this space is truly free of enclosures. Later, while flying over the Zone in a hot-air balloon, he mentions to Schnorp that they are flying into the Russian zone. Schnorp also corrects Slothrop, echoing Geli, "There are no zones . . No zones but the Zone” (333). Slothrop's experience in the Zone, at least initially, corroborates these notions of openness, as if no new regime were replacing that of enclosure. At one point during Slothrop's travels through a series of fenceless heaths and meadows, the text likens the Zonal countryside to the sea: "This morning it looks like what the Vikings must have seen, sailing this great water-meadow south, clear to Byzantium. All Eastern Europe their open sea: the farmland rolls gray and green as waves . . ponds and lakes seem to have no clear boundaries" (549). By using the sea as a metaphor for the Zone, the novel not only suggests that this is a space devoid of organizing structure, an anti-enclosure, but also implies that this is a space that resists the construction of future structures or maps, for how is one to mold or chart a space in constant flux? And the Zone opens up more than just the physical land. Immediately following the sea metaphor, we are told, “The Nationalities are on the move. It is a great frontierless streaming out here"(549). All barriers and markers, national and otherwise, have come crashing down with the 
end of the war.

While the Zone is obviously characterized by a spatial shift away from spaces of enclosure, it is not, however, free from the residue of the preceding regime. Soon after Slothrop's entrance into the “openness" of the Zone, Slothrop's investigation leads him to one of the archetypal spaces of enclosure mentioned by Deleuze. Specifically, Slothrop visits the Mittlewerke, a former rocket factory that lies in the heart of the Raketen-Stadt, or Rocket-City. This well-defined factory space is, of course, strikingly out of place when positioned within the decompartmentalized space of the Zone. Once inside this structure it is "hard . . . to live in the present for very long," for this is a site haunted by the assemblage of the rocket, by "knuckles . . bloodied against grinding wheels, pores, creases and quicks ... stabbed by the fine splinters of steel" (303). To put it another way, this former factory is haunted by the means of production that accompanied spaces of enclosure. No wonder Slothrop feels encouraged that he might find the "clue" he is looking for in this very place, for in its former state as a closed system of efficient production, this factory space would certainly have supported such detective logic. Reflective of new modes of production, the Mittlewerke, has, however, been converted into a tourist site, a service-oriented space indicative of a transition from industrial capitalism, or what Jameson terms monopoly capitalism, to late capitalism. While the existence of a residual space, a space in the process of conversion, within the Zone reflects the radical spatial crisis that Western culture at large is experiencing, at this point in the narrative we remain at best on the threshold between two different forms of spatial production. Given his detective-like desire to remain in the more clearly defined spaces of enclosure and the fact that this one-time space of enclosure is now being transformed, it is not surprising that Slothrop gets lost in the tunnels—while being chased by Major Marvy. Nonetheless, 
Slothrop is able to exit the Mittlewerk relatively unscathed due to the help of a former employee of the factory, his Ariadne's thread. Inside the Mittlewerke, then, we recognize that a transition is indeed underway that will spawn a new space within the Zone, but we also come to realize that this new space is only just emerging.

The example of the Mittlewerke reminds us that while the end of the war has meant the deterritorialization of the Zone, this does not necessarily mean that this space is as truly open as the anarchists might hope, but neither does this mean that the old spaces of enclosure will simply be reinstantiated. Rather, the open/closed binary is quickly replaced by another spatial form altogether. Using the railroad as metaphor, the narrator suggests that the track, which in a society of enclosure runs from point to point, has not simply been removed, but rather, the "track runs in different networks now. What appears to be destruction is really the shaping of railroad spaces to other purposes, intentions he [Slothrop] can only, riding through it for the first time, begin to feel the leading edges of . . " (257). Thus, what appears at first glance to be deterritorialization is in fact reterritorialization by new forces to new purposes, creating new spatialities. In his reading of Gravity's Rainbow, which focuses on mapping the postmodern, José Liste Noya suggests that while 'the Zone, that eminently 'unmappable' site" (515), promises a certain freedom from conventional cartography it also "includes its negated other, the map, by pluralizing and disseminating it" (528). Similarly, while the Zone promises openness, the disappearance of the territorializing structures, Slothrop discovers that it also includes its "negated other" as well. That is to say, the Zone is not complicated solely by the existence of maps, as Noya suggests, but also by its inclusion of physical and imagined spatial networks that have not been fully eradicated by its openness. As Kathryn Hume points out, in the novel such networks are commonly 
represented by among other things grids, circuits, railroad tracks, underground networks, as well as various "labyrinthine cityscapes" (629). Yet just as the maps included in the Zone are not the maps of conventional cartography, the crux of Noya's argument, the new "railroad spaces" that we find in the Zone do not portend the reestablishment of a dis-empowered spatial regime, that of enclosure. Rather, the Zone produces a new set of tracks, "shining steel roads ... crisscrossing and peeling off to all parts of the Zone" (572), that now ramify into the modulating networks more indicative of a space of vague control.

One of Pynchon's primary examples of these new networks is the grid, both fantastical and literal, which crops up throughout the Zone. The implications of the grid are most clear in "The Story of Byron the Bulb." Byron is just one bulb, one point, in the all-controlling "Grid" through which "messages" are transmitted. The Grid, or the circuit for electricity flow, ultimately links Byron to "other kinds of electric appliances, in homes, in factories and out in the street' (654). Reminiscent of Eco's rhizomatic net, the Grid we are told is "wide open" (655), accommodating multidirectional flows. Like Eco's net, the Grid is not limited to any one building, nor does it have a clearly identifiable center. And whereas in the net "every node can be connected with every other node" (Eco 82), similarly, one could eventually link into Byron from any of the other points on the Grid. Furthermore, the text links this Grid to the omnipresent "they-systems" that emerge throughout the novel, making the Grid part of a larger "pattern" that Byron comes to fear. As with the rhizome, we cannot locate an "outside" to the Grid. Under the regime of enclosure, an outside, at least to each individual structure, would be fully conceivable, for it is a discernibly closed system. The Grid, however, no longer operates under such a regime, but rather produces new networks through which neo-imperialism as well as neo-capitalism 
might express itself.

The Grid and the railroad tracks are not the only structures in the Zone that signal to us that we have entered a transitional phase concerning the production of space. The Zone's cityscapes, destabilized by the war's reconfiguring of physical space, also reflect this shift. For instance, when Slothrop enters Berlin, he quickly recognizes that the war machinery has transformed much of the formerly enclosed streets into "open spaces" (367). Berlin, a city that once represented order and structure, has been violently exploded: "The straight-ruled boulevards built to be marched along are now winding pathways through the waste-piles ... Smooth facets of buildings have given way to cobbly insides of concrete blasted apart" (373). In place of the rationally organized space of the city inside which the detective could comfortably operate, we now find a Berlin that "proves to be full of ... tricks" (368). Gravity's Rainbow further describes Berlin as "an inverse mapping of the white and geometric capital before the destruction," where "everything's been turned inside out" (373). The war has not merely opened Berlin's "straight-ruled" streets, it has in fact called the very notion of inside and outside into question, and with it the entire ideological fantasy that supports the social reality of enclosure.

Gravity's Rainbow further questions the idea of inside/outside, of structural permanence and order, by introducing us to cities of the Zone that lie in the realm of the fantastic. Inside one of these fantasized cities, apparently from Slothrop's subconscious, Slothrop and the Floundering Four search for the Radiant Hour, a quest that leads them deeper into the Rocket-Capital: "Travel here gets complicated—a system of buildings that move, by right angles, along the grooves of the RaketenStadt's street grid" (674). Like Eco's rhizomatic net, where "the structure changes through time" (83), 
in this fantasized space, or hyper-space, the city not only changes shape, but does so at a hyper-speed symptomatic of Deleuze's spaces of control, which, again, "are a modulation, like a self-deforming cast that will continuously change from one moment to the other." The contrast between pre-war Berlin and the Rocket City reflects, then, a shift from stabile enclosures, "straight-ruled" streets designed for a highly visible fascist regime founded on discipline (space inside which the detective could effectively map out his case), to vague, fluctuating spatialities of control (which the detective can no longer rationally organize). It is also inside Slothrop's fantasized city that the open/closed binary problematized in Pynchon's description of post-war Berlin is fully deconstructed. Earlier in the novel Pointsman himself asks, "Could Outside and Inside be part of the same field?" (144). We receive at least a tentative answer when Slothrop, inside his fantasized Rocket-Capital, discovers "Outside and Inside interpiercing one another too fast, too finely labyrinthine, for either category to have much hegemony anymore" (681). The loss of such distinctions introduces our detective into a cultural logic that no longer produces distinct boundaries or orderly boulevards along which he might rationally pursue and end his search. In fact, the detective can no longer tell if he is inside or outside the case; such categories have collapsed. 


\section{The Subject in Hyperspace or, No Body is Safe}

One of the distinctive traits of societies of control, as Deleuze describes them, is that the controlling elements are not as visible as within societies of discipline. In societies of discipline the family, the school, the factory are all distinctly bounded power structures that make overt attempts to define the subject. This is not the case under the regime of control, in which the subject confronts a far more nebulous social order. In short, the control must always remain elusive, or in effect unmappable. This explains the uncertainty surrounding Slothrop's freedom as a subject. As I mentioned, once The White Visitation turns Slothrop loose it is never fully clear if he remains inside a tightly monitored structure or if he simply wanders the countryside aimlessly. While at times Slothrop appears free, he is repeatedly confronted with the possibility that he is not, and may never be "outside" at all, for as a member of the Zurich underground suggests, "There must be a pattern you're in right now" (257). He is left, as are we, to wonder whether Slothrop is not still being watched, if he does not still travel a closed system. On the one hand, "all in his life of what has looked free or random, is discovered to've been under some control, all the time" (209). On the other hand, Enzian insists that Slothrop has become a "free agent," and the anarchists posit that once inside the Zone, Slothrop can find a truly open space. Slothrop's experience does not, however, validate this conclusion, for just when Slothrop appears most free, to be most clearly acting on his own, it turns out that he is actually being lured into an intricate trap. Ultimately, it is not clear if Slothrop is "inside" or "outside" of a pattern, or even if those are the only two options. Again, categories have collapsed, leaving only something like a liminal space, a threshold that is not definitively "inside" or "outside." In fact there might not even be a forward or backward. For Slothrop, there is certainly no return: "But nowadays, some kind of space 
he cannot go against has opened behind him, bridges that might have led back are down now for good" (490). Similarly, Enzian, at least momentarily, loses his ability to maneuver: "What is turn? Don't know which way to begin to move ... don't know how to move" (524). In the space of vague control, then, Slothrop and the others lose the ability to grasp their own present position: inside? outside? trapped? free?

Despite Squalidozzi's vision regarding the openness of the space of the Zone, as we have seen that space is being re-colonized at a rapid pace, making Slothrop's hopes of freedom, for an outside to these new borderless spatialities laughable. Springer literally laughs at Slothrop's request for a "discharge," an exit or return home. Slothrop, however, does not appear to get the joke. Like the classic detective, he assumes the ability of the subject to chart his own position as well as the larger social space in which he moves. In one of the closing vignettes, Slothrop remembers as a child returning home through something like a classical or linear labyrinth: "If Slothrop wants to get home from here, he has to slide into a pathway next to the two-story brick wall of Hick's Garage, a green path whose entrance is concealed behind the trash-fire of the store, and the frame shed ... You cut through two lots ... You have to cross a street then, go down Mrs. Snodd's driveway. . through a wire gate ... over the rail fence" and so on (744). But while the alley symbolizes the enclosed space of Slothrop's childhood—a space for which he has grown nostalgic — the newly conceived networks that populate the Zone have irretrievably complicated the idea of such pathways. As the last line of the vignette indicates, "It may be too late to get home" (744). While Slothrop longs for secure alleyways with exits, he confronts instead the modulating space of Rocket City, a ramified space that leaves him bewildered to say the least. Unable to locate an exit from the rhizomatic space of the Zone, Slothrop 
can only hope that "by riding each branch the proper distance, knowing when to transfer ... this network of all plots may yet carry him to freedom" (603), yet given the growing complexity of these new spatial structures, "knowing when to transfer" is no longer a simple task.

Given the spatial colonization of the Zone and its reterritorialization to new purposes, it is no wonder that those who search for freedom look to the sky and the power of the Rocket to transcend the literal and symbolic networks inside of which they live. As Franz Pökler, a rocket engineer, tries to explain to his wife, "We'll all use it, someday, to leave the earth. To transcend" (400). He further imagines, "Borders won’t mean anything. We'll have all outer space" (400). For Pökler, and he is not alone in his hope, the Rocket offers the possibility of reaching a truly un-colonized or un-netted space. Despite Pökler's fantasy, however, the Rocket possesses the capacity to defy gravity only temporarily; it eventually falls back onto the street-grid. Even more damaging to Pökler's dream, Zonal networks are not confined to land only. The open Airspace above is also being rapidly interlaced with various networks of communication: "one more overlay on the Zone, antennas strung in the wilderness like redoubts, radiating half-spheres of influence, defining invisible corridors-in-the-sky" (620). In fact, the rocket itself, the very object that symbolizes the possibility of transcendence, appears unable to extract itself from the newly developing networks of the Zone. At one point, the rocket is described as being "electric-shocked as any rat into following this very narrow mazeway of clear space" (517). Thus, the net extends vertically as well, making the idea of a closed system obsolete as the system as a regime of vague control continues to expand.

As if the colonization of airspace were not a radical enough example of spatial reconstruction, these new networks also extend onto and into the body, as Slothrop's experience in the Zone reveals. 
What is arresting about Slothrop's efforts at detection is not only that he fails to recover any evidence or to solve any crimes, but that he loses his identity, as well as any hope for a stabile identity, along the way (one of those dangers Squalidozzi alluded to?). Slothrop's subjectivity begins to break down shortly after he first leaves London, supposedly for a little rest and relaxation on the Riviera. It is there that the scientists intentionally begin to strip Slothrop of his identity: "His friends old and new, every last bit of paper and clothing connecting him to what he's been have just, fucking vanished" (205). While he eventually concedes the loss of "his ID, his service dossier, his past," he remains "interested, and sometimes a little anxious, about what they seem to be adding on" (210). The minor alterations to his identity that he suffers at the hands of Pointsman are nothing, though, compared to what happens after he enters the Zone, where, again, he begins "to thin, to scatter" (509).

This scattering is prefigured by Slothrop's various costume changes as well as by his name changes. He goes from Ian Scuffling, to Rocketman, to Max Schlepzig, while dressing in a variety of costumes including a zoot suit, a cape and helmet, workman's clothes, a tuxedo, a Russian uniform, and even a pig suit. In the latter pages of the novel the following is said of Slothrop: "Scattered all over the Zone. It's doubtful if he can ever be 'found' again, in the conventional sense of 'positively identified and detained"" (712). Slothrop's scattering ultimately causes him to "become a cross himself, a crossroads, a living intersection" (625). The networked landscape has invaded or linked onto his bodyscape. As Lefebvre suggests, "Bodies — deployments of energy — produce space and produce themselves ... according to the laws of space" (171). Thus, once the laws of space as dictated by societies of enclosure experience radical transformation, the bodies within that space, as well as how those bodies are imagined, necessarily also undergo considerable adjustment. In one of the text's final 
mentions of a now-scattered Slothrop, we are told that some even "believe that fragments of Slothrop have grown into consistent personae of their own. If so, there's no telling which of the Zone's presentday population are offshoots of his original scattering" (742). What better metaphor for the space of control and its erosion of boundaries than the reconfiguration of Slothrop's corporeal space? Not only can Slothrop not exit the reterritorializing networks he confronts, he has become those networks, knotted into the web himself, netted across the Zone.

In his analysis of postmodern culture, Fredric Jameson discusses at length the kinds of spatial reconfiguration that Slothrop experiences. Jameson suggests that recent alterations to space resulting from late capitalism and its technological by-products have combined to form what he terms “postmodern hyperspace”- fitting terminology for Pynchon's Zone. He contends that this hyperspace has "finally succeeded in transcending the capacities of the individual human body to locate itself, to organize its immediate surroundings perceptually, and cognitively to map its position in a mappable external world" (44). Jameson argues further that "distance in general (including 'critical distance' in particular) has very precisely been abolished in the new space of postmodernism. We are submerged in its henceforth filled and suffused volumes to the point where our now postmodern bodies are bereft of spatial coordinates and practically ... incapable of distantiation" (48-9). This loss of distance obviously presents a daunting problem for the detective (as well as for the readers of detective novels) who relies on his ability to distance himself from the case so that he might critically analyze and solve the mystery from a seemingly objective viewpoint. Pynchon's metaphysical detective becomes, in fact, the very mystery-laden web he attempts to unravel.

I introduce Jameson's reading of postmodern space at this point for two primary reasons. 
First, Jameson adds to Deleuze's theory of space a more thorough account of the effect that recent transitions in spatial production have on the subject's, in this case Slothrop's, experience of the world. Secondly, in "hyperspace" Jameson provides us with a usefully descriptive term that when added to Deleuze's terminology helps us more accurately discuss the space that Pynchon offers us in the Zone. Reading Jameson and Deleuze against each other, it becomes clear that the space of which they write is ultimately the same space. In both cases, while the net is all-encompassing, the center as well as the outside have disappeared, and, again, it is the very unnavigable quality of postmodern space, a space that erodes enclosing structures, that creates a climate of ambiguous control. In short, the space in Pynchon's novel that I have referred to up to this point as a space of control might even more accurately be termed a "hyperspace of control," a space that controls precisely because it resists the subject's attempts to map—spatially or historically—its structure.

While Pynchon's fiction has been interpreted as providing a vision of postmodern space similar to that of Jameson, we should recognize that Pynchon ups the ante, for not only can Slothrop not distance himself from the reterritorialized networks — grids, tracks, shape-shifting cities—so as to view them in their entirety, which would enable him to chart the space of the Zone as well as his own position, he has finally become the network. His knotting into the network is so extensive that we can no longer differentiate Slothrop the individual from the larger net. No wonder Springer laughs at Slothrop's request for a "discharge."

What should be clear by now is that inside Gravity's Rainbow, at a diegetic level, webs branch out well beyond the physical space of the Zone: into the sky, into the mind, and onto the body. But the branching does not stop there, does not stop within the fictional world of the novel; even the 
text itself, at a meta-diegetic level, is symptomatic of a hyperspace of vague control. To begin with, the sheer size and volume of the multiple narrative strands in Gravity's Rainbow along with the author's habit of shifting between ontological levels without anything like a transitional clue have a disorienting effect on the reader to say the least. The novel includes so many characters, plots-in both senses of the word—and sub-plots, that it is frankly impossible to account for all of them. We cannot gain a global vantage point; we cannot see all the narrative strands at once. The text spiders out in too many directions, connecting too many characters and storylines for us to grasp them simultaneously. Possibly even more so than Slothrop's story, these meta-fictional gestures on Pynchon's part make the notion of an ontologically marked "outside" or a distantiated position, for the characters or readers, utterly untenable. At times, our own chances of a discharge, or exit, appear as improbable as Slothrop's. This engulfing effect is further heightened by Pynchon's repeated use of the second person pronoun, "you," which (on at least one "narrative plane") ${ }^{2}$ implicates us, or an extra-diegetic reader, as the guilty party $^{3}$ as well as suggests that we too produce and travel Pynchon's hyperspatial networks. Such passages are particularly striking because the narrative voice is not, as readers might expect, inviting or comforting; rather, the narrator is often overtly antagonistic to the imagined reader or extra-diegetic narratee (the detectives of the text) as if he were toying with "us," or controlling "us" from some elusive position. Pynchon's use of "you" creates a relationship between the narrator and the readers that is itself symptomatic of a hyperspace of control, inside which the reader experiences discomfort when confronting a narrator and text that appears to taunt the reader and exploit the detective-like desire for a conclusion or an out which never materializes, at least not in any conventional sense. 


\section{The Production of (Hyper)Space}

While we have seen, both in fiction and theory, what a hyperspace of vague control might look like as well as its potential for expansion, we have yet to sufficiently address the question as to just what has brought about this recent transition in spatial production. What social, material, or intellectual factors have created such a space? Significantly, it is in answer to this question that we see somewhat of a parting of ways between Pynchon and theorists such as Jameson and Deleuze. According to both Jameson and Deleuze the primary cause of the transition from a modernist to a postmodernist hyperspace of control can be located in the transition from earlier forms of capitalism to what Jameson terms late capitalism, a form marked by among other things new technology. Deleuze contends that the "technological evolution must be, even more profoundly, a mutation of capitalism" (311), which in turn produces a mutation in spatial production. Jameson goes so far as to argue that the "alarming disjunction point between the body and its built environment ... can itself stand as the symbol and analogon of that even sharper dilemma which is the incapacity of our minds, at least at present, to map the great global multinational and decentered communicational network in which we find ourselves caught as individual subjects" (44). Of course, like Jameson and Deleuze, Pynchon implicates evolving technologies in the production of the postmodern hyperspace and its regime of control. More than once Gravity's Rainbow raises the frightening possibility that "secretly" the war is "dictated ... by the needs of technology . . . by a conspiracy between human beings and techniques" (520-21). If this is so, then we certainly ought "to look into the technology of these matters" (167). Further in agreement with Deleuze and Jameson, Pynchon traces the production of post-war space to the "mutation" of capitalism. One underlying theme of Gravity's Rainbow is that the temporary alliances created by the 
war have produced multinational corporations that have succeeded in reconstructing geo-political boundaries: "like Shell, with no real country, no side in any war, no specific face or heritage: tapping instead out of that global stratum" (243). Deleuze suggests that recent alterations in the money form reflect the shift toward societies of control: "discipline always referred back to minted money that locks gold in as numerical standard, while control relates to floating rates of exchange, modulated according to a rate established by a set of standard currencies" (311). Similarly, in the space of the Zone "truer currencies come into being" (105). As Enzian notes, in the Zone "There's no money any more" (522); what is being exchanged is something far more abstract, such as information, a sign of our arrival in late capitalism and its hyperspace of vague control.

One might argue, then, that Pynchon like Deleuze, Jameson, and other prominent spatial analysts such as Soja and Harvey, links the mutations in spatial production directly to the mutation in capitalism, to an economic base that produces current technological networks which have no doubt reconfigured our experience of space. However, what makes Gravity's Rainbow so important to a discussion of postmodern space is that it remains a step ahead of much of the contemporaneous theory, including the work of Jameson and Deleuze, which explains the production of postmodern space in solely economic/technological terms. While, on one hand, Gravity's Rainbow points to late capitalism and its global networks as the producer of postmodern hyperspace, on the other hand, the novel undermines such a conclusion, tauntingly even: "Go ahead, capitalize the $\mathrm{T}$ on technology, deify it if it'll make you feel less responsible" (521). By undercutting the notion that technology, a product of the evolution of capitalism, is the sole source of post-World War II cultural forms, Pynchon suggests that there is not one cause through which we can explain, or map, the new spatial networks that populate 
the Zone, or the space of postmodernism. In Pynchon's account this space is produced by both shifting modes of production and multiple sets of social relations. This is an important distinction because the major flaw in Jameson's theory of postmodern space, as Doreen Massey and Derek Gregory have noted, is that it does indeed appear to capitalize the T on Technology, and in so doing, fails to account for other factors. The same critique can be applied to Deleuze's theory of a space of control, which he also links solely to an techno-economic base.

As Massey suggests, while "recent changes in space-time have clearly been propelled by capitalism and developments in technology ... [t]o reduce them to the cultural logic of late capitalism (Jameson) or of flexible accumulation (Harvey) is severely to reduce their meaning and their variety" (164). She adds, "Ethnicity and gender, to mention only the two most obvious other axes, are also deeply implicated in the ways in which we inhabit and experience space and place, and the ways in which we are located in the new relations of time-space compression" (165). Thus, if we inhabit a hyperspace of control, we do so not only because of the evolution of capitalism. Along similar lines, Lefebvre suggests that the spatial shift we have undergone in the second half of the twentieth century, in conjunction with the effects of economic-technological mutations, also "stems from the dominance of the male principle, with its violence and love of warfare" (409). Lefebvre identifies three distinct "formants," beyond the economic, that participate in the production of space: the geometric, the optical (or visual), and the phallic (285-86). The first two formants work collectively to produce space as a void; they empty out space. The phallic formant then "fulfils the extra function of ensuring that 'something' occupies this space, namely, a signifier which, rather than signifying a void, signifies a plenitude of destructive force" (287). He argues, "Phallic erectility bestows a special status on the 
perpendicular, proclaiming phallocracy as the orientation of space, as the goal of the process" (287).

While Jameson and Deleuze ignore such factors, Pynchon's fiction recognizes the role of the "male principle" in the arrival of "new relations" regarding spatial and temporal networks. In Gravity's Rainbow the Rocket, quite obviously, both embodies phallic power and dramatizes its participation in the production of space. As Enzian recalls being taught, "Beyond simple steel erection, the Rocket was an entire system won, away from the feminine darkness, held against the entropies of Mother Nature: that was the first thing he was obliged by Weissmann to learn ... He was led to believe that by understanding the Rocket, he would come to understand truly his manhood. ..." (324). Gravity's Rainbow also equates the Rocket with The Tower in a deck of tarot cards, The Tower representing "victory over splendor, and avenging force" (747). This analogy between the Rocket and The Tower lends the Rocket further symbolic import, making it reminiscent of the monument and its attempt to stake phallic dominance over the generally urban space (social and physical) it inhabits. Lastly, in a futuristic vignette we find that "the City has grown so tall that elevators are long-haul affairs, with lounges inside" (735). This futuristic City is the product of the long hoped for "Vertical Solution" (735), which Pynchon again equates with the Rocket and Pökler's dreams of transcendence. In each of these instances, the Rocket represents the phallic formant par excellence as well as the end goal, attempting to occupy and vertically orient all space as well as our perspective of space. By connecting the production of space to gender relations in addition to techno-economic factors (and Gravity's Rainbow also implicates race as a contributing element $),{ }^{4}$ Pynchon complicates and ultimately enhances both Deleuze's and Jameson's analyses of postmodern space. This is not to say that Pynchon's fictional account makes it any easier to navigate the hyperspace of postmodern culture. If anything, by 
linking the construction of gender to spatial production, Gravity's Rainbow suggests that the set of relational networks out of which the space we experience is produced is even more complex than either Jameson or Deleuze imagines, for inside the reterritorialized space of the Zone, the subject is required to navigate far more than the multinational web that is late capitalism, as if that were not intimidating enough.

While linking gender relations to spatial production is an important step, Pynchon does more than simply make the connection; rather, he critiques the hegemonic forces that construct the space(s) that arise from the rubble of World War II. As Keesey argues, rather than attacking the "militaryindustrial complex" as an isolated element, "Pynchon's meta-detective fiction reveals the 'masturbat[ory]' desire for 'male supremacy' driving the detective's quest," which is made "to conform to a phallocratic order" $(51,50)$. We might remember here the irony that Slothrop's map of his sexual conquests appears to celebrate his phallic power-as does classic cartography and its colonization of space in general — but turns out to be merely an illusion. This critique of the phallic drive is further present both in Slothrop's failure to even so much as keep his attention focused on the case, that is in Pynchon's undercutting of the cultural logic of the classic, male detective as well as in the novel's questioning of the Rocket's hegemonic claims. While on the one hand, the Rocket appears to be all powerful, taking on a life of its own after reaching the Brennschluss, and is capable of mass destruction from which there is little protection, it ultimately cannot maintain the vertical solution, cannot sustain its defiance of "Mother Nature." In fact, while Blicero imagines the Rocket as a masculine presence "won" from the feminine earth, its end result is an absence, a hole in the ground, or on Roger Mexico's map, not a pin, or a presence, but "a pinhole in paper that someday will be taken down, 
when the rockets have stopped falling" (138). The Rocket embodies both the drive toward male supremacy and its failure, both a phallic presence and a disturbing (or in Enzian's case downright deadly) lack, disturbing or deadly for those who assume its power.

While Pynchon critiques the phallic driven detective, eschewing his totalizing logic, Jameson and Deleuze both at times can be seen as actually reinforcing the ideology of classic detection. Massey argues, "Those who today worry about a sense of disorientation and a loss of control must once have felt they knew exactly where they were, and that they had control" (165), an experience she suggests is reserved to white males in first world countries and not shared by those among the controlled. She further suggests that “Jameson's (and others') apparently vertiginous terror ... in the face of the complexity of today's world ... has a lot in common with the nervousness of the male modernist ... faced with the big city" (259). Given the detective's connection to and reliance upon the modernist city, and its underlying epistemology, we can also assert that Jameson's position has much in common with the male detective who, faced with a crime that threatens to destabilize the social and spatial order, works diligently to reestablish that order. In other words, Jameson's "terror" in the face of a hyperspatial culture can be read as tantamount to the terror of the detective who discovers that neither his personal logic nor his once culturally dominant belief system can any longer explain or organize the world. And while Deleuze claims not to suffer from the same terror, remarking that there "is no reason to fear or hope, but only to look for new weapons" (309), his word choice suggests otherwise; he repeatedly uses the very word "terrifying" to describe the new networks of postmodernism, and, obviously, the term "control" itself suggests fear or retreat as a valid response to the space we confront in the late twentieth century, in which case we might think of Deleuze as one of those "others" to whom 
Massey refers.

Jameson, however, extends his complicity in the downfall of detective logic by offering a new plan of action—something Deleuze and Pynchon avoid—-through which we might once again locate our position, assuming we once could, within postmodern hyperspace. While Slothrop, unable to navigate the space of the Zone, abandons his attempts to do so, at least through conventional means, Jameson, our detective of postmodern culture, also admittedly unable to navigate the hyperspace of control, is not so willing to give up on the possibility of regaining a position from which this would be possible; he readily admits the mystery but holds on to the hope of a future solution. To accomplish this task, Jameson suggests "cognitive mapping," an operation that would "enable a situational representation on the part of the individual subject to that vaster and properly unrepresentable totality which is the ensemble of society's structures" (51). As Noya points out, however, Jameson's cognitive mapping comes "perilously close . . to the type of paranoid mapping indulged in by Pynchon's questers" (315); in other words, it comes dangerously close to reinscribing the detective's drive to solve (dominate) the space(s) he confronts. In fairness to Jameson, after publishing his initial essay on postmodernism, he has admitted to the shortcomings of his program for mapping postmodern culture: "cognitive mapping, which was meant to have a kind of oxymoronic value and to transcend the limits of mapping altogether, is, as a concept, drawn back by the force of gravity of the black hole of the map itself . . . and therein cancels out its own impossible originality" (416). As Noya points out, Jameson's language is hauntingly reminiscent of Gravity's Rainbow itself, in which gravitational forces repeatedly stifle attempts to transcend or distance oneself from the newly arriving networks of the Zone. In that he admittedly attempts to work against these forces, Jameson, despite his intentions otherwise, ultimately falls into the 
same trap as those who chase the Rocket as a way out, as a distantiating device that would once again grant them that point of observation — the privileged position that the scientific disciplines, and the detective, once occupied—from which they might reestablish (phallic) control over that space.

Conversely, for Pynchon, even distance does not equal transcendence. While Enzian explains to Katje, that he can indeed show her the Raketen-Stadt: "Plexiglass maps of the webs we [the Schwarzkommando] maintain across the Zone" (660), his purported position on the "observation deck" reveals only that he has become an "estranged figure at a certain distance ... who has lost everything else but this vantage" (661). As he says, "I haven't transcended. I have only been elevated" (661). His distance, or attempt at distance clearly does not satisfy his quest to realize the power of the Rocket, which in turn would mean, according to Blicero, the realization of his phallic wish for verticality, a wish Enzian harbors but can never attain. In fact, his quest for transcendence leads to suicide, as he himself boards the rocket, ending in the absence that is the hole of its remainder. For Pynchon, then, the drive to cognitively map the Raketen-Stadt results in frustration or violence. 


\section{"The Counterforce"?}

We might ask, then, how Gravity's Rainbow suggests that we meet the newly multi-layered and networked space(s) of postmodernism. To begin with, Pynchon avoids the mistake of committing himself to a plan of action as Jameson does; the elusiveness of the author as well as the narrator is clearly an attempt to avoid having to regain control of or solve the space at hand. One of Pynchon's characters, however, namely Enzian, does offer the intriguing suggestion that "as the maps grow another dimension, so must we" (321), or to put it another way, as the spaces of postmodernism continue to ramify, so in a sense must those who inhabit them. One of the problems with Jameson's cognitive mapping is that it implies the re-insertion of the monad, the unified subject that Jameson himself links to modernism. To assume the possibility of locating one's position is to assume that one's position is singular. Conversely, Slothrop's scattering suggests that a singular position or unified space has died along with the unified subject, that there truly is no returning home to one's stable position within a system of enclosure. This is, of course, terrifying to those who attempt to uphold the position of the classic detective, the monad par excellence. Yet Slothrop's integration into the hyperspace of the Zone need not be read as a failure in all respects. To attempt to remain unified in or set apart from the reterritorialized networks of postmodernism is ultimately to attempt to remain an agent of the very system that a novel such as Gravity's Rainbow attacks, a system comprised of well-defined subjects inhabiting well-defined spaces. Ironically, then, Slothrop's dispersal throughout the networks of the Zone can be read as a possible form of resistance, though not consciously so on Slothrop's part. That is to say, the detective defies his own logic in a sense by using the dispersal of the newly arriving spaces of postmodernism to elude the constraints of the earlier regime of enclosure. This is, of course, ironic 
because it would seem that by integrating Slothrop into the net, the space of postmodernism has gained an even stronger hold on him than was maintained by the previous system. At the same time, however, he is no longer of any use either to Pointsman or the other scientists, nor is he of use as a detective who enforces the system, precisely because he cannot "be 'found' again, in the conventional sense of 'positively identified and detained"' (712); the system seems to have lost sight of Slothrop just as Slothrop has lost sight of the system. Ultimately, if there is a way out for our detective, at least inside this text, it is not up but down, through an anti-phallic journey to the earth's center where in one of the narrative tangents, Lyle Bland actually locates the mysteries of gravity and history and appears to beat the system (589-90). Of course, it is never clear how exactly one is to penetrate those mysteries; we have no map nor is one forthcoming. And certainly, Slothrop is no hero in the conventional sense, especially given the fact that we cannot even say for certain who, what, or where he is. For in the space of the Zone, in this uniquely reterritorialized entanglement, we not only confront the prospect of losing our way or of being cognitively overwhelmed by the sheer number of paths available; we also incur the possibility, simultaneously frightening and promising, of being ourselves scattered, branched, netted across the globe and into space. 


\section{NOTES}

1. While Merivale and Sweeney argue that Pynchon's fiction may not fit into the genre of metaphysical detective fiction at all- 'The problem with Pynchon is not the 'metaphysical' but the 'detective story' part of our rubric: not the mode, but the genre" (19)—Slothrop's explicit identification with the popular detective figure suggests that detection fiction is at least one of the genres in the context of which Gravity's Rainbow, as well as other Pynchon novels, ought to be placed.

2. In Constructing Postmodernism, Brian McHale has devoted an entire chapter to the discussion of Pynchon's use of "you," which he notes is not only ambiguous but "multiguous" in that "any instance of you may function in any of several different communicative circuits, located on different narrative levels or planes of the text" (90). One difficulty the reader may experience with Gravity's Rainbow, then, is "to determine, for any instance of you, on which plane it functions" (90). McHale determines, however, that the "second-person passages in Gravity's Rainbow are rarely reducible" to one narrative plane, but rather "hover ambiguously among several alternative communicative situations, or switch disconcertingly from one to the another" (96). In light of his argument, it is important to note that in highlighting one possible communicative circuit, author/reader, created by the use of "you," I am not ruling out the fact that the pronoun in most instances simultaneously functions in other circuits.

3. Eco concludes his "Postscript to The Name of the Rose" with the compelling remark that "any true detection should prove that we are the guilty party."

4. Gravity's Rainbow also implicates race as a significant factor in the production of space, though the novel's treatment of race is complicated and would require a fairly lengthy discussion. We can get a brief glimpse at Pynchon's treatment of race as it relates to spatial production in the story of the Schwarzkommando, a group of Heroro's who after surviving the colonialist genocide that the Germans perpetrated in Southwest Africa (an event more fully narrated in Pynchon's $V$ ) are later brought to Germany and instructed in the launching of the Rocket. The novel's allusion to Germany's colonialist activities in Africa reminds us that the belief on the part of German leaders in their ability to colonize all space, to literally conquer the world, arose in large part from their investment in whiteness. Men like Weissmann/Blicero can justify their dreams of dominating all space, including air-space, precisely because they buy into a reified construction of whiteness as an indicator of racial superiority. In short, whiteness was perceived as entitlement to spatial expansion. 


\section{CHAPTER 2}

\section{Supposing an Urban Space: Paul Auster's The New York Trilogy}

While Gravity's Rainbow dramatizes the onset of the spatial logic of postmodern culture, Paul Auster's The New York Trilogy, its first book set some forty years later, provides a glimpse into the results of that transition for the American city and its subjects, who now live the postmodern city. A compilation of thwarted efforts to bring the case to something approaching closure, Auster's trilogy stands as a three-part prototype for metaphysical detective fiction, each case extending from potential crimes to the mysteries of identity and language. In each of the three books, the detective "becomes a pilgrim searching for correspondence between signifiers and signifieds" and finds himself undertaking "a quest for his own identity" (Russell 72-3). These are impossible tasks, however, for in the world of these novels signifiers have been divorced from signifieds, while the dividing line between self and other has dissolved. Uncannily, in each of the narratives the detective in his attempt to locate missing persons becomes himself the missing person.

In City of Glass, Daniel Quinn, who writes mystery novels under the pseudonym William Wilson, is transformed into a real-life detective when he mistakenly receives a phone call intended for one Paul Auster, private detective, requesting his assistance. The call is placed by Virginia Stillman, who wishes to hire Quinn/Auster to protect her husband, Peter Stillman Jr., from his father whom she fears intends to kill his own son. She later tells Quinn/Auster that some years prior Stillman Sr. locked his son away in a dark room for nine years as an experiment in the possibility of recovering a prelapsarian language, an act that landed Stillman Sr. in prison. Now Stillman Sr. is being released, causing Virginia Stillman to fear for Stillman Jr.'s life. For reasons even Quinn cannot explain, rather than ignoring the mistaken call, he pretends to be Auster, taking on the identity of a detective, and 
accepts the case, which he initially sees as little more than a "glorified tail job" (34). The Stillman case becomes much more, however, to the point that it consumes Quinn's entire life, quite literally. Unfortunately, once Quinn has fully committed himself to his new role as a detective, the case dissolves and with it his reason for being. Toward the end of the novel, Quinn, having lost both his home and his name, lies naked in a dark room. Exhausted by a case he can neither penetrate nor close, Quinn vanishes with the final words of his red notebook, inside which he documents his entire ordeal, into an “atextual, nonspatial void" (Alford 623).

The second Book of the trilogy, Ghosts, tells the story of a professional detective, Blue, whose job is to watch a man he knows only as Black and to write down what he observes, which is not much considering Black spends most of his time alone in his apartment either writing or reading. Despite the apparent insignificance of such a job, Blue, like Quinn, obsesses over the case, often imagining it must involve more than what he himself has witnessed, and like Quinn, Blue allows his own life to slip away as a result. He loses his fiancée, as well as his home, and in another metafictional moment, he also eventually disappears into a space beyond the confines of the story, a space to which even the narrator claims not to have access. In the final book, The Locked Room, our nameless narrator, who at one point proclaims himself the author of all three books in the trilogy, receives notice that his childhood friend, Fanshawe, has gone missing. Fanshawe's wife Sophie hires a detective, named Quinn no less, but still cannot locate Fanshawe and so concludes he must be dead. In steps our narrator, who falls in love with and marries Sophie; he even adopts Fanshawe's son, firmly establishing himself in the position Fanshawe has vacated. The narrator, then, appears to find domestic certainty: "By belonging to Sophie, I began to feel as though I belonged to everyone else as well" (274) — that is until Fanshawe 
writes to our narrator revealing that he is still very much alive. If Fanshawe remains alive, our narrator's position obviously becomes far less secure. So arises the narrator's obsessive search, detective style, to find the real, living Fanshawe, whom he concludes he must kill; he must rid himself of this ghost, the other, who, ironically, has both made our narrator's existence possible and now threatens to destroy that existence.

What becomes apparent in each of these cases is that the detective's downfall arises in large part from his devotion to the ideology of detection, despite the fact that the world he attempts to solve repeatedly overwhelms the very empirical logic he employs. In City of Glass, Quinn's devotion to the ideology of detection seems particularly misplaced in that from the very beginning of the story his life already makes little sense. He lives alone; his wife and son have died; he no longer has any friends, and his only contact with his publisher or agent is conducted through the mail. It is "as if he were somehow living a posthumous life" (6). To complicate matters, he is not only Quinn but also Wilson, as well as his "private-eye narrator, Max Work." Add to this "triad of selves that Quinn had become" (6) his role as Auster and it is no wonder Quinn's sense of identity is thrown into crisis.

The senselessness of Quinn's "real" life would explain his attraction to the world of detective fiction:

What he liked about these books was their sense of plenitude and economy. In a good mystery there is nothing wasted, no sentence, no word that is not significant. ... Everything becomes essence; the center of the book shifts with each event that propels it forward. The center, then, is everywhere, and no circumference can be drawn until the book has come to its end. (9) In this neatly diagramed world, the "detective is the one who looks, who listens, who moves through 
this morass of objects and events in search of the thought, the idea that will pull all these things together and make sense of them" (9). The detective "looks out from himself into the world and demands that the world reveal itself to him" (9-10). The world is a text laid bare before the eyes of the master reader, the detective. Such a schema provides Quinn with the security and comfort he lacks; it promises him the possibility both of making sense of his world and consequently of securing his position in that world.

As Quinn's thoughts on detective fiction reveal, the detective's reliance on his ability to decode the world reflects a closely linked belief in both a tightly formed linguistic economy as well as the possibility of maintaining a singular, stable identity, a correspondence that Auster repeatedly evokes and dismantles. For instance, at the beginning of Ghosts, Blue reasons like the conventional detective, or possibly more like the naive reader of detective fiction, assuming that all cases come to a close, that all mysteries end in order. These assumptions surface in the writing of his reports: "His method is to stick to outward facts, describing events as though each word tallied exactly with the thing described, and to question the matter no further. Words are transparent for him, great windows that stand between him and the world" (174). Blue does not question his place in the world; in his mind the signifier grants unhindered access to the signified, and subjects and objects remain distinct and distinguishable. Likewise, regardless of the obvious splintering of Quinn's identity, he continues to believe that "he could return to being Quinn whenever he wished" (62), assuming that a "true" self remains unchanged and accessible beneath his various facades.

Unfortunately, for Auster's three protagonists, unlike the cases they write and read, the cases they "live" not only fail to produce tidy conclusions, but in failing indicate the instability of the world as 
well as the indeterminacy of language and the self. Quinn eventually loses track of Stillman Sr. as well as Virginia and Stillman Jr., the target of his surveillance as well as his reason for being on the case in the first place. He finds himself inside a case in which there "were no clues, no leads, no moves to be made" (109). Still, Quinn does not pack it in and return to his former life, nor apparently can he. Unwilling to give up on the mystery prior to the moment of revelation, the kind of revelation one might find in Quinn's own mystery novels, Quinn decides instead to place Stillman Jr's apartment under surveillance. To watch the Stillman apartment day and night, Quinn takes up residence in the alley across the street, settling in for months on end. When Quinn finally exits the alley, he discovers that he has been investigating a case that does not actually exist. Even before he entered the alley, Stillman Sr. committed suicide, and the Stillman apartment was vacated prior to Quinn's surveillance, meaning he has kept watch on nothing. As a result, Quinn "had nothing, he knew nothing, he knew he knew nothing" (124). The detective's logic fails Quinn in part because language does not behave according to the detective paradigm through which each of Auster's three sleuths views his world. While Blue begins his case believing in the transparency of language, he later "discovers that words do not necessarily work, that it is possible for them to obscure the things they are trying to say" (176). And in all three volumes, the characters experience major crises regarding their sense of self; they find they have no access to that core they assume exists, and since they have no access, they can no longer say with certainty if it does indeed exist or not. As the narrator of The Locked Room explains, "Every life is inexplicable ... the essential thing resists telling" (291), and, therefore, eludes the detective's drive to locate that central truth beneath the surface clues.

\section{Space and the City}


Just as Auster's fiction calls into question the notions of language and identity that subtend the logic of the traditional detective, his trilogy also undermines conventional or modernist notions of urban space. Significantly, Auster's novels suggest that our concept of space is inextricably intertwined with our understanding of language as well as identity. Facing the loss of both a coherent identity and a determinate language, each of Auster's detectives seeks spatial solutions, which, as we will see, fail to provide the security each desires. While the trilogy subverts the spatial logic of the conventional detective in general, it focuses this attack at a number of specific fronts, each of which requires discussion. The trilogy reconceives the spatial concept of "home," a space that Auster compares to and contrasts with the pedestrian spaces of the roaming city walker. It also counters the notion that space can be read as a text, an idea that involves both the mapping and subsequent reading of spaces. Finally, Auster's fiction dramatizes the connection between the production of space and the construction of identity.

While each of the books in Auster's trilogy is relevant to a discussion of postmodern space, my reading concentrates on City of Glass for the simple reason that of the three it most directly addresses the space of the city and the detective's relationship to that space. This does not mean that I will ignore Ghosts or The Locked Room. As the narrator of The Locked Room tells us all "three stories are finally the same story" (346), the difference being that each "represents a different stage" in the narrator/author's "awareness" of what the story is ultimately about (346). In this spirit, while what follows is primarily a reading of City of Glass, the latter volumes of the trilogy heavily inform that reading, or add to our awareness of what Quinn's metaphysical foray into the city is really about.

\section{Home is where the Detective is Not}


Contrary to the desire of each of Auster's detectives, space in these novels, the space of New York City, does not behave as it does within the paradigm of detective fiction. At the beginning of their quests, however, none of Auster's detectives is conscious of this; it is only after the failure of detective logic that these metaphysical private eyes recognize the need to reconceptualize the spaces inside which they operate. In the opening pages of City of Glass Quinn, in keeping with his high regard for the detective's ability to center the world, operates under the notion that he can locate a stable place for himself in a well-ordered universe. Quinn maintains this outlook despite the fact that from the opening of his story he already seems out of place; he has no secure familial or communal ties and prior to entering a detective fiction, spends much of his time walking the city aimlessly in an effort to lose himself, in every sense:

New York was an inexhaustible space, a labyrinth of endless steps, and no matter how far he walked, no matter how well he came to know its neighborhoods and streets, it always left him with the feeling of being lost. Lost, not only in the city, but within himself as well. Each time he took a walk, he felt as though he were leaving himself behind ... reducing himself to a seeing eye ... On his best walks he was able to feel that he was nowhere. And this, finally, was all he ever asked of things, to be nowhere. New York was the nowhere he had built around himself. (4)

There are a variety of issues at stake in this passage, some of which I will return to later, but what I wish to note here is how Quinn's attempts to lose the self directly contrasts with his high esteem for the detective and the centered world the detective produces. While to "walk is to lack a place," being "the indefinite process of being absent and in search of a place" (de Certeau 103), detective fiction is about 
keeping or restoring everyone and everything to his, her, or its "proper" place. Despite the seeming disparity here between Quinn's belief in the fictional world of the detective and the displacement he experiences in his "real" life, ironically, his walks to "nowhere," to a no-place are actually made possible by his belief in the stability of place, and the detective's role in maintaining that stability. Regardless of Quinn's efforts to lose his place, underneath his excursions through the city lies a deepseated belief in his ability to be placed once again. That is to say, Quinn's ability to wander the city without destination, to lose himself, is made possible only by his certainty that he can always return home, a certainty that is eventually stripped away.

Stability, one's sense of having a place, has long been symbolized by the home. As Massey argues, a "place-called-home" is an anchoring point that provides both spatial stability, an unchanging geographical or architectural structure to which one can repeatedly return, as well as "a source of unproblematical identity" (151). Even the detective, as Auster's work dramatizes, no matter how willing to roam the urban landscape, has always required such a place. While the armchair detective finds sanctuary in his house or apartment, the hardboiled detective seeks comfort in the security of his office space, each respectively providing a retreat from the chaos of the city. The relationship of Quinn's walks in the city to his anchoring at home recall not only the detective figure but also the detective's opposite, the missing person. Plundering the annals of American literature, Auster suggests that we read Quinn's ordeal, as well as that of Auster's other two detectives, against the backdrop of a long history of male protagonists who have left home. In particular, Auster calls our attention to the title character of Nathaniel Hawthorne's short story "Wakefield," a story that Black actually tells to Blue. As I argue in “Approaching the Threshold(s) in Postmodern Detective Fiction: Hawthorne's 
'Wakefield' and Other Missing Persons," the story of "Wakefield"functions as a mise-en-abyme within Auster's trilogy, or as a foundational missing person narrative upon which Auster draws in order to dramatize the relationship of identity to the space of the city. Briefly, the original "Wakefield" tells the story of an apparently typical man who decides to play a "joke" on his wife by leaving for work one day and inexplicably not returning home for another twenty years. And after the twenty years? The narrator tells us that Wakefield simply "entered the door one evening, quietly, as from a day's absence, and became a loving spouse till death" (290). Despite the seeming lack of consequences for his prank, during his exile Wakefield is forced to confront the central question that the story poses, whether or not, after having taken an extended walk, he can return to his former "place" in the world. At times it, in fact, appears that Wakefield cannot go home even if he so desired. The narrator even suggests that the "dead have as much chance of re-visiting their earthly homes, as the self-banished Wakefield" (295). Uncannily, Wakefield "had contrived, or rather he had happened, to dissever himself from the world— to vanish— to give up his place and privileges with living men, without being admitted among the dead" (296). Thus, Wakefield's narrative evokes the fear of losing one's place, the fear that one might simply wander outside the system that is society, might unintentionally cross a threshold of no return — breaking the very boundaries of containment that the detective strives to secure. This anxiety, however, is resolved, re-contained, once Wakefield returns to his "forsaken domicile." As in the murder mystery, the rational replaces the irrational, the mysterious missing person no longer remains missing. According to the cultural logic out of which Hawthorne writes, the same cultural logic in which detective fiction thrives, the world has a certain order in which every person and thing has a proper place; consequently, Wakefield not only can but must go home. His return is possible, then, because 
no matter how much Wakefield changes, no matter how much his identity appears to fluctuate, his home remains virtually unchanged, his wife waiting for him as if he had been absent only a day. In Hawthorne's missing person story as long as the home remains stable so does one's position in society and consequently one's identity.

Unlike the original Wakefield, Auster's missing persons, ironically the detectives themselves, "must confront the possibility of never returning, of having no home to return to, or even of not knowing which self is to return" (Swope 211). In the postmodern city the very notion of "home" is thrown into question, and with it the social and individual stability with which it is ideologically infused. When we first meet Quinn, his apartment is all he has left that provides him with any security or sense of having a place. Unlike his literary ancestor Wakefield, Quinn has no wife — traditionally the embodiment of domestic security - to maintain his place of residence while he ventures out to solve the Stillman case. Furthermore, Quinn does not own his home; it is a rented space, an already temporary dwelling rather than the symbol of permanence that ownership implies. From the beginning, then, Quinn teeters between place and no-place. Still, he appears strikingly unaware of his predicament; his belief in his ability to return home, no matter how far into the city he ventures, never wavers, that is until he literally loses or is evicted from his apartment.

In effect, City of Glass reads like the story of one man's slow drift away from his "home," the home ironically that does not really exist in the first place. Crouching in the alley across from the Stillman apartment, Quinn literally becomes homeless (one of the inexplicable inhabitants of the city who defy the detective's logic that accords to every subject a place of physical as well as ontological certainty). Since Quinn operates under an assumed identity, however, he continues to believe that his 
predicament is "all an illusion," that "he could return to being Quinn whenever he wished," and up until this point he has the "home" to insure him of this seeming inevitability. When Quinn finally does leave the alley, at which time he discovers the Stillmans' fate, he notices his reflection in the glass of a shop window. Yet, uncannily, "he did not recognize the person he saw there as himself . . . He tried to remember himself as he had been before, but he found it difficult" (142-43). At this moment of crisis, Quinn walks to his apartment expecting that, in a replay of the Wakefield story, nothing has changed, that he can reclaim what he assumes must be his proper place in the world, and with it his old self. But just as his former name and appearance have slipped from his grasp, the apartment that acted as a spatial anchor for his sense of identity has also vanished. When Quinn finally returns "home," upon entering the apartment, he discovers that another person inhabits his abode: "Everything had changed. It seemed like another place altogether, and Quinn thought he must have entered the wrong apartment" (147). At this moment he realizes, "He had come to the end of himself. He could feel it now, as though a great truth had finally dawned in him. There was nothing left" (149). Quinn has no family, no friends, no proof of his identity, or possibly no identity at all, and now no home, no "place" in the world. In an urban nightmare, his experiment as a detective has swallowed up his former position as if it never existed.

Despite the fragmenting of his identity that Quinn undergoes early in the story, it is not until he loses his apartment/home that he gives up all hope of returning to the old Quinn. Having absorbed conventional notions of space, Quinn holds to the one constant, the container that he assumes stands apart from the societal and individual flux he experiences. Assuming both the identity and the logic of a detective, Quinn makes the mistake of investing in his apartment, as an anchor for his position, and, 
therefore, when his apartment vanishes, so do his hopes of regaining his previous life. Even the change in his appearance, does not have as much of an effect on him as does the recognition that what he assumed was his material space in the world no longer exists. Auster's version of the "Wakefield" story suggests, then, that in the postmodern space of the city, the subject risks more than being temporarily alienated from his or her home, a place which remains, ideological speaking, permanent even in the modernist urban environment. In the postmodern city, however, place, home, the "proper" is exposed as an illusion—no wonder Quinn cannot locate Stillman. Quinn's residence is as unstable as his repeatedly changing name, that is, "home" is little more than a tag, a-place-called-home.

It is important to note that Auster's preoccupation with "home" reveals more than the relationship between the lone subject and his position in the world. The trilogy suggests that the notion of "home" has a larger ideological function, especially when we consider the middle-class investment in the concept of a domestic space separated out from the deteriorated streets. Auster evokes this spatial separation when, in a metafictional moment, he takes Quinn to the domicile of none other than Paul Auster, a writer no less—-we never do see the detective-who not coincidentally lives with a wife and son, much as Quinn once did, in a comfortable apartment. Quinn meets Auster shortly after being given the slip by Stillman, Auster's apartment representing the final safe haven for Quinn just prior to his fall into nothingness. Auster's apartment, both its spatial positioning high above the street as well as its symbolic import as a sign of stability, of home, reflects a class-conscious spatial logic that clearly influences the conventional detective story. The novel describes Auster's home as having "an air of bourgeois sobriety" (111). Auster's use of the word "bourgeois" places the eleventh-floor apartment in direct contrast with the space of the street where Quinn will eventually lose both his home and his belief 
in the existence of such a place. Highlighting this contrast, the sight of Auster's domestic security causes Quinn to feel "as though Auster were taunting him with the things he had lost" (121), not to mention what he is about to lose. Similar to the broken yo-yo that Auster's son finds in the street, which drops down its string but does not rise again, once Quinn leaves Auster's apartment, descending into the alley he will never recover his former "place" in the world again; he will never rise again to a bourgeois space of security.

Further dramatizing the contrast between the stability of the middle-class home above and the streets of the homeless below, the day immediately following Quinn's visit to Auster, he takes a walk through the city, a walk that will eventually carry him to the alley, during which he becomes cognizant of "many things ... he had never noticed before" (126). Specifically, Quinn becomes acutely aware of "the tramps, the down-and-outs, the shopping-bag ladies, the drifters and drunks" (129), those perpetual missing persons for whom the detective has located neither a solution nor a place. Anthony Vidler argues that space itself, or a particular production of space, has been used to cover over the homeless element of the city: "space is assumed to hide, in its darkest recesses and forgotten margins, all the objects of fear and phobia that have returned with such insistency to haunt the imaginations of those who have tried to stake out spaces to protect their health and happiness" (167). First and foremost among such spaces of "health and happiness" is, of course, the (modernist) bourgeois home lifted above, or set apart from the contagion of the city. ${ }^{1}$ Vidler argues further that "space as a threat, as harbinger of the unseen, operates as medical and psychical metaphor for all the possible erosions of bourgeois bodily and social well being" (167), a threat he directly connects to "the person of the homeless" (168). Once Quinn enters the street, everything that Auster's and his own apartment above 
the city is designed to escape becomes visible and, therefore, threatening. Indeed, in Quinn's case the contagion of homelessness in the city literally erodes his "bourgeois bodily and social well being." Thus, City of Glass, as its title indicates, suggests that the security of the middle-class notion of home is itself little more than an ideological fantasy, as this space is continuously invaded by that which it seeks to erase or escape: that homelessness to which Quinn has in effect always belonged.

By drawing our attention to the effect that class consciousness has had on the production of urban space, Auster's fiction cannily recognizes the class demarcation of spaces as a crucial element in even the earliest forms of detective fiction. According to Robin Woods, the role of the conventional detective was "not only to capture the criminal, but also to protect society from the criminal's moral influence." (16). The detective's job, then, was to secure bourgeois space and all that it symbolizes. Ironically, in his attempt to maintain middle-class morality, "the fictional detective himself became an outcast, a link between crime and society who, by the nature of his task, had to work alone in order to protect his community from the taint of criminality" (Woods 16). In other words, the detective sacrificed his own position, or home, within the bourgeoisie to insure the system's survival. This explains why detectives have always been "outsiders"; they do without such middle-class staples as family or conventional employment. The detective moves in both the middle-class and criminal worlds but belongs to neither, a liminal figure who for all intents and purposes "does not really exist when he is not on the case" (Holquist 142). This explains why the detective requires a space, apartment or office, to which he can return after collecting clues, for without such an anchor he would drift into nothingness, as indeed Quinn does. It is worth noting that the detective's office is itself a bourgeois space of sorts. Since the bourgeois typically practices a profession in an office space, to the degree that the detective 
works out of an office, he maintains a foothold in the middle-class world—-though, again, this foothold is tenuous at best; for the detective every trip out of his office into the city means the possibility of not returning. Furthermore, as the hardboiled tradition shows, the detective's office is far from impermeable and repeatedly fails to maintain the bourgeois illusion of being isolated from the street. While the office appears to be a fortress against the criminal element, as the apartment space of a conventional detective such as Dupin truly was, in a hardboiled detective story the detective's office is typically violated by that very element. How often have we seen the detective's office ransacked by thugs? The hardboiled version of detective fiction suggests, then, that the detective's version of a hermetically sealed space, free of the taint of the street, is at least questionable. ${ }^{2}$

Auster's metaphysical variation on the detective genre extends this critique of the bourgeois segregation of space even further by blurring the separation between the street and the supposedly sanitary space above; his version exposes the boundaries that isolate and protect the apartment or office above as a fiction, as spatial productions that can be deconstructed just as easily as they were once erected. The strict separation of the two worlds, as the detective's ability to traverse both spaces indicates, is untenable, for as Quinn notes, his apartment is not the sanitary space he had supposed; rather, "the city encroaches with its soot" (125). Thus, by dramatizing Quinn's loss of his abode, City of Glass does more than undermine one individual's place in the system. By suggesting that the bourgeois "home" is a fiction, a fiction perpetuated by the detective and his belief in the proper, Auster's novel critiques an entire cultural logic whose production of space hinges on its very notion of "home." Once the "home" is gone, all is out of place, including the detective whose function it is to maintain such spaces. 


\section{Walking in the (Un)Readable City}

Quinn's belief in the constancy of home is far from his only misunderstanding of the city space he inhabits. As I have been arguing, Quinn takes the Stillman case because it holds out the promises of recapturing a former cultural logic, that of the detective, which includes the previous spatial regime, under which everything and everyone has a clearly demarcated, or enclosed place. In accordance with this logic, once Quinn is on the case, his walks cease to be about losing himself and are transformed into efforts to place the other inside a definitively bounded or mapped space. While following Stillman, Quinn charts the path they walk, recording their every step in his red notebook. While Quinn's earlier pedestrianism is described as little more than "aimless motion," mere "wandering," once he becomes the watcher, it is no longer possible for him to be a mindless peripatetic; this is now "a privilege denied to Quinn" (74-5). He has become, rather, the one who polices, a keeper of place, and, therefore, begins to "set down with meticulous care an exact itinerary of Stillman's divagations" (76). Stillman spends day after day wandering the city collecting seemingly "valueless" "bits of junk." Since Stillman's daily walks have nothing to do with Stillman Jr., Quinn begins to wonder if he has not "embarked on a meaningless project" (73). As a detective Quinn desires to make meaning from Stillman's steps, to make sense of the pedestrian in the city; therefore, he later translates his notes into maps of Stillman's travels. To Quinn's amazement, the map of each day's walk appears to form the shape of a letter; combined, these letters spell out "OWER OF BABEL." Since Quinn did not record the first four days of Stillman's walks, he surmises that Stillman has been leaving a text of footsteps that spells out "THE TOWER OF BABEL," a topic, not coincidentally, on which Stillman published a book prior to his incarceration. 
As both Steven Alford and Ralph Willett have noted, de Certeau's theorization of the walker in the city is particularly relevant to a discussion of Auster's accounts of pedestrianism. De Certeau's critique of conventional spatial logic is, in fact, aimed at intellectual efforts which, like Quinn, attempt to construct a map/text of the walker's path. De Certeau argues that walking "is a spatial acting-out of the place (just as the speech act is an acoustic acting out of language)" (98). He suggests, therefore, "a preliminary definition of walking as a space of enunciation" (98), a definition that appears to reaffirm the notion that space can be read as a text. De Certeau qualifies this definition, however, noting that while walkers "write" the city, they do so "without being able to read it" (93). Together the city's pedestrians "compose a manifold story that has neither author nor spectator, shaped out of fragments of trajectories and alterations of spaces" (93). Thus, as I mentioned in the introduction, these "spatial stories" run contrary to what de Certeau terms the "erotics of knowledge" which seek the "pleasure of "seeing the whole,' of looking down on, totalizing the most immoderate of human texts" (92). By way of example, de Certeau likens this will-to-knowledge to the plight of Icarus whose "elevation transfigures him into a voyeur. It puts him at a distance. It transforms the bewitching world by which one was 'possessed' into a text that lies before one's eyes" (92). Similarly, such architectural phenomena as the World Trade Center, which provides another position above, "construct the fiction that creates readers, makes the complexity of the city readable, and immobilizes its opaque mobility in a transparent text" (92). From such a vantage point the observer can capture the sense of "seeing the whole" and, consequently, of being able to know the city. As seductive as such a position might be, according to de Certeau, the position above in fact symbolizes the "lust to be a viewpoint and nothing more," a viewpoint that appears to produce knowledge, but which constructs only "the fiction of knowledge" (92). Regardless 
of the form taken by the "vertical solution," the city experience remains unreadable and unknowable.

This position of knowledge, this viewpoint, is, of course, the very place Quinn tries to occupy, both in his earlier walks and in his attempts to map Stillman's actions. Again, while walking Quinn attempts to reduce "himself to a seeing eye." (4). By doing so, "Quinn endeavors to transcend the limitation of the walker, to become an all-seeing voyeur" (Willett 56). This desire becomes only stronger once he assumes the role of the detective, whose very function has been to immobilize the mysteries of the world by constructing a coherent text. In this respect, the detective both thrives on and perpetuates the "erotics of knowledge"-which sounds a good deal like Pynchon's "pornographies of deduction." As a writer of mysteries, Quinn knows only too well that his story must end with the "fiction of knowledge." The problem is that the conclusion he desires from the Stillman case fails to materialize, leaving him bereft of the moment of pleasure at which the perfect geometry, the "circumference," of the mystery comes into focus. Nonetheless, he continues to jot down every move that Stillman makes in the hope that the moment of gratification is yet to come. And indeed, Quinn's observational efforts do appear to produce a readable text, a clue that ought to lead to knowledge. Yet Quinn's map/text of Stillman's urban travels does not produce such a moment, in part because the question remains as to who produces the text/map found in Quinn's notebook: the walker or the reader? Quinn himself doubts his own discovery: "The letters were not letters at all. He had seen them only because he wanted to see them ... Stillman had nothing to do with it. It was all an accident, a hoax he had perpetrated on himself' (86). If this proves true, then Quinn has failed miserably as a detective, for the detective operates under the fiction that he is little more than a viewpoint collecting clues that have an existence a priori and apart from the detective's imagination. In Quinn's scenario, 
however, the very clue, the map, that would bring knowledge, or even the fiction of knowledge, arrives after the fact. Furthermore, Quinn's doubts suggest the possibility that the spatial act and its reader, the one who occupies a position distanced from the walker, do not coincide, meaning the detective is not so much reading the acts of the pedestrian as he is constructing his own story of the city.

While the novel allows for the possibility that Stillman actually does walk the path that Quinn traces in his notebook, even if Stillman intends to leave Quinn a message or clue, ultimately this message exists only in Quinn's reconstruction of the earlier acts, as a representation removed from the pedestrian's experience of the space, distanced from that of which Quinn is attempting to make sense. Thus, a gap exists between the experience of space and the attempt to know, read, or represent that experience. Auster highlights this gap in his description of Quinn's initial efforts to document Stillman's movements. While following Stillman, Quinn attempts literally to unite the act of writing and walking (signification and spatial practices) into a single, seamless act. Quinn discovers, however, contrary to his desire to know Stillman fully, that "walking and writing were not easily compatible activities" (76). Since Quinn must maintain constant surveillance, recording every gesture, he finds it "especially difficult to write without looking at the page" (76). The difficulty of performing the two tasks simultaneously frequently causes Quinn to transcribe "two or even three lines on top of each other, producing a jumbled, illegible palimpsest" (76). Auster's choice of words here is reminiscent of Lefebvre's answer to the question of whether it makes "sense to speak of a 'reading' of space" (142). While Lefebvre grants that 'it is possible to envisage a 'reader' who deciphers and decodes and a 'speaker' who expresses himself by translating his progression into a discourse"- the detective and the object of his pursuit — he argues that reading space is ultimately not possible "in that social space can in no way be 
compared to a blank page upon which a specific message has been inscribed ... Both natural and urban spaces are, if anything, 'over-inscribed': everything therein resembles a rough draft, jumbled and self-contradictory" (Lefebvre 142), and, therefore, inscrutable. While Quinn's will-to-knowledge does eventually convert Stillman's strolls through the city into a seemingly legible text, that on the surface appears to mean, this fact only highlights the gap that exists between the moment of observation, which in itself produces a palimpsest, and the moment at which the spatial act is converted into a readable text. This gap suggests once again that the detective is producing a fiction of knowledge rather than discovering out there in the world a concrete text waiting for him to decipher its meaning.

Quinn's inability to walk and write simultaneously is not the only moment in the novel that "defers the expectation that the city can be read" (Bernstein 138). To begin with, Quinn has failed to record the first four days of Stillman's travels, meaning his text can never be complete. Secondly, as Stephen Bernstein remarks the message itself, "THE TOWER OF BABEL" provides "yet another suggestion of the fragmentation, the unrecoverability, of reality as text" (138). Lastly, Quinn himself notes, "Stillman had not left his message anywhere. True, he had created the letters by the movement of his steps, but they had not been written down. It was like drawing a picture in the air with your finger. The image vanishes as you are making it. There is no result, no trace to mark what you have done" (86). As de Certeau explains, acts of walking "can be traced on city maps in such a way as to transcribe their paths ... But these thick or thin curves only refer, like words, to the absence of what has passed by" (97). The remaining written text or illustrated map, though "[i]tself visible . . has the effect of making invisible the operation that made it possible ... The trace left behind is substituted for the practice" (97). The act of walking, the moment of experience in urban space, leaves only a trace; 
furthermore, this trace is conceived only after the fact, as substitute for the act itself. The missing person vanishes, ironically, with a trace, but with only a trace that leads nowhere. Quinn hopes that Stillman's steps are indeed like words because, similar to his fellow detective Blue, he sees words as providing direct access to the objects they signify. Yet just as language is severed from the world, representations of space are severed from the spatial practices as well as the material spaces they supposedly reflect. Quinn assumes that he can know the meaning of the urban space that surrounds him, but discovers that he himself has constructed both a meaning for that space as well as that space itself. Just as he cannot recapture the first four days of Stillman's walks, he cannot fully recapture even the days during which he was present. The map/text comes always after the fact, at one remove. Auster's trilogy suggests, then, as Alford argues, that "our contact with space qua space is always secondhand; it is always a representation. Like the attempt to find an 'essential self,' interiorized and below or prior to language, we are forever consigned to inventing a nonexistent spatial 'ground"' (622). While Quinn's efforts to construct a text of the city produce a multi-layered jumble, Auster's fictional account of New York City, the urban text we read is impenetrable because it is all surface, as if nothing exists beneath the glassy veneer. As both Willett and Jarvis have pointed out, Auster's "cityscape itself is flat, uniform, without depth, its repetitions and lack of features creating what Edward Relph called the placelessness of place" (Willett 57), as instanced by Quinn's last trek through the city prior to entering the alley which is accompanied by a mere list of place names, a string of tags without descriptions. While both Willett and Jarvis read Auster's "aesthetic code of flatness" as a commentary on late capitalism, which in its penchant for reproduction robs every thing and place of a unique identity, ${ }^{3}$ I would argue that while their account is accurate it is also somewhat limited. Late capitalism 
has created a sense of placelessness not only because of its reproduction, but also because of the speed with which that reproduction occurs. Once circulation is sped up, it is much more difficult to determine where in the circuits of exchange the commodity, or walker, belongs; the idea is, in fact, to keep both commodities and consumers in constant motion. And it is also worth noting that the flatness of Auster's New York landscape is created by a complex set of social relations, that we term the city, of which economics plays only a part, even if a significant part. What Jarvis and Willett miss is that the placelessness of Auster's city is primarily a product of the very motion, the walking that the postmodern city demands. As de Certeau explains,

The moving about that the city multiplies and concentrates makes the city itself an immense social experience of lacking a place — an experience that is, to be sure, broken up into countless tiny deportations (displacements and walks), compensated for by the relationships and intersections of these exoduses that intertwine and create an urban fabric, and placed under the sign of what ought to be, ultimately, the place but is only a name, the City. The identity furnished by this place is all the more symbolic (named) because, in spite of the inequality of its citizens' positions and profits, there is only a pullulation of passer-by, a network of residences temporarily appropriated by pedestrian traffic, a shuffling among pretenses of the proper, a universe of rented spaces haunted by a nowhere of dreamed-of places. (103)

De Certeau indicates here that the city is not so much a place as a set of signifiers, representations of space that again defer the detective's attempts to penetrate the heart of the urban environment. Again, we are reminded of Quinn's walks prior to his becoming a detective, during which “all places became equal" (4). These walks allow Quinn to construct a city of his own making: "New York was the 
nowhere he [Quinn] had built around himself' (4). According to de Certeau, however, this is always the case for the walker, who rather than producing a stable place, "a-place-called-home," repeatedly reproduces a no-place of names. The palimpsestic jumble created by the network of pedestrian acts in the city, ultimately leaves the detective suspended at the surface, as if the city space were indeed flat. As with Quinn and his map of Stillman's travels, the detective has access to symbols only, beneath which he fails to find the meaning, or the proper place of which he dreams.

If as de Certeau argues the city, that "universe of rented spaces" is always "haunted by a nowhere," then when Quinn finally recognizes the homeless, those perpetually placeless walkers, he also comes to recognize what has been his predicament all along, that from the very beginning he, along with all the inhabitants of the city, has lacked a place. Rather than the secure, stable position he imagined, his rented space was little more than a representation of a home, and self. Quinn's lack of a place reminds us again of an irony inherent to detective fiction, that the detective, the one whose function is to place, himself lacks a "proper" home. On one hand, the detective, particularly the classical or armchair detective, constructs a position for himself that is removed from the urban space he observes, a position of knowledge which embodies both his place and his function simultaneously. From this position, the detective reads the urban environment, much as does de Certeau's voyeur, constructing a coherent narrative of clues that provide closure to the urban narrative. On the other hand, the detective, primarily though not exclusively the hardboiled detective, inevitably must enter the city, must leave the voyeuristic vantage point of knowledge and become a participant in the urban flux. In so doing, he exposes himself to the threat of becoming one of the homeless, placeless wanderers he observes. By having Quinn suffer this very fate, Auster suggests that the tramp, a figure reminiscent of 
Wakefield, is both the detective's opposite — one maps the individual in the city while the nomadic other cuts across the grain of urban planning — and the detective's kindred spirit, for the detective also inhabits a liminal space that offers only "pretenses of the proper."

Thus, as de Certeau indicates regarding the need for knowledge to construct a position for itself, it is not only Quinn's map that takes on the qualities of a fiction, but also the very position from which Quinn writes and reads this map. As Alford notes, "The map is not a simple representation of space. It represents a space from which perspective has been removed. The viewpoint of a map is an impossible one, one which no human could ever occupy, because to be human in space is to possess a perspective" (627). By constructing the map of Stillman's walks from a distance, from his home no less, Quinn removes himself, and his perspective - which as we have seen produces a jumbled, inscrutable text—from the experience. He becomes a mere viewpoint, but as we have also seen the very position, the homing point from which Quinn reads his map is always, already itself destabilized. Unlike Wakefield, whose point of origin remains constant, a home from which he might know his place in the world, the vantage point from which Quinn attempts to solve his case proves itself to be a construct. Auster's novel suggests, then, that the myth of "home" and the myth of a perspectiveless point of knowledge from which one maps or reads urban space are inextricably linked; both perpetuate the notion that the autonomous subject, or the detective, can stand apart, in a position from which he can demand that the urban environment "reveal" itself to him. Such a position turns out to be, however, yet another perpetually dreamed-of place. As Blue recalls from Thoreau's Walden, "We are not where we are ... but in a false position. Through an infirmity of our natures, we suppose a case and put ourselves into it, and hence are in two cases at the same time, and it is doubly difficult to get out" 
(200). Or in Quinn's case, he has supposed a space where he is not, and, therefore, is doubly trapped, another walker seeking a place where he only pretends to be.

\section{The Self/Other in the City of Glass}

The un-homing that Quinn experiences in the postmodern city is notably heightened by the structures or buildings that he confronts during his excursions through New York. If New York is a "city of glass" as Auster's title suggests, it is so in a dual sense, that is according to both a modernist and postmodernist architectural logic that co-exist in most contemporary cities. On the one hand, as Anthony Vidler argues, modernity was "haunted . . . by a myth of transparency; transparency of the self to nature, of the self to the other, of all selves to society, and all this represented . . . by a universal transparency of building materials" (217), i.e., glass. These new transparent materials were to produce a "new and modern subject" capable of "spatial penetration" $(220,217)$, much as this subject was thought to be capable of penetrating the mysteries of the universe as well as the human psyche. Access to the transparent buildings reproduced a feeling of knowledge, knowledge of the inner workings of both machines and humans. Furthermore, "Transparency, it was thought, would eradicate the domain of myth, suspicion, tyranny, and above all else the irrational" (168). The detective, obviously, would thrive in such a space, the fiction of transparency being amenable to the panoptic gaze under which surveillance is perpetuated and maintained. In postmodernist architecture, on the other hand, while transparent materials remain prominent, they signify something quite different than the ability to penetrate and know the space one inhabits. Once we move into the postmodern, we discover that what appeared to be unmediated access is yet another spatial illusion. As Vidler notes, glass also acts as a deterrent, a boundary that forbids access rather than granting it; thus, transparency "quickly turns 
into obscurity (its apparent opposite) and reflectivity (its reversal)" (Vidler 220). One of the best examples of this is the Los Angeles Westin Bonaventure Hotel of which Jameson has written at length. Sheathed in mirrored glass, the Bonaventure, as Jameson describes it, possesses a "great reflective glass skin" that "repels the city outside" (42). Jameson suggests that this glass skin "is not even an exterior, inasmuch as when you seek to look at the hotel's outer walls you cannot see the hotel itself but only the distorted images of everything that surrounds it" (42). Synecdochic of the larger postmodern city of glass to which Auster calls our attention, the Bonaventure by evoking former transparent glass structures simultaneously both invites the subject to look inside, to uncover the meaning beneath the surface, and refuses that very possibility. In the postmodern city, what once appeared as architecture of transparency "allows us neither to stop at the surface nor to penetrate it, (arresting us in a state of anxiety)" (Vidler 223). This is the liminal space inside which Quinn is trapped, perpetually on the verge of uncovering some great mystery, while remaining interminably on the surface, not so much looking in as looking back at a distorted image of himself and the space he inhabits.

Quinn's predicament becomes most apparent when, after his extended stay in the alley, he sees himself in the mirror on the facade of the building and, again, does not recognize the image as himself. "Feature for feature, he studied the face in front of him and slowly began to notice that this person bore a certain resemblance to the man he had always thought of as himself ... He tried to remember himself as he had been before, but he found it difficult. He looked at this new Quinn and shrugged. It did not really matter. He had been one thing before, and now he was another. It was neither better nor worse. It was different, and that was all" (143). While Quinn does not feel the anxiety of which Vidler speaks, a point to which I will return, his experience is certainly that of someone being suspended somewhere 
between penetration, of both space and self, and reflection, or better yet deflection. He is compelled to look deeper as if he will discover some kernel or essence that will assure him of his existence, yet what he finds in the mirror is always other, the other by which, ironically, he "knows" himself. As Lefebvre explains,

The mirror is a surface at once pure and impure, almost material yet virtually unreal; it presents the Ego with its own material presence, calling up its counterpart, its absence from—and at the same time its inherence in — this 'other' space. Inasmuch as its symmetry is projected therein, the Ego is liable to 'recognize' itself in the 'other,' but it does not in fact coincide with it: 'other merely represents 'Ego' . . Here what is identical is at the same time radically other, radically different — and transparency is equivalent to opacity. (185)

While urban space is haunted by the modernist ideology of transparency, just as it is haunted by the specter of the detective who participates in the production of transparent space, ultimately this is the space of a former logic.

Auster's commentary on the uncanny effect of postmodern architecture dramatizes a shift in the logic of surveillance, which Vidler suggests is "no longer panoptical" (160). Vidler quotes Alice Jardine who argues that we are "no longer in the system of the panopticon described so accurately by Foucault .. . we are rather in a mode of self-surveillance: we watch ourselves as someone else" (160). In other words, the city of glass has not so much facilitated the observation of the other as it has culminated in the observation of the self (a self to which the subject has no access). Auster's trilogy highlights this very point when it reveals that Quinn, as well as Blue and the narrator of The Locked Room, has been tracking only himself all along. He is the person who has gone missing, yet when he appears to 
rediscover himself, in the mirror, it is as if he were watching someone else, the other, as if he were condemned to monitoring himself while at the same time being denied entrance, unable either to resist seeking what is inside or to penetrate the surface. This is, in fact, the primary theme of Ghosts, in which Blue watches a virtually identical man in a virtually identical room for days on end: "in spying out at Black across the street, it is as though Blue were looking into a mirror, and instead of merely watching another, he finds that he is also watching himself" (172). The startling revelation for Blue is that, as Black tells him, he "needs" Black, the other "to prove he's alive" (216), just as Quinn needs the mirror to prove he still exists after vacating the alley. Again, though, full access is denied; both men are suspended on the surface of a city of glass, knowledge remaining other.

\section{Locked Rooms}

A symbol of denied access to knowledge, the locked room provides Auster with yet another spatial motif with a longstanding history in the genre of detective fiction. Although there are many variations on this motif, in the conventional detective plot it supplies the space of the crime; typically, a dead body is found inside a room that locks only from the inside, the question being how did the murderer get out, or in for that matter. In short, the locked room is both the site of mystery as well as a part of the mystery itself. Nonetheless, in the world of the conventional detective story, these rooms can eventually be unlocked as can the mysteries they held. In each of the books in the trilogy, Auster includes more than one allusion to or variation upon the locked room motif, but as one might guess in the world of the metaphysical detective story, such rooms are not so easily opened. In City of Glass, the final space inside which we find Quinn is a "windowless cubicle," formerly a room of the Stillman apartment, where he strips naked and finally disappears altogether-apparently the inexhaustible space 
of the city proves exhaustible after all. And in Ghosts, Blue spends his time alone in a room watching another man alone in an identical room. But it is only in the aptly titled final novel that Auster fully dramatizes the relationship of the locked room to both postmodern subjectivity and space.

As it turns out the narrator of The Locked Room, and writer of the first two books, does locate his missing person, or at least he comes close, for when he finally confronts Fanshawe, he does so through a locked door rather than face to face. The detective is suspended on the very threshold of locating the object of his pursuit, the locked door symbolizing the inability of the biographer/detective or subject in general to locate or know the other, a condition which ultimately comments on the ability of the subject to penetrate the self. As the narrator says, "No one can cross the boundary into another-for the simple reason that no one can gain access to himself' (292). As with the homeless wanderers in City of Glass, who "locked inside madness" are "unable to exit to the world that stands at the threshold of their bodies" (131), there is no way in or out of the locked room that is "located inside" the "skull" (345). The spatial barrier of the body itself represents an impenetrable ontological barrier within which lies an unsolvable mystery. The self remains a final locked room to which the detective has no key. This is the condition of the metaphysical detective, as one trapped in a city and self that denies both exit and entrance, a locked room of his own construction.

\section{"How to get out?"}

When confronting such spaces, spaces that resist attempts to intellectually contain or penetrate them, the common reflex has been to continue to try to solve them, to seek solutions detective style. As we saw in the previous chapter, Jameson's program of cognitive mapping exemplifies this kind of solution-oriented thinking. Auster's fiction, on the other hand, offers no such solutions. In fact, the 
trilogy critiques a number of proposed "spatial fixes," especially attempts to construct utopian spaces, a tradition to which belongs Stillman's hope of restoring the world, of making it "whole" again, by resurrecting a "new Babel" in the year 1960. According to Stillman, who proposes his ideas through the fictitious Henry Dark, "once completed the Tower would be large enough to hold every inhabitant of the New World [America]. There would be a room for each person, and once he entered that room, he would forget everything he knew. After forty days and forty nights, he would emerge a new man, speaking God's language" (59). Like the proponents of salvation through technological progress in Gravity's Rainbow, Stillman promotes yet another "vertical solution," as if the skyscrapers would eventually lift all urban inhabitants to that position of knowledge of which de Certeau writes, a spatial position from which the subject can literally be erased, and in this case eventually remade. Stillman's theory supports the notion that the secret to a utopian existence lies in altering one's spatial position, evoking a longstanding American tradition of utopian texts, and imagined utopian spaces, from the puritans, to the transcendentalists and on down to the modernist architects who sought to separate out their prized structures from the "degraded and fallen city fabric" (Jameson 41). ${ }^{4}$ Interestingly, unlike premodernist utopian dreams such as those of Thoreau, however, which sought a utopian space outside the confines of the city, Stillman suggests that the city itself will lead to salvation, somewhat analogous to the notion that the transparent building materials used to erect the modernist city would indeed lead to a moment of unimpeded knowledge. Yet, Auster's detectives find that such a construction leads not to lucidity but rather to more Babel, more confusion, for Stillman imagines yet another space designed to produce a moment of knowledge that never arrives, the dark room remains locked as it were, allowing neither exit nor entrance. 
Despite this resistance to spatial solutions, the narrator/author does, nonetheless, arrive at a discovery of sorts. He realizes, "My true place in the world, it turned out, was somewhere beyond myself, and if that place was inside me, it was also unlocatable. This was the tiny hole between self and not self, and for the first time in my life I saw this nowhere as the exact center of the world" (275). This does not mean that he has found a way out: "I don't claim to have solved any problems. I am merely suggesting that a moment came when it no longer frightened me to look at what had happened" (346). The metaphysical detective's conclusion is yet another non-conclusion; he locates a place that is a noplace, that resists the proper. Nonetheless, and this is likely why Quinn does not experience extreme anxiety upon not recognizing himself in the mirror, he at least comes to accept his condition (the postmodern condition?), freeing him from some of the terror of losing the very spatial certainties upon which he once comfortably relied. In short, the narrator comes to a point at which he resists the detective-like compulsion to suppose a place, accepting rather a non-place, a "neither here nor there" as Alford has it, to which he has no access. Unlike the detective, he accepts not knowing as part of the business of living in the space of the postmodern city. 


\section{NOTES}

1. Jameson argues that modernist architects such as Le Corbusier sought to isolate "the new Utopian space of the modern from the degraded and fallen city fabric which it thereby explicitly repudiates" (41).

2. One of the more striking scenes in Chandler's The Big Sleep is when Carmen Sternwood invades Marlowe's apartment — one of the few times we see him there. Her transgression of his home space, or the infiltration of someone connected to his present case, suggests that he, in fact, has no "place" to retreat from his life as a detective in the city; this might explain why he appears so uncomfortable with her presence. In Robert Aldrich's Kiss Me Deadly, based on Spillane's novel, Mike Hammer's office is, in fact, his home, which not only further suggests that he has no life outside the case but also indicates that he has no space to which he might retreat when the criminal element comes calling; his home is also in effect missing.

3. Jarvis argues that Auster's "aesthetic code of flatness . . is isomorphic with the economic code and spatial structuring of commodity capitalism" (88). He suggests, "Depthlessness here can be interpreted as an index of a socioeconomic system which perpetuates the establishment of placeless places and as a formal mimesis of the opacity and illegibility of its urban spaces" (89).

4. We could include as the postmodern entry on this list the clearly constructed Disneyland or Disney World fantasy versions of utopian space that keep cropping up in contemporary culture. 


\section{CHAPTER 3}

\section{In-Between Subjects and In-Between Spaces: the Out of Place Detective in Don DeLillo's The Names and Joseph McElroy's Lookout Cartridge}

As has been well documented, postmodernist fiction has exhibited a great deal of antagonism toward polarized thought. Discarding the dictates of binary logic, postmodernist fiction has sought to explore what Pynchon calls the "excluded middle." While the excluded middle has been read as primarily a spatialized metaphor representing a philosophical approach, according to the fictional accounts of Joseph McElroy and Don DeLillo, it is also itself a literal space, both imagined and lived, that is the space in between. I take the notion of "in between" directly from McElroy's Lookout Cartridge and DeLillo's The Names, two metaphysical detective novels which both use this exact phrase to describe the position of their respective protagonists. In tandem, these novels contribute to our story of detection and the history of Western space by highlighting, even more so than Pynchon and Auster, the neither-here-nor-there, the space in between which these novels reveal is not simply a space imagined by writers of postmodernist fiction, but is also a literal space created by and experienced within the conflicted history and logic that comprises postmodern culture and late capitalism. While the detectives in these two novels invoke once again a belief in the rational, compartmentalized space of modernism, they are unable to locate such a space-always in transit, they never arrive. Placed within the modulating space of the postmodern world, these metaphysical detectives find both themselves and the spaces they encounter repeatedly stranded somewhere in between.

Lookout Cartridge and The Names share more than a common phrase. Published nearly ten years apart-Lookout Cartridge in 1974, The Names in 1982 - they bear a strong family 
resemblance in terms of both storyline and subject matter; in both narratives a traveling businessman turns detective in an attempt to crack a case that itself spans multiple geographic regions. In Lookout Cartridge, we have the highly complicated story of an "International Businessman" named Cartwright—an American expatriate living in London—who turns amateur sleuth in search of several missing reels of an experimental film he has shot with his friend Dagger. Having been informed by Dagger that the entire film was burned by an unknown saboteur, Cartwright decides to investigate just who would have done such a thing and why. Through what becomes a geographically expansive investigation, Cartwright finds that the initial whodunit spiders into subplots, conspiracies, and subconspiracies, which, reminiscent of Gravity's Rainbow, even the conspirators themselves cannot fully comprehend or control. While Cartwright appears always on "the verge of a formulation" (470), his detective work repeatedly fails to connect all the dots, primarily because his case does not coincide with the closed circuit of the classic detective novel; rather, he stumbles into what he describes as a "multiple system" (439), not one crime, plot, or conspiracy but a rapidly growing network involving anti-government subversives, multinational corporate giants, as well as "common" criminals—often it is difficult to tell which is which.

Despite his failure as a detective to resolve the situation, Cartwright does eventually learn what happened to the film. As it turns out, Dagger, fearing for his safety, has only staged the film's destruction because he realizes that they have filmed, whether inadvertently or not is never fully clear, members of a hodgepodge gang of revolutionaries in the middle of hatching a grand scheme to overturn corporate America. Cartwright discovers that part of this "revolutionary" scheme involves blowing up a warehouse owned by the Flint family who head a multinational conglomerate "so complex in its indirect 
holdings not even Jack [the eldest of the Flint brothers] had it all in his head" (406). But despite the fact that Cartwright gathers what appears to be significant information, he still fails as a detective. While he unearths the plan to attack the Flint warehouse prior to the actual event, he can do nothing to stop it from happening — Cartwright witnesses the explosion from a helplessly distanced position, hovering over New York City in a helicopter. And by the time the supposedly revolutionary act takes place it is no longer clear who is still in on the plan. Ironically, the idea supposedly originated with one of the Flint brothers, Paul, a capitalist turned revolutionary whose loyalties are unclear to say the least; however, Paul later attempts to call off the bombing, having given up on "effective political action" (406). By the time of the bombing, not even the members of the group of subversives are sure who is or is not still in on the scheme, nor is even its purpose any longer clear; some in the group are more interested in violence for its own sake than political change. To complicate matters, Jack Flint himself knows of the plan well in advance, and it appears that he will actually benefit financially from the warehouse's destruction, as if the revolutionaries were working for him all along. In the end, Cartwright is left with lots of information but nothing that would cause "things . . to come together" (358); the system continues to multiply. In a final bit of irony, Cartwright himself burns the film after realizing that it is not so much the film as what various parties think is on the film that is important. The detective himself commits the crime. Thus, the detective not only fails to fully crack the case; he himself becomes the criminal in the process, much in the tradition of Alain Robbe-Grillet's The Erasers in which the detective literally shoots the man whose murder he is trying to solve. ${ }^{1}$

Also a work of metaphysical detective fiction, Don DeLillo's The Names tells the story of a man, James Axton, who is like Cartwright an American turned world traveler; he travels so much in fact 
that he begins to think of himself as a "perennial tourist" (43). A risk analyst who projects the possibility of terrorism in various countries and regions, Axton traverses the globe in an effort to aid "the world's biggest, richest companies" in "protecting their investments" (12). ${ }^{2}$ While living in Greece, Axton becomes engaged in a mystery after learning of a cult—a group of men and women from a variety of nationalities and backgrounds who have fled their respective cities — that has committed and continues to commit a number of murders targeting vagrants and invalids. Axton's interest in this group involves the question of motive, of why they murder. Though the answer to this question is never perfectly clear, we do find out, mostly through Owen, an archeologist who actually lives with the cult at one point, that the murders constitute an attempt on the part of the cult to reconnect language to the world, to things. After chasing a number of leads, Axton, now "the social theorist, the interrogator, the criminologist," discovers almost by accident that each victim is killed in a village whose initials match those of the victim. This discovery contents Axton for a time, almost as if understanding the cult were tantamount to making sense of the world. However, despite Axton's initial elation at his discovery, merely knowing the pattern does not in the end solve anything for him. The fact the initials match does not create closure but only more mystery, for, ultimately, neither the cult nor its motivation makes "logical sense." The cultists have no homes, no jobs, and no nationality — they even speak more than one language. Transients in the truest sense, they represent all that opposes the logic-based assumptions of the detective, that people fit in the world, that we all have a unique place or position within the order of the universe. Unlike Axton, who maintains a foothold in the supposedly ordered space of western civilization, the cultists have ventured into the deserts of the world, those spaces ostensibly outside societal purview. While Axton and Owen repeatedly discuss possible "theories" concerning the cult, 
Axton confesses, "We knew in the end we'd be left with nothing. Nothing signified, nothing meant" (216). As with his job as a risk analyst, Axton's ability to gather information has no impact on subsequent events. He merely predicts terror; he does nothing to stop it from happening. Because he fails to fully explain or stop the cult murders, the system the detective safeguards itself becomes vulnerable; by defeating the detective, the murders threaten society's maintenance of social order. As Owen explains, "These killings mock us. They mock our need to structure and classify, to build a system against the terror in our souls. They make the system equal to terror. The means to contend with death has become death" (308). These are crimes the detective simply cannot rationally resolve.

Even more startling, the detective, the agent of order, himself becomes equal to the terror he has attempted to analyze and evade; Axton's final discovery is that the insurance firm he works for is connected to none other than the CIA, an organization engaging in terror across the globe. Thus, Axton's information not only fails to stop terror but appears to be used to create more violence, making him an accomplice. He remarks, "Those who engaged knowingly were less guilty than the people who carried out their designs. The unwitting would be left to ponder the consequences" (317). Similar to Pynchon's indictment of the ideology of detection, DeLillo suggests here that the detective is part and parcel of the system, used in this case to advance its program for global economic and political domination. Axton's discovery of his role in the world of intelligence makes him simultaneously the good-guy detective out to rescue a fallen world and the initiator of violence, of murder no less. Finding himself perpetually in between, Axton appears unable to stake a claim to any "side" in this affair, and Cartwright is no different. Cartwright's ability to gain information results from the fact that others fear he knows too much, an assumption they base largely on the fact that he kept a written diary of the 
making of the film. As is common in the detective genre, Cartwright uses the fear of others to manipulate the multiple systems he encounters, leading others to believe he knows even more than those in on the "caper." But, unlike in the classic or hard-boiled detective novel, this ploy does not so much thwart future violence as it implicates Cartwright himself: "I found myself to be helplessly a collaborator, mingling beyond mere will with the mixed obsessions of others" (395). He comes to the distressing realization that his investigation has "actually increased the chances of violence" (408) rather than containing it. In fact, Cartwright is partly responsible for the deaths of at least two men, though in both cases the deaths can be explained away as accidents, making his role again ambiguous. Cartwright is not only implicated in the acts of the revolutionaries; he also seems to have participated in the corporate web that is the Flint family firm. In regard to one of several of his "random enterprises," Cartwright is unknowingly an "erstwhile U.K. rep” for a science firm in which Jack Flint owns “controlling interest," meaning Cartwright has all along "been working part-time for Jack perhaps" (465-66). Like Axton, Cartwright is a detective caught in between, a solver of crime and its precipitator simultaneously.

While these plot summaries show how each novel uses "in between" as a metaphor for a moral or ethical crisis suffered by the detective, in both novels "in between" also refers to an actual physical, as well as metaphysical, space or spaces. As we will see, both novels offer a picture of postmodern space in which the detective finds not only that he is in between spaces but that these spaces themselves are now, paradoxically, in between; this includes the space of the home, the one-time symbol of spatial stability. 


\section{Familial Space In Transit}

As I mentioned, Cartwright's all-consuming investigation requires him to leave his home for extended periods of time - "home" for him, as an American expatriate living in England, being not exactly a stable position from the start. The mystery carries Cartwright overseas to New York, that is ironically "back home," as well as to such isolated spots as the Hebrides. While Cartwright travels the globe in search of clues, his family life back "home," i.e., in London, begins to unravel. Guilty of his own infidelities, Cartwright discovers that his wife has become friendly with another man; furthermore, his daughter is dating a young man connected to the political activists Cartwright suspects of wrongdoing and who eventually try to kill Cartwright. Even more troubling is how Cartwright discovers these facts, by spying on his own family. Having returned to London without his family's knowledge, Cartwright intends to return home; however, while standing across the street from his house, Cartwright discovers another man kissing his wife goodbye (120). Reduced to a voyeur in his own life, Cartwright does not intervene but passively watches and then leaves without even letting his wife know where he is, as if he had no responsibility to his family at all. Still, Cartwright continues to identify himself with his London home, and, eventually, he does return, but only to find, in another variation of Hawthorne's "Wakefield," that he no longer possesses a key to his front door. While he was in New York, someone burglarized their home to steal the film diary, damaging the lock which had to be replaced. Cartwright's inability to access his own home symbolizes the extent of his displacement from his familial space. Cartwright is the family man now without a family; the homeowner without a key. While he makes intermittent stops at his house throughout the novel, he remains an outsider, or both inside and outside simultaneously. 
The most extreme instance of Cartwright's position simultaneously both in and out of his familial space comes when he spies on his own daughter in New York. While she has apparently traveled there to save his life, and has, consequently, placed herself in danger, Cartwright simply trails her without intervening, refusing to fill the traditional roles of father, husband, or detective as if he were merely a lookout. In some senses, this allows Cartwright to be a better detective; detached from familial entanglements he can devote himself to solving global mysteries. As we saw in the discussion of Auster, the classic detective has typically lacked attachment to either a home or family, responsibilities which might muddle his social function. Cartwright, however, appears to want it both ways, to be the detective — one gaining knowledge and mastery through distanced scopophilia—and still be able to maintain a connection with a familial space, with a home. As with the classic detective who keeps a foot in both the world of crime and that of the middle class, this attempt to maintain two, often conflicting positions places Cartwright in a precarious spot, that is somewhere in between. ${ }^{3}$ DeLillo's detective, Axton, inhabits an equally liminal position, but in his case no one has stayed home to maintain the familial space as the locus of stability. Axton's wife, Kathryn, and his son, Tap, have themselves become expatriates and world travelers, temporarily living on an island off Greece where she works at an archeological dig. Contrary to patriarchal assumptions, in this instance, the wife no longer holds down the home. There is in fact no "home" left. It too appears to be in transit. Axton's familial problems have progressed further than Cartwright's; he and Kathryn are officially separated, though not divorced. The family unit is eroding but has not completely crumbled. In an attempt to preserve what remains of his familial space, Axton has taken the job as a risk analyst because the main office is closer to his family, that is, in Athens where Axton frequently stays but refuses to take up 
permanent residence. Ironically, then, he abandons his American home because despite the travel involved, his job actually allows him to see his family more often. At the same time, however, the "boundaries" that Axton sees his family as providing him have become undeniably blurred once his family turns nomadic, causing Axton to realize, "There was nothing to come back to if I failed, no place in particular I belonged" (49). Unlike Cartwright, or Auster's Quinn, Axton from the beginning does not even have a space he can imagine as his home; his familial space, or at least that which represents it, is already half-way around the world. It is no wonder Axton feels like an "outsider" in his own family (8). Nevertheless, ignoring the advice of his boss Rowser, a CIA operative who has severed all familial ties, Axton refuses to divorce, remaining both married and not married, another form of in-between. He holds on because his family provides him the only sense of "place" he knows. While spending time with Kathryn, Axton undergoes a renewed sense of connection, not only to her but "to the physical world" as well, a sense of "Being here. Everything is where it should be" (32). This feeling of belonging does not last, however. Axton discovers that his wife and son are going to move to British Columbia, meaning the familial boundaries that temporarily provide him a sense of his "place" in the world will once again be stretched and possibly ruptured. Realizing that his position in the world has become tenuous at best, Axton concludes, "My life is going by and I can't get a grip on it. It eludes me, it defeats me. My family is on the other side of the world. Nothing adds up. The cult is the only thing I seem to connect with." (300). Unfortunately, his discoveries concerning the cult do nothing in terms of helping him relocate his place, either within the family or in the world at large. As his name suggests, Axton is split, condemned to a life apart.

The familial status of both of these metaphysical detectives highlights, then, a disruption of the 
once central, and centralizing space of the family unit. Interestingly, by placing their respective protagonists within the network of multinational capitalism, both novels suggest that the erosion of the home - the space which the family unit has both produced and required to sustain itself — has resulted, in part, from the expansion of global capitalism and its effect on our perception of space. In both novels the familial space is rapidly becoming a residual space, a longed for haven without which, as Axton recognizes, the idea of locating one's place requires serious rethinking. This becomes even more apparent once we recognize what the production of familial space has meant to the production of social space in general. According to Lefebvre, "Familial space, linked to naturalness and genitality, is the guarantor of meaning as well as of social (spatial ) practice. Shattered by a host of separations and segregations, social unity is able to reconstitute itself at the level of the family unit, for the purposes of, and by means of generalized reproduction" (232). Thus, by destabilizing both the family unit as well as the enclosed space of the home which it requires to sustain itself, both novels dramatize a crisis of significant consequence to the production of space within the conventions of Western metaphysics. While Axton and Cartwright never fully reject either their belief that familial space can recover its position as the locus of social stability or that they still possess the ability to reclaim their former places within that space, both detectives find that within the modulating space of the world markets in which they participate, the space of the family is in fact vanishing before their eyes, and with it the broader social unity it once insured. Only the hazy specter of a once securely bounded space remains. This explains why men like Rowser abandon the familial space altogether, opting instead for the developing politico-economic networks that spread across the globe; the latter seems to be the only space that counts. Yet, as the plight of our detectives reveals, entering these networks does not provide one with 
a new "home" or sense of unity but rather, leaves one perpetually in between.

It is worth noting that the sense of loss coinciding with the breakdown of the home is, in both novels, an experience reserved almost exclusively to men. In Lookout Cartridge Cartwright's wife Lorna, although she may not remain completely faithful, still continues to maintain the home-space, and in The Names while Axton's wife, Kathryn, has exchanged the stability of home for international travel, this does not appear to trouble her in the way it does Axton. The difference in response, particularly between Kathryn and James Axton, suggests that the production of space and the construction of gender identities are mutually informing. Gender is, of course, especially pertinent to the production of the home space, a space that as Doreen Massey argues, has been simultaneously a haven for men and a site of limitation for women. Massey suggests that 'the identities of 'woman' and of the 'home-place' are intimately tied up with each other" (180). She explains further, "The construction of 'home' as a woman's place has . . . . carried through into those views of place itself as a source of stability, reliability and authenticity. Such views of place, which reverberate with nostalgia for something lost, are coded female" (180). This explains why Axton mourns the erosion of his familial space; it costs him both a physical place to live and a sense of stability. Formerly, men such as Axton were free to roam the fragmenting networks created by capitalist expansion while still retaining a sense of unified identity precisely because the home remained in place, the wife there to insure its stability as well as the stability of masculine identity. For Kathryn, however, the home is not so much a source of comfort as a means of confinement. As Massey contends, “The limitation of women's mobility, in terms of both identity and space, has been in some cultural contexts a crucial means of subordination. Moreover the two things - the limitation on mobility in space, the attempted consignment/ confinement to particular places 
on the one hand, and the limitation on identity on the other-have been crucially related" (179). The opening up of familial space that we see in DeLillo's novel allows Kathryn, therefore, to explore spaces and identities formerly closed off to women; she is transported from America to Greece, transformed from housewife to archeologist. She does not mourn the loss of home as does her husband because for her the breakdown of the home equals a new sense of mobility. This does not mean that she is any less in between than Axton, only that because of the spatial limitations to which she has been subjected, she perceives the space in between as a space of possibility, a space in which she can recreate her place and her self. To Axton, however, Kathryn's mobility presents a threat to both his sense of self and place. Once Kathryn is on the move, he can never go home again; he cannot recover either the stability or sense of spatial domination he once enjoyed. The familial center no longer holds; it has been re-placed with the space in between.

\section{In-Between Geography}

As Axton and Cartwright's involvement in world finance and travel would indicate, the spatial commentary offered by these novels extends well beyond the state of familial space. Even prior to undertaking the quest to solve their respective global mysteries, both Axton and Cartwright must respond to the geographical condition of late capitalism, under which, again, space is "being recast: in response to the growth of air transport, particularly in its geopolitical dimensions; in response to various new industries (computers, leisure, the extraction of petroleum and other resources); and in response to the expanding role of the multinationals" (Lefebvre 351). Participants in these retooled spaces of burgeoning economic, political, and technological networks, Cartwright and Axton find themselves as a result not only in between homes but in between home countries as well. 
Reacting to the "expanding role of the multinationals," Cartwright imitates their efforts to create and take advantage of a global marketplace. A "regular globe-trotter" as one character puts it (38), Cartwright frequently travels to and buys goods in one country with the intention of selling those goods in one or more other countries so as to maximize his profit. Already a man of many nations, his willingness to take on the case of the missing film only exacerbates his condition, uncannily, allowing him to be "two places at once" (115). Cartwright can spy on his family in London as well as investigate the London branch of the revolutionaries without fear of being found out because the concerned parties assume he is still visiting New York-each one of the characters at some point is confused as to Cartwright's precise whereabouts. Relishing his new found evasiveness, Cartwright, when asked by his wife why he went to New York in the first place, answers, "I'm in New York right now" (124). And, later, when Cartwright, who while supposedly in New York has actually been in London, returns again to New York, he suggests this "was not a return, except to my true whereabouts" for he was always "virtually in New York though in London" (163). Cartwright exists in the perpetual paradox of being where he actually is at a given moment as well as where everyone else thinks he is - this includes the reader who, due to the text's frequent spatial, temporal, and ontological shifts, can easily lose track of the detective's position. Tracking Cartwright becomes even more difficult once his travels extend beyond the confines of America and England. His global investigation leading him to such places as Glasgow and the Hebrides, Cartwright's "American trip" quickly grows "many centers" (413). Like the case itself, his whereabouts ramify, placing him "between many people in many directions" (378), as well as between multiple geographical locations. What begins, then, as a simple geographical misunderstanding becomes a running joke with significant geographical as well as metaphysical 
implications.

Cartwright's sense of being both physically and metaphysically in between is, as Lefebvre's remarks would indicate, a direct product of the technologies of the second half of the twentieth century. McElroy emphasizes in particular the effects of air travel on Cartwright's experience of space. During his frequent flights across the Atlantic, Cartwright loses track not only of time, a common enough experience, but also of his sense of place, a less common experience. Just as Cartwright is the detective who never reaches a conclusion, due to the speed of air travel, he has become a traveler who never arrives, or departs. Furthermore, Cartwright suggests that the plane itself creates a new space in between. Alluding to the title of a section of the film, he remarks, "The plane was like an Unplaced Room" (109), that is a space void of national or geographical markings or borders. McElroy also implicates the telephone in the production of this space in between. Throughout the course of the novel, Cartwright engages in a number of phone conversations to and from a variety of locations in which the recipients of his calls have no knowledge of Cartwright's physical position. As Cartwright notes, “On the phone one may lose some sense of where places are" (501), calling into question the very notion of place. Technology has created, then, a new space, what Cartwright calls "a dimensionless space in between" (292) that escapes former geographical definitions and delineations. This new space has restructured the once tightly sealed geographical boundaries that maintained both nation and national identity, creating gaps where there were once only walls, an in between where there was once only a here or there. Of course, the development of the computer and cyberspace has produced a much more radical example of placeless spaces; however, writing in the early 1970's, McElroy is actually ahead of the game in recognizing the potential for technology to alter our experience of space, to 
produce a space that lacks land-based, geographical dimensions.

While one might argue that Cartwright's condition is anomalous - not everyone travels that frequently-McElroy's novel suggests that his sense of displacement is quickly becoming commonplace. In fact, Cartwright's highly sought after film has as its theme "the American's increasing disjunction from his environment and the need and arresting capacity to assert an existence and a self in a departicularized setting" (70). Cartwright and Dagger attempt to capture this "departicularized setting" in the opening episode of the film, "The Unplaced Room." While the segment is shot in an undeniably particular setting, a house in England, the scene features only two men, one a deserter from the American army no less, conversing inside a a generic, bare-walled room. Thus, the room is made to appear as "a room that could be anywhere, that was the point, a point" (106). Cartwright describes the effect as follows: "At that moment the room, unplaced in word or light or sign, resumes a power it first had had in the bare tableau like a still. So place is felt to be not always or at least visibly the one of national coordinates or crystallized history" (141). Both the impetus of the scene as well as Cartwright's description of the room implies that place need not necessarily be defined by geographic or temporal boundaries, as if the room is itself a "dimensionless space in between." Later, Cartwright, upon noticing the "liquid stir" of New York, wonders if "Terminus the god of boundaries and property may be subject to Mercurial delusions" (512), suggesting that although imagined as static, places are actually in flux. Add to this Cartwright's perplexing experience of being from or in two or more geographic locations simultaneously, and the land-based markers by which we define the urban, national, or other geographic regions or spaces certainly appear to be in crisis right along with the space of the family. 
McElroy's emphasis on the way this crisis involves "national coordinates" is especially

significant. While the family unit centralizes the production of space in a localized setting or under a specific ideological regime_ one's city for instance — as an extension of familial space, the nation has a similar impact on how one imagines space on a global level, particularly for Americans who tend to see the space of the world as an extension of our own economic and political systems. Once the spatial parameters by which we define nations begin to break down, however, another spatial anchor through which we identify, or place ourselves is lost. Although the nation still exists, Cartwright finds that having entered the unmappable space of the newly arising economic networks crisscrossing the globe (the hyperspace of control), he can no longer use the space of the nation to orient himself because the global space of late capitalism has reconstituted both national coordinates as well as his experience of space; the postmodern subject now belongs to all places as well as to no place, as does capitalism itself. At the same time that the expansion toward a global economy has placed more spaces at capitalism's disposal, it has also, somewhat paradoxically, left capital, much like the floating signifier, without a place (home) of its own; it is everywhere but nowhere in particular. While monopoly capitalism sought to organize clearly defined, and enclosed circuits of exchange, in its advanced form, capital is defined more accurately by flows, ${ }^{4}$ those (non)structures that arise in keeping with the regime of control so effectively portrayed in Gravity's Rainbow. In this respect, we might argue that Cartwright, and Axton, both literally and figuratively, merely follow the lead of capital, which is itself always in between. Notably, the very form of McElroy's novel evokes a sense of disjunction, transferring Cartwright's displacement to the reader. Although it appropriates the detective genre, unlike its model, with its insertion of frequent, unannounced temporal, spatial, and ontological shifts- - we find ourselves 
repeatedly asking “where am I ?"-Lookout Cartridge purposefully sets out to disorient the most astute reader. ${ }^{5}$ Even our narrator, Cartwright, sympathizes with the reader's plight; recognizing the difficulty of keeping up with his narrative, he reminds us, "If you are not sure where you are, you have me" (8). Having the advantage of anchoring ourselves to Cartwright would provide some comfort if he were a classic detective, whom we could trust to lead us to a satisfactory conclusion, or place. However, while the classic detective novel moves toward a specific destination, Cartwright is the detective who never arrives, remaining both morally, psychically, and physically in-between. The novel leaves us not only without a solution to "the crime" but also without a clear sense of how to orient ourselves temporally or spatially, of where to position the detective or by extension ourselves. Fittingly, the novel ends with Cartwright in New York, his home that is no longer his home, at his friend Sub's apartment, where he continues to feel "out of place yet also not wholly here" (529). In regard to both the space of his home and nation, at the conclusion, or anti-conclusion, of the novel, our detective remains in between, as does the reader.

Themes of national and global displacement figure prominently in The Names as well. Participants in multinational capitalism, Axton and his friends comprise a subculture of "corporate transients" (54). Although they continue to identify with and claim America as their home, these men and women actually have no permanent residence, spending much of their time literally "in transit," that is inside airports or aboard airplanes, outside traditional geographical boundaries. While the ability to travel at high speeds purports to offer Axton and his circle the possibility of connecting to increasingly more spaces, it actually intensifies their growing sense of disconnection. As Lindsay, the wife of a multinational banker, notes, "They keep telling us it's [the world] getting smaller all the time. But it's not, 
is it? .. . It's one big tangled thing . . . Modern communications don't shrink the world, they make it bigger. Faster planes make it bigger" (323). Lindsay's comments suggest that Axton, like his fellow metaphysical detectives, suffers from the "dilemma which is the incapacity of our minds . . to map the great global multinational and decentered communicational network in which we find ourselves caught as individual subjects" (Jameson 44). The technology imagined to connect Axton to more people and more places, by reconstructing the very notion of place, has led, paradoxically, to stark feelings of displacement. Where our detective once imagined distinct spatial coordinates, he now finds a worldwide entanglement of expanding economic and technological networks, inside which, again, capital itself has no place, but, rather, remains in constant, rapid circulation.

Although he seemingly desires a fixed place in the world, Axton realizes finally that, like Cartwright, he has "traveled between places, never in them" (my emphasis 143). This is true even of Athens, where Axton supposedly "lives.” As he says, “Athens was my legal home but I wasn't ready to give up tourism, even here" (44). Remaining a tourist appeals to Axton, despite his conflicting need for a place, because as he explains, "To be a tourist is to escape accountability" (43). As long as he remains in transit, Axton feels responsible to no place. Despite the appearance that Axton's "living apart" is of little consequence, as if it affected no one or nothing but himself, DeLillo's novel gradually reveals that this refusal to be grounded in a place has a very real effect on the production of space. Being a perennial tourist requires the discarding of traditional spatial definitions, under which space is static and every one and thing has a stable place. Once our detective, a guardian of spatial stability, refuses to accept a "place" in the system, the very concept of place-home, nation, etc. . - - becomes increasingly destabilized. The politico-economic networks that have enabled Axton and his friends to 
live in transit have along the way produced a space void of permanence. Thus, Axton is trapped within a spatial contradiction. While he continues to desire the stability of the family unit, once central to the production of social space in the West, he simultaneously takes advantage of, and, therefore, helps reproduce the very global spatial logic that is largely responsible for the destabilizing of formerly fixed places such as the home.

Interestingly, much like Lookout Cartridge, The Names implies that this contradiction between desiring a fixed space with which one can identify and a flexible space in which one can move freely is somewhat of an American tradition. On one hand, in both writing and speech, Americans, from European contact up to the present, have undeniably exhibited a striking preoccupation with the land that defines America geographically. Characterizations of the space that is America have, moreover, been used regularly to define what it means to be an American; for instance, there is an obvious connection between the fact that America's land stands physically apart from Europe and the identification on the part of Americans with independence. On the other hand, as Axton's film maker friend Frank Volterra suggests, "aimlessness" and "drifting" are "the pure American thing" (155), which implies that Americans have no attachment to the land or space that is geographically speaking designated America, but rather are defined by their ability to defy geographical limitations. This contradiction, seemingly inherent to American cultural logic, becomes increasingly difficult to deny once America's sense of identity, both spatial and otherwise, is extended to a global arena. As Eliades, a Greek operative, astutely observes, under late capitalism, “Americans learn geography and world history as their interests are damaged in one country after another" (58). That is to say, Americans imagine the world's spaces as an extension of their economic networks rather than according to 
geographic dividing lines. The problem is that by doing so Americans erase the geographic delineations by which they are identified, making it increasingly difficult to maintain a sense of place within the expanding global territories that Axton navigates. As he discovers, the harder he works at recovering a place for himself, the more aware he becomes of the impossibility of doing so. Once again he finds himself in between, or inside a new globalized space that, reconstituted to facilitate the rapid flow of multinational capital, allows one to travel only between and never in places. If it were not troubling enough that our detectives seem hopelessly unable to solve the respective "crimes" and in so doing repair the social order the detective is supposed to safeguard, we now find that they stand idly by as the very spaces by which that social order is defined and reproduced come under attack. In fact, just as their search for clues perpetuates more violence, their global, technology-assisted search for spatial permanence contributes to its disappearance.

\section{Consumable Spaces}

While postmodern spatial production has altered our perception of both home and nation, as well as geography in general, these are certainly not the only spaces that are affected by the increasing globalization that our detectives confront. Along with the space of the home and nation, both metaphysical detective novels also pay close attention to various tourist spots around the globe which, though produced under a former spatial regime, remain within the postmodern landscape. As we will see, both novels portray such spaces themselves as being caught in between, historically as well as ideologically.

In their travels, both Cartwright and Axton are associated as much with tourism as they are with world finance. Not only do these global detectives often act like tourists, frequently consulting maps or 
purchasing souvenirs, but both actually pay visits to popular tourist sites; Axton visits the Parthenon and Cartwright travels to Stonehenge as well as the Stones of Callanish. One implication of connecting these men to tourism is that the detective, whose job it is to observe the landscape as if from an outside position and, for the contemporary private eye, to record those observations on film, has always been a tourist of sorts. While we saw in Auster's fiction that the detective is necessarily an outsider, maintaining a foothold in at least two worlds, in Lookout Cartridge and The Names the detective's ability to stand apart has now become a state of passing through. By conflating the work of detection and tourism both novels expose a rift inherent in the ideology of detection, that the one who once placed is now himself without a place. At the same time, these novels also dramatize tourism's effect on the production of space, and the subject in space, in the late twentieth century. Although tourists assume that they occupy the position of observer, as if they look only, without altering the space in question, both novels indicate that tourism, especially in the age of high speed travel, has significantly altered space and our perception of space. As Dean MacCannell contends, "tourism is not just an aggregate of merely commercial activities; it is also an ideological framing of history, nature, and tradition; a framing that has the power to reshape culture and nature to its own needs" (1). Much as the detective purports to stand apart but in reality perpetrates a strict set of spatial representations and perceptions, the tourist, who passes through as if without consequence, also in actuality helps "frame" postmodern space as well as our notions of space. Specifically, tourism constructs space itself as a consumable object. Lefebvre explains, "neocapitalism and neo-imperialism share hegemony over a subordinated space split into two kinds of regions: regions exploited for the purpose of and by means of production (of consumer goods), and regions exploited for the purpose of and by means of the 
consumption of space" (353). Just as the proliferation of multinational corporations expands the available spaces of production, it also, by extending the geographical limits of capitalism, makes available to the tourist a variety of readily consumable spaces.

The question is what has the imperative to make spaces fit for consumption done to our experience of such spaces? David Harvey argues that through "entertainment palaces like Epcot and Disneyworld ... it is now possible to experience the world's geography vicariously, as a simulacrum" (300), but what about the historic sites themselves, such as Stonehenge, that such amusement centers often replicate? While Harvey stresses the virtual experience of spaces which are clearly reproductions, DeLillo and McElroy suggest that the increase in tourism has managed to transform the original places themselves into simulacra. As one of Axton's friends recognizes, "New places are a kind of artificial life" (130), a simulacrum of what it means to live in places. For both Axton and Cartwright this holds true even when the "new places" come in the form of extremely old structures. For example, when Cartwright visits Stonehenge, a setting for his film, despite the religio-political history of this place, it has no more impact on him than would a cheap reproduction. Concerned only with the making of his movie, Cartwright appears to see Stonehenge as if it were already on film, as if at one remove. Interestingly, Cartwright and Dagger are not the only ones shooting a film at Stonehenge. As it turns out, another party is making the same film, or at least a parallel film, staged at the same location — at times the respective cameramen film each other filming, removing themselves further from the space in question. Whether the Stonehenge Cartwright visits is the "real" thing or not matters little because this filming and re-filming transforms Stonehenge into what amounts to a Hollywood backdrop, a simulacrum of itself. ${ }^{6}$ 
Cartwright's inability to make a connection to Stonehenge takes on further significance when considered alongside the novel's implication that the mysteries of the world might be solved by linking a variety of historic and geographic points of interest throughout the world, most notably the two sets of stones and the Mayan ruins. But, while each of these ancient sites possessed at one time a symbolic, religious, or political function, they have now become mere tourist attractions, robbed of their former meaning. It is no wonder, then, that Cartwright cannot make the connection either to these "sacred" spaces or between them. He is the detective - the one who conventionally reconstructs, preserving the social and symbolic — become tourist, an ineffectual onlooker who sees only as if through a camera, making no contact himself. Cartwright's reaction, or non-reaction to Stonehenge also speaks to the “increasingly pronounced visual character" of the spaces of late capitalism (Lefebvre 75), or what DeLillo describes as the "evolution of seeing" (179). Cartwright, our detective, in the shadow of Stonehenge fails to react to its purported magnificence because, reproduced by and for the tourist, this space has been made both consumable and disposable; it is to be seen, not lived, as if the tourist photograph were already built into the experience of this space. A simulacrum of its former self, the tourist space like Marx's commodity is both material and abstract at the same time, or always somewhere in between. It is both an original — historically imbued with an ideological function—and a reproduction—made for consumption—simultaneously. Unlike the classic detective who studied the spaces he confronted carefully and thoroughly, Cartwright, the metaphysical detective/tourist, quickly moves on to the next point of interest.

While Lookout Cartridge reflects the ways in which tourism has transformed historical spaces into simulacra, The Names stresses more emphatically the ways in which global tourism has isolated 
such sites from their former spatial logic, as we will see, producing new spaces of conflict and contradiction. From the opening page of the novel, Axton fixates on the sightseers overrunning Athens, "tourists in striped sneakers, fanning themselves with postcards ... laboring uphill" toward the Acropolis (3). Axton himself avoids joining their ranks; he refuses to make the climb. His resistance may seem like odd behavior for someone who claims to be a "perennial tourist," but Axton has an explanation for his hesitance to visit the temple: "For a long time I stayed away from the Acropolis. It daunted me that somber rock. I preferred to wander the modern city, imperfect, blaring. The weight and moment of those worked stones promised to make the business of seeing them a complicated one. So much converges there. It's what we've rescued from the madness. Beauty, dignity, order, proportion. There are obligations attached to such visits" (3). In short, Axton resists the temple because he fears that it retains the residue of the unifying cultural logic within which it was erected. ${ }^{7}$

According to Lefebvre, the Greek city was constructed within the dictates of "absolute space," which conceived space as both unified and harmonious. He explains further that in ancient Greece, from whence we inherit geometry, the seeds of western spatial logic, absolute space "assumed a strict form: that of volume carefully measured, empty, hermetic, and constitutive of the rational unity of Logos and Cosmos" (238). As Lefebvre notes, the temple played a crucial role in establishing this imagined spatial harmony: "The Greek city, as a spatial and social hierarchy, utilized its meticulously defined space to bring demes, aristocratic clans, villages, and groups of craftsmen and traders together into the unity of the polis ... Its centre— the agora—served as focus, as gathering-place. At the highest point of the acropolis, the temple presided over and rounded out the city's spatio-temporal space" (249-50). Yet while the space of the temple brings with it this history as a symbol of social and spatial unity, the 
structure Axton confronts is surrounded by a far less harmonious metropolis, making its claims to rational organization now highly suspect. At the same time, Axton's reaction suggests that the temple continues to evoke its former spatial logic, as if the Cosmos were indeed operating according to a rational order that is accessible to the human mind. I would argue that Axton finds the Parthenon frightening precisely because it stands as a reminder of the "order" and "proportion" his own life, and the postmodern city, lacks. As Owen remarks, Greece still "contains" a "mysterious absolute" (113). But while Axton, our detective, stands, as we have seen, at the cultural center of the absolute, social and spatial, he fails to access its core. Now empty at its center, the Greek temple and its history embody this dilemma. Interestingly, in its original state, the Parthenon housed a colossal representation of Athena, patroness of the city. To the ancient Greek, the absolute was representable, and by extension accessible. However, as history would have it, the Parthenon no longer houses any thing at its center. Uncannily, while in its original form, the temple symbolized the accessibility of the absolute, in its altered state, now empty at its center, it has come to symbolize a modernist sensibility, which sees the "mysterious absolute," or the Sublime as the unrepresentable. It is as if the history of the temple's structure mirrors the history of Western thought which, following Protestant iconoclasm and Kantian aesthetics, has come to view the absolute as defying representation. That is to say, the temple's very history reflects the loss of "place" at the center which once held. When Axton does finally visit the temple, he, in fact, notices this lack, sensing "a grief for what has escaped containment" (330), as if to say that the temple evokes simultaneously both the concrete representation and accessibility of the absolute it once contained and, paradoxically, its opposite, its absence. Layered with these spatial histories and perceptions, the temple, as both harmonizing force and empty tomb, thus, elicits both 
Axton's desire for a "place" to which he belongs as well as his terror of that which he can neither locate nor penetrate, the placelessness at the center of place.

Nonetheless, while Axton wishes to avoid these ambiguities inherent to the space of the temple, the Parthenon, towering above the city, continues to call him, and eventually, he does make the climb, at which time he offers a number of intriguing observations. Upon his visit, Axton describes the temple as follows:

And this is what I mainly learned up there, that the Parthenon was not a thing to study but to feel. It wasn't aloof, rational, timeless, pure. I couldn't locate the serenity of the place, the logic and the steady sense. It wasn't a relic species of dead Greece but a part of the living city below it. This was a surprise. I'd thought it was a separate thing, the sacred height, intact in its Doric order. I hadn't expected a human feeling to emerge from the stones but this is what I found, deeper than the art and mathematics embodied in the structure, optical exactitudes. I found a cry for pity. This is what remains of the mauled stones in their blue surround, this open cry, this voice we know as our own. (330)

Unlike Cartwright, Axton appears to make a very deep connection to the historic site he visits, which would at first glance seem to indicate that he has rediscovered his place in the world by reuniting with the centralizing logic, the same logic that produced the Greek polis as a distinct political and spatial formation, responsible for producing this remnant of unified space. ${ }^{8}$ Reading Axton's trip to the temple as a moment in which he rediscovers his place in the world is further implied by the very structure of the novel itself. Paula Bryant argues that since the concluding pages of the narrative proper, of Axton's story, end with his visit to the temple, the novel appears to follow a "modernist" pattern. She explains, 
"Jim Axton returns to an image, the Parthenon, which held negative connotations for him at the novel's opening, and which now holds positive ones in the light of his new experiences. Thus the book appears to culminate a neat, circular return to its own beginning, the protagonist infused with new insight into old dilemmas" (24). This reading is reinforced by the fact that the "image" in question has been retrieved from the pre-modern world, as if Axton were recuperating the absolute which has been lost within the fragmenting experience of modernity.

Bryant, however, argues that the novel's appropriation of the "modernist pattern" is ultimately a ruse, meaning there is no tidy ending. To understand how she arrives at this point, and more importantly how this alters our understanding of the novel's commentary on the history of space, we first need to clarify what Bryant means by "old dilemmas." The vast majority of DeLillo criticism, including Bryant's, has suggested that Axton's primary "dilemma" involves first and foremost a crisis of representation, of language. This would explain his obsession with the cult which is preoccupied primarily with linguistic aporias. Bryant remarks, "In a perverse version of Wittgenstein's logical positivist search for one ideal language that will redeem confusion by establishing an inexorable equivalence between word and world" the cult "becomes enraged with the old language and spawns a new logic of violence" (19). Axton himself, a former writer no less, becomes caught up in this search to restore language to the world around it, to recreate "the rational unity of Logos and Cosmos." But just as the cult's violence is doomed to failure, restoring nothing, Axton's efforts to make sense of the cult murders is equally doomed. He matches the initials to places, but this gets him nowhere; these matches appear as arbitrary as the linguistic disjunction the cult seeks to repair. Nonetheless, inside the temple, having felt the "cry for pity," Axton concludes, "Our offering is language" (331). We might surmise, 
then, that Axton has in fact rediscovered the unity between Logos and Cosmos, has found a way to refill the empty temple, and with this has realized a new attachment to his world. However, the language Axton actually offers, and the tourists with him, is far from an ideal language able to reconnect word and world, as a modernist ending or Axton's return to the temple might imply. As Bryant points out, the text is not so unified after all. First, it does not actually end with Axton's return to the temple, but rather with an appended story, or glossolalia, that his son Tap has written and shown to Axton prior to his visit to the temple. Not only does Tap's glossolalia not reunite word and world, it actually celebrates language's ability to fragment and divide, to create multiple meanings. Secondly, when we revisit the temple scene in light of Tap's appended narrative, we recognize that during his tour of its grounds, Axton himself emphasizes the fragmentation that surrounds him. More than once he points out the cacophony of languages being spoken simultaneously among the other tourists, "one language after another, rich, harsh, mysterious, strong" (331). Thus, the offering may be language, but not a language that would restore word and world, but rather one that is recognized for its inherent ability to multiply and defer meaning. Thus, the representable absolute at the center of the old temple has become that which Axton, despite the invitation of his son's name, cannot tap. Ironically, in the very Western birthplace of rational order, Axton comes to grips with his inability to rationally unite Logos and Cosmos.

While prior critics such as Bryant have articulated Axton's insights into the nature of language, there has been scant acknowledgment, despite the seminal role that the temple has played in the history of Western space, that Axton's visit to the Parthenon has as much to say about Cosmos, or space, as it does about Logos. We can, however, make use of Bryant's analysis of The Names' commentary on 
language in our attempt to understand what this novel adds to our discussion of space, for just as Axton's experience at the temple causes him to reconceive language, it also causes him to revisit his previous assumptions regarding space. During his tour of the temple, Axton concludes that the structure is neither "rational" nor "timeless," as the spatial logic of ancient Greece, as well as a modernist aesthetic would have him believe. Axton insists otherwise, seeing the temple not simply as a "relic" of its former cultural logic but as rather "part of the living city," of present-day Athens. Axton provides some clues as to just what it might mean for Athens to be part of a postmodern city by describing this city intermittently throughout the text.

Among other things, Axton notices in Athens "the pressure of remembrance. The black memory of civil war, children starving ... There were times when I thought Athens was a denial of Greece, literally a paving over of this blood memory ... Then I realized the city itself was an invention of people from lost places, people forcibly resettled, fleeing war and massacre and each other, hungry needing jobs. They were exiled home to Athens" (104). Here, Axton characterizes Athens as a city of exiles, or an exiled city, whose history has been effaced by ongoing development and the influx of more people. In a companion passage, Axton observes that along with its historic ruins Athens "contains" the "tension and paralysis of the superficial new" (179). Taken together, Axton's descriptions portray Athens as a city comprised by a number of co-existing, often competing spatial logics. Still housing the remnants of rational unity alongside the "superficial new," places designed under the logic of visualization, Athens is itself a space caught in between spatial paradigms. That is to say, it too is a space perpetually in transition, paralyzed by its inability to fully discard the spatial logic of the past, whether ancient or modern. Athens is, simply put, a postmodern city, "fragmented, a 'palimpsest' of 
past forms superimposed upon one another" (Harvey 67). As part of this conflicted city space, the temple has, thus, become a symbol not of order but of competing spatial histories. On one hand, it is the residue of rational unity, of a unified and politically independent city state whose borders are clearly marked by literal walls. On the other hand, as the multicultural mix of tourists on its premises suggests, it is now part of a globalized space, inherently scattered and conflicted.

The point here is not simply that the postmodern city is fragmented or full of contradiction. Prior cultural analysis has already discussed at length how postmodern space, particularly urban space, is characterized by its inclusion of contradictory elements; for instance, Harvey as well as such theorists as Linda Hutcheon and Charles Jencks have documented the ways in which postmodern artists and architects build competing historical and spatial narratives right into their work. ${ }^{9}$ However, DeLillo's metaphysical detective fiction extends and complicates these prior analyses of postmodern space by suggesting that the spatial and conceptual conflicts exist not only because postmodern artists consciously include competing cultural logics within a single built environment, but also because historical sites, such as the temple, have remained intact beneath, alongside, and amidst the "superficial new." Thus, postmodern architect has not created the conflict so much as highlighted a point of tension that already exists within the history of Western metaphysics as well as Western urban space. DeLillo's emphasis on spatial tension correlates with Lefebvre's argument that contradiction and conflict are endemic to the space of late capitalism. Lefebvre contends that this "principle of contradiction" is to be found " $[\mathrm{b}]$ etween the capacity to conceive of and treat space on a global ... scale on the one hand, and its fragmentation and multiplicity of procedures or processes, all fragmentary, on the other" (355). Thus, "space 'is' whole and broken, global and fragmented at one and the same time” (356). It would 
seem, then, that Axton is correct both in his original notion that the historical space of the temple is separate from the now globally networked city of Athens as well as in his subsequent realization that it is at the same time part of the city. In fact, although the temple is reproduced as a space of consumption and, therefore, made part of the global space of late capitalism, ironically, its desirability as a space of consumption arises from the fact that it has been partitioned off, has been marked as a sacred, mystical, or symbolic space. The temple is simultaneously subsumed by the economic circuitry of late capitalism and allowed to evoke its ancient, mysterious past. Moreover, it can only be subsumed into the late-capitalist economics of tourism on condition that it continue to evoke its ancient past. The same could be said of the historical spaces in Lookout Cartridge, such as Stonehenge, which are desirable because of their former politico-religious function, meaning their former spatial logic is somehow retained, and, yet, these spaces have been radically transformed by the onslaught of tourism and technology. By placing such spaces on film Cartwright converts them into specters of their former selves which may haunt the new spatial imaginary but can never fully resurrect the absolute space in which they were once centerpieces. These spaces themselves, not just the detective who experiences them, are left betwixt and between. Just as our metaphysical detectives defy spatial and ontological limits, the schizophrenic spaces of the Parthenon and Stonehenge also appear to be, in both senses, two places at once.

\section{A Space Apart?}

While they seek to combat this fragmented and fragmenting space of global capitalism, interestingly, the cult Axton investigates does not enter the temples of the past, despite the fact that such spaces once symbolized the harmonious union between Cosmos and Logos that they claim to desire. 
Possibly aware that although produced under the aegis of rational unity, such spaces are now absorbed by the ramified space of late capitalism, the cult, instead, seeks out spaces which appear to have remained outside the system: the caves and deserts of the world. As one cult member explains, they seek a "place where it is possible for men to stop making history" (209), a quest that ultimately leads them to the deserts of India, which the cult sees as "a solution" (294). Despite the temple's now empty center, it has from its inception been part of a system of representations; it has an unavoidable history that involves a literal attempt to concretize the absolute. Alternatively, from the cultist's perspective, the open desert appears to have escaped the ideologically imbued symbolic, economic, and linguistic systems they wish to transcend, as if it were a blank page that will remain blank, a space always prior to and outside. Interestingly, one of our most prominent theorists of postmodern culture, Jean Baudrillard has similarly suggested that we "should always appeal to the deserts against the excess of signification" (64), as if to say that the desert does indeed stand apart. Yet, despite the cult's, or theory's, hopes of "inventing a way out" (209), an antidote to the excesses of signification produced by late capitalism, the desert fails to provide such as space for the simple reason that the place outside history that they desire is a spatial impossibility.

Significantly, in the same desert where Owen locates the cult, he also spends time studying a variety of alphabetic "inscriptions" cut into the rock, that is, left on the landscape itself. The desert, then, is already marked, introduced into the fragmented and fragmenting world of representation, the very system the cult is looking to transcend. In short, the sign has already arrived. Thus, what Baudrillard labels the "desertification of signs" proves to be yet another myth, or as Lefebvre argues, the desert as an alternative to an excess of signification is yet another representation of space. Lefebvre 
explains, "The notion of space which is at first empty, but is later filled by a social life and modified by it, also depends on this hypothetical initial 'purity,' identified as 'nature' and as a sort of ground zero of human reality. Empty space in the sense of a mental and social void which facilitates the socialization of a not-yet-social realm is actually merely a representation of space" (190). Thus, while the cultists attempt to escape systems of representation, they do so, ironically, by appropriating a representation of space. Just as the temple's empty center is a space rife with symbolic import, the "empty" space of the desert is, as Owen notes on more than one occasion, already filled with and coded by a history of social production. In fact, the emptiness itself plays a role in our spatial imagination. As Volterra, who wants to make a movie featuring the cult, observes, the desert has a long-running history in American film and, consequently, has heavily influenced the American psyche. He explains to Axton that the "classic thing" about the American western "has always been the space, the emptiness ... Figures in open space have always been what film is all about. American film ... The space is the desert, movie screen, the strip of film, however you see it. What are the people doing here? This is their existence. They're here to work out their existence. This space, this emptiness is what they have to confront" (198). Volterra suggests here that, through the movies, the myth of the desert's emptiness has come to play a significant role in the symbolic economy of twentieth-century America. The desert in effect represents a space in which we imagine that one might locate one's self. Given the daunting task of locating one's place amidst the growing entanglement that is late capitalism, any hope of working out one's existence requires an empty space, requires a desert—Baudrillard's travels through the American desert as a means of understanding America seems only to reconfirm this notion. In this respect, the desert is the imaginary other that the global entanglement needs both to identify itself against as well as 
to minimize its own engulfing effect— the promise of an outside allows for the possibility of recovering what we wrongly imagine once existed but has now been lost. While the desert offers a space apart, a way out, it is in fact central to western spatial production which places the subject between an emptiness/entanglement dialectic. Out of the conflict between the psycho-social search for an open space outside and the political, economic, and technological drive to dominate and colonize all space is born the conflicted and contradictory space of twentieth-century experience.

Interestingly, Volterra posits a spatial "solution" not in seeking a place outside the parameters of Western spatial logic but, as his name implies__flight" [vol, Fr.] + "earth" —_by eliminating the need for place altogether. While observing the desert, the "frame and background" for his next film, Volterra explains to Axton, "I can't surrender myself to places . . . I'm always separate . . . I would never give myself up to the place [the desert] or to any other place. I'm the place. I guess that's the reason. I'm the only place I need" (143). Like the cultists, Volterra attempts to live his theory of space, staying only in "borrowed apartments" rather than grounding himself in a permanent home (110). It would seem, then, that Volterra offers Axton a legitimate solution to his between-ness by arguing that Axton does not need to relocate to a definitive place at all but simply needs to return to the self as his true place. It is, however, difficult to view Volterra as a source of eternal truths, for he is portrayed as both egomaniacal and self-delusional. Furthermore, despite his claims, he too seems to be in search of a place; his movement can be interpreted as meaning not that he no longer needs a place, but rather that he simply has not found his place. What Volterra seems to overlook is that the self exists and is formed always within a given set of spaces and is, therefore, defined by those spaces. The self, which he claims is the only place he needs, does not exist autonomously, but is both a participant in and a 
product of social space: of the deserts, the temples, and the techno-economic networks Axton struggles to navigate. In fact, the last time we see Axton he is very much defining himself within the context of a place, the temple. Ultimately, both DeLillo's and McElroy's novels reveal a striking correlation between the spaces their protagonists confront and the formation of their identities; both suggest that these spaces in between produce subjects in between and vice versa. While in a rational unified space, the detective could imagine himself a Cartesian subject, within the almost schizophrenic space of global capitalism, these metaphysical detectives find themselves fragmented, living multiple lives in multiple places at once, that is, in the "dimensionless space in between."

Lookout Cartridge and The Names add to our discussion of metaphysical detective fiction and the space of postmodernism by dramatizing the ways in which postmodern spatial production creates and encapsulates spaces which no longer correspond to either the order of Ancient Greece or the compartmentalizing dictates of modernism. Whether such spaces come in the form of historically displaced ruins or technological enhancements, the result for the detective is ultimately the same; he himself is caught betwixt and between. While the classic detective guaranteed arrival, a concluding point for both the modern reader and the modern subject, the metaphysical detective remains in transit, the spaces he encounters in transition, perpetually in between. 


\section{NOTES}

1. There is a tradition of metaphysical detective fiction in which the detective either turns out to be the guilty party or unknowingly precipitates the crime that includes most notably Robbe-Grillet's The Erasers as well as Borges' "Death and the Compass." Moreover, the fact that Robbe-Grillet's work alludes to and in many ways is a retelling of the Oedipus tale suggests that this tradition actually begins when Oedipus, after a detective-like attempt to find the murderer, discovers that he himself is the "criminal."

2. There is a precursor to DeLillo's link between detection and risk analysis. In Billy Wilder's Double Indemnity, co-written by Raymond Chandler, Barton Keyes, an insurance man, actually uses actuarial work toward a solution of the crime.

3. Arthur Conon Doyle's Sherlock Holmes novels offer an interesting comparison to Cartwright's case since many of the Holmes tales begin and end at Baker Street; in fact, on numerous occasions, Holmes and Watson never leave the house, the adventure being related to Watson by Holmes. For Holmes, then, the domestic space, or home base, remains a permanent space of refuge available when he is through solving mysteries.

4. For more on this, see Deleuze and Guattari's A Thousand Plateaus: Capitalism and Schizophrenia, which I address at length in chapter five in regard to Reed's Mumbo Jumbo.

5. For a more thorough account of McElroy's poetics see Brian McHale's Constructing Postmodernism.

6. By highlighting the artificial nature of Stonehenge as a tourist space, McElroy does not, however, invoke the nostalgia for Stonehenge's spatial past. Rather, Lookout Cartridge recognizes that despite the ability to offer the sightseer the hope of connection, such sights possess power over the viewer in part because of the mystery that surrounds them, because of their ability to elude definitive connection or placement. The appearance of transcendence is maintained by their lack of place.

7. Interestingly, in his study of tourism Dean MacCannell observes, "Sightseeing is a kind of collective striving for a transcendence of the modern totality, a way of attempting to overcome the discontinuity of modernity, of incorporating its fragments into unified experience." (13). He also notes, "Of course, it is doomed to eventual failure: even as it tries to construct totalities, it celebrates differentiation" (13). According to MacCannell, then, tourism by nature involves an effort to recover a former social and spatial regime which, as with the ancient Greeks, posits a rationally ordered universe.

8. Paul Maltby actually reads DeLillo's novel as an attempt to rediscover the "visionary moment" of "romantic metaphysics." In particular, he sees Axton's visit to the temple as an example of just such a moment in which the quest comes to a point of resolution. 
9. Hutcheon contends that "postmodernism is a contradictory phenomenon, one that uses and abuses, installs and then subverts, the very concepts it challenges - be it in architecture, literature, painting, sculpture, film, video, dance, TV, music, philosophy, aesthetic theory, psychoanalysis, linguistics, or historiography" (3). Similarly, Jencks argues that postmodern architecture is marked by a "double coding," that is "elite/popular, accommodating/subversive and new/old" (30).

10. There are other possible interpretations for "Volterra"; some possibilities include "Volt," or electrical energy + "earth" or, with a New York accent, "terra" = terror. 


\section{CHAPTER 4}

\section{Returning to the Scene of the Crime: The History of Social Space by Kathy Acker}

While the novels I have addressed in earlier chapters position the production of postmodern space within the context of the previous history of spatial production in the West, they trace spatial histories of Western experience from a postmodern perspective as well as in a primarily postmodern spatial setting. Of the novels of Pynchon, Auster, De Lillo, and McElroy, all four have as their point of departure, as the scene of the crime, a late-twentieth-century space, whether it be post-World War II Europe, 1980's New York, or the global space of late capital. This is not the case, however, with our next piece of metaphysical detective fiction, Kathy Acker's “The Case of the Murdered Twerp," which begins in mid-nineteenth century Paris. We saw through Gravity's Rainbow and Deleuze that Western space has been constructed and policed under a disciplinary regime which was born out of the Enlightenment and rose to its height in the mid-nineteenth century, the time at which the detective-a product and producer of Enlightenment logic_ comes to prominence. As Harvey argues, "the conquest and rational ordering of space" were "an integral part of the modernizing project," which created a "new organization of space dedicated to the techniques of social control, surveillance, and repression of the self and the world of desire" $(249,213)$. Thus, by setting her narrative in a nineteenth-century city, the place and time at which such "techniques" took hold, along with invoking the classic detective whose positivistic assumptions help produce a social space that accords with the dictates of western metaphysics, Acker returns us to the scene of the crime: a vantage from which she indicates that Western spatial logic has not so much been deconstructed by postmodern culture as it has been from its inception fraught with conflict and contradiction.

While Acker's detective story transports us to a former regime of spatial dominance, this is no 
simple return, primarily because the novel which houses Acker's murder mystery does not take place solely in nineteenth-century Paris. "The Case of the Murdered Twerp" actually appears as one of the multiple narrative strands that comprise Acker's larger work The Adult Life of Toulouse Lautrec by Henri Toulouse Lautrec - a text that consists of a collage of narrative fragments and disparate worlds, from the Paris of Van Gogh to the Hollywood of James Dean. Due to the narrative structure of Acker's text, which undermines temporal and spatial convention, it is often difficult to identify a single time or place as the mystery's primary setting. An entanglement of narrative threads, "The Case of the Murdered Twerp" frequently collapses two or more ontologically mutually exclusive worlds within the same narrative space: seemingly stable built-spaces bleed into other built-spaces—at times all cities appear to be the same city— and interior spaces and exterior spaces become at times indistinguishable. Furthermore, Acker's characters not only inhabit multiple worlds, but they also inhabit multiple bodies. Despite its spatial and temporal indeterminacy, Acker's narrative, nonetheless, has as its point of departure the classic detective as well as both his urban environment and his fictional space, the classic detective novel which itself reinforces the notion that space can be intellectually ordered and policed. Although the classic detective novel frequently invokes spatial mysteries, a locked room for instance, implying that space may not be so easily rationalized, by the close of its pages such ruptures to the social fabric are repaired; space appears rational once again. Acker's murder mystery is, however, not a conventional piece of detective fiction, but rather a metaphysical detective story which, again, evokes the positivistic "impulse to 'detect' ... in order to violently frustrate it by refusing to solve the crime" (Spanos 171). "The Case of the Murdered Twerp" begins in what appears to be late nineteenth-century Paris (the text includes too many anachronisms to be certain) when a character 
named Marie, or the twerp, claims to have witnessed a murder. Later, during a party at Norvins' brothel, Marie herself is found mysteriously murdered, an event that calls Poirot, of Agatha Christie fame, onto the case. The rest of the narrative, though fragmented and involving various digressions, is taken up with Poirot's attempt to solve the crime by searching for potential clues. But while Acker's mystery initially possesses the characteristics of a classic work of detective fiction, its plot stubbornly refuses to move toward a resolution. After interrogating several potential witnesses or sources of information, Poirot discovers nothing that would help him solve the crime. Throughout the entire investigation, only one piece of information surfaces that could be construed as anything like a clue. This comes from a source, T.T., who tells Poirot of a variety of other murders that all appear vaguely connected to a person in attendance at the brothel party, a lawyer named Zidler. This "clue," however, gets us nowhere because first of all the connections are hazy at best—Zidler's name keeps surfacing as if it should mean something but it signifies nothing — and, furthermore, as soon as Poirot gains this tenuous link, Acker drops the murder mystery thread of the narrative altogether. Poirot's quest to solve the crime leads him, and us, nowhere and eventually fizzles out entirely.

Acker's novel suggests that Poirot's failure results in large part from an inability to contain, cognitively as well as physically, the rationalized space upon which the detective relies. That is to say, Acker's subversion of detective logic takes as one of its targets the history of space as articulated within Western metaphysics. The very structure of Acker's fiction suggests a breakdown in spatial order; Poirot cannot be certain even of the city in which he is searching. Spatial transgressions at a narrative level, are not, however, the only obstacle Poirot faces. Acker's thwarting of narrative convention works, rather, to highlight a more pressing problem, the ideological conflict inherent to the 
rationalized space of the detective: specifically, as we will see, that all spaces produced under this spatial regime are from their inception disorderly, themselves threatening to rupture the cultural logic out of which both the detective and the modern city he safeguards are constructed. By returning us to the nineteenth-century city, Acker's metaphysical detective story shows us that the Enlightenment's rationalized spatial order was not so much disrupted by the onslaught of postmodernism and the technologies that came with it, but was in fact from its inception in a state of disorder.

\section{Back to the Urban Order}

In choosing Paris as the nineteenth-century city in which to set "The Case of the Murdered Twerp," Acker invokes a particularly striking example of the modernizing project's efforts toward repression through spatial control. Under the imperial reign of Napoleon III, mid-century Paris underwent one of the most explicit attempts to rationalize urban space in Western history (arguably the attempt to order urban space par excellence) at the hands of Baron Georges Eugene Haussmann, whose ambitious designs to restructure the city were openly predicated on the notion that one could impose social order through spatial delineations. Haussmann's primary plan was to open up the city by replacing the cramped space of old Paris with broad boulevards networking across the city. According to Marshall Berman, "Napoleon and Haussmann envisioned the new roads as arteries in an urban circulatory system ... The new boulevards would enable traffic to flow through the center of the city, and to move straight ahead from end to end ... In addition, they would clear slums and open up 'breathing space' in the midst of layers of darkness and choked congestion. They would stimulate a tremendous expansion of local business at every level" (150). Furthermore, Haussmann's boulevards were thought to facilitate military movement and, therefore, to shore up imperial rule. Walter Benjamin 
goes so far as to argue that the "true goal of Haussmann's projects was to secure the city against civil war" by making the "erection of barricades in the streets of Paris impossible for all time" by simply widening those streets (23). This explains why many Parisians viewed "the transformations made by Haussmann ... as a monument to Napoleonic despotism" (Benjamin 23), an insight only further supported by the fact that he preserved the old monuments of Paris while destroying thousands of dwellings which housed the poor of the city. Nineteenth-century Paris is a prime example, then, of spatial planning used to reinforce or strengthen power structures, the result being that "after centuries of life as a cluster of isolated cells, Paris was becoming a unified physical and human space," making it the “model of modern urbanism” (Berman 151, 152), a model that Acker's fiction, by blurring historical periods, recognizes continues to be copied in contemporary settings such as New York. In Haussmann's Paris, rational planning had, presumably, led to a rationally ordered urban space (we will see later that Haussmann's project was itself beset by contradiction). ${ }^{2}$

Not coincidently, Poirot's investigation mirrors the Napoleonic impulse to rationally structure social space. Poirot begins his investigation, as is common in detective stories, by attempting to gain intellectual control of the space in which the murder reportedly occurred. Poirot inquires, "Who exactly was at the party and what was the layout of the place?" (198). He again asks, "What's the layout of the brothel?" (198). Tellingly, this question is met not by a verbal explanation but by an actual map, included in Acker's text. It appears that Poirot indeed will be successful in controlling the space of the crime when the party goers assure him that no one from the outside street could have entered the party. As is typical in Agatha Christie novels, the crime occurs in an ostensibly bounded space to which a limited number of suspects have access. Thus, Poirot logically concludes, "Then it was someone at the 
party" (209). His next step is to get a list of those in attendance. After doing so, he again deduces, "The murderer must be one of these people" (209). Having contained the space in which the crime occurred, Poirot seeks to limit the number of possible suspects. By attempting to rationally order space, he also attempts to control that which would seek to disrupt the social fabric, an operation that directly links the ordering and observation of space to social control. Poirot's deduction that the murderer must be one of the party goers is met, however, with a rebuke from Rhys, one of Norvins' prostitutes, who replies, "Listen, Poirot, you have to stop thinking like that. We all love each other here" (my emphasis 209). On one hand, this appears to be the cliched response of one who simply does not want to believe that an acquaintance could be a murderer. On the other hand, it can be read as a direct rejection of the Poirot-like, or Haussmann-like ratiocination that has produced a repressive urban space.

\section{Into the Urban Disorder}

Acker challenges Poirot's spatial assumptions more directly by taking him out of the seemingly ordered space of the brothel and into the anarchic slums of Montmartre, where the historic ToulouseLautrec actually spent much of his time. Lacking any leads, Poirot warns the frequently morphing Toulouse, "we're going to have to visit Marie's family. They live in the poorest section of Montmartre. I hope you won't be disgusted by what you're going to see" (216). Outside the brothel, they discover that the "streets of Montmartre are filthy. Garbage cans and dogshit lie strewn over the sidewalks. Bums lie under garbage for warmth" (217). In these filth-ridden streets there is “only one law: don't stop walking as fast as possible ... Thefts, pushing, kidnappings, tricks, murders: all these crimes take place in the open" (217). While questioning Marie's mother, Poirot attempts to convince her that 
solving Marie's murder will have a positive effect on the larger social order: "If we can find out who murdered her, we might be able to prevent future murders" (217). In the context of the slum, however, this statement smacks of irony. For as Toulouse tells us, in Montmartre, "People die in front of other people on the street ... Poirot and I have to rush down the Rue Cailancourt. We don't want to see any murders. If we see any murders, we might have to solve them" (217). Here, the classic detective and his belief in rationality and resolutions as well as his notions of spatial order confront a historically disorderly space. Inside the dystopic space of the ghetto, either of the nineteenth century or today, Poirot's desire to resolve and contain is literally laughable, for at the moment that Poirot questions Marie's mother, her brother is himself being murdered "near the brothel" (218). Poirot's logic not only fails to solve "the" crime; it has no impact on the proliferation of yet more murders.

While, in classic detective fashion, Poirot's investigation prioritizes the "truth," or finding a solution to the mystery of Marie's murder, as T.T. tells Poirot, "No one who's poor cares much about the truth" (222). The rejection of positivistic solutions on the part of the poor is significant because the classic detective's ability to solve crimes, to locate truth, is used to legitimize the claims of those in power; their ability to discover truth indicates that they can indeed dominate and order social space and its inhabitants through ratiocination. But while solving cases maintains the illusion of order for those who reside in the bourgeois world, it cannot provide the same illusion to those who experience daily the disorder of the ghetto, where "truth" has no value. Even though, as T.T. acknowledges, "Every day thousands of murders occur in Montmartre" (222), none of the poor trouble themselves by getting involved with the, here pointless, question of whodunit, for regardless of the truth, Montmartre remains a disorderly space. It would appear, then, that the space of the ghetto operates under a separate logic 
from that of the rest of the city. This is not, however, entirely the case. The ghetto's disorderliness is, in fact, built into the founding logic of the city. Notably, the chaotically violent space of Montmartre results in large part from Haussmann's grand designs to rebuild Paris as a site of urban order. Along with producing the boulevards and city squares, Haussmann's plans also stratified the city along social, or economic lines, reproducing spaces of economic depression and subsequent criminal activity. While Haussmann's Boulevards were places where "fortunate Parisians circulated . . f freely, seeing and being seen,” as Toulouse-Lautrec's biographer Julia Frey notes, Haussmann's efforts created an “urban wasteland ... around the periphery of Paris" (184). She explains, "The rebuilding had destroyed a number of decaying neighborhoods, forcing their poverty-stricken inhabitants to the outskirts of town, where they lived in a squalid zone of tenements and hovels ... These dreadful slums, which included Montmartre, sheltered beggars, prostitutes and outlaws, and were full of disease and suffering" (185). Montmartre stands out in particular among the slums of Paris because, according to Frey, it has always maintained an identity as separate from the rest of the city, primarily because it sits atop "a steep hill which isolated it geographically from the flatter parts of Paris" (131), where Haussmann constructed his new city. "In fact, Montmartre was so separate from the rest of Paris that until 1871, Parisians had to pass through a gate and pay a toll in order to enter this area" (131). Already marginalized, Montmartre offered an ideal space in which to segregate those left poor and homeless from Haussmann's demolition of the old city. We might argue, then, that Poirot avoids seeing any murders in the streets because Montmartre is ultimately a carceral city. Literally gated, Montmartre is the space of the criminal, or of all those who would present a threat to the order and spectacle of the hegemonic center. There is no need to solve crimes here because this space, delineated under a positivistic ideology, is itself a solution 
to crime, at least for those living outside the ghetto- the boulevards remain the pristine space of commerce and fashion. Inside, however, Montmartre has slipped from the detective's control; it eludes and contests positivist logic and, therefore, threatens to disrupt the larger urban order.

While excavating the history of Paris, we should remember, of course, that Acker's is not a strictly historical novel. Acker is not nearly as interested in portraying the "authentic" nineteenth-century Paris as she is in using it as a vehicle for addressing the late-twentieth-century city. Ultimately, the glimpses Acker provides of slum-life in Montmartre have less to do with Toulouse-Lautrec's Montmartre than with the twentieth-century metropolitan slums, including some areas of Montmartre today or sections of the other cities that appear in Acker's text such as San Francisco, a city that Giannina, one of the prostitutes, describes as the "place where all the criminals and perverts live" (206). Giannina conjectures further, “They've got lots of earthquakes there so the U.S.A. government encourages all its misfits to live there so maybe the earthquake'll kill em" (206). While clearly this is intended as tongue in cheek, the passage, nonetheless, draws our attention to the carceral slums of today's cities. Acker's Montmartre actually looks a great deal like a ghetto space much closer to home for her, namely the South Bronx, only here slightly displaced. The Bronx, in fact, has a strikingly parallel history to Paris. As Berman, a native of the Bronx, notes, when urban planner Robert Moses, a disciple of Haussmann no less, introduced an expressway—a descendent of the Boulevard—-through the heart of the Bronx, the city quickly became "an image of modern ruin and devastation" (290). Berman continues, “The Bronx ... has even become an international code word for our epoch's accumulated urban nightmares: drugs, gangs, arson, murder, terror, thousands of buildings abandoned, neighborhoods transformed into garbage- and brick-strewn wilderness" (290). This, then, is the city 
space Acker's Montmartre evokes, a space that still today suffers under Haussmannian efforts to rationalize the city without any concern for the city's economically deprived, who are only further segregated; of course, this in the end appears to be part of the plan. For, as the dystopian landscape in John Carpenter's 1980's sci-fi film Escape from New York indicates-in the movie New York has been transformed into a literal prison— the American urban slum has become or is fast becoming, much like the Montmartre Poirot avoids, a carceral space walled off from the rest of the population or the "respectable" citizens.

Despite such efforts to extricate the city's unwanted, according to Acker's fiction, the slum as solution has not, however, been effective, either in nineteenth-century Paris or in the metropolises of the present day. As Vincent, Van Gogh presumably, tells one of Norvins' prostitutes “they're about to close off the cities cause our government can't handle the city problems any more" (211). Again reminiscent of Escape to New York, Vincent worries, assuming the poor or marginalized would be left behind, "We'll never get out again" (211). It is not just the slum, then, that potentially baffles the detective, but the entire city. According to Vincent, the supposedly separate space of the slum may be winning out over the ratiocination of the totalizing city. As Berman notes, this, in fact, was somewhat the case with Haussmann's Paris: "Haussmann, in tearing down the old medieval slums, inadvertently broke down the self-enclosed and hermetically sealed world of traditional urban poverty" (153). In other words, the boulevards opened the city up to the poor as well as the middle class, and Berman points out, just "as they [the poor] see, they are seen" (153). That which the new Paris was designed to eliminate was, ironically, brought to light. Berman suggests that similarly the Cross-Bronx Expressway offers travelers a glimpse, though only a glimpse due to the high speeds of travel, of 
"dozens of blocks covered with nothing at all but shattered bricks and waste" (291). In both cases, rationalized urban "progress" is constantly threatened by that which it seeks to discard, or pave over. Thus, by leading Poirot into the streets of Montmartre Acker not only highlights the tension between the slum and the privileged center, that which we would rather not see lest we be forced to resolve it, but also reminds us that this tension is itself part of Paris's constitutive logic and lives on in today's cities.

\section{Foucault and the Brothel}

In contrast to the streets of Montmartre, the mappable space of Norvins' brothel appears far more conducive to rational ordering. While out in the space of the street, prostitution is viewed as clearly both criminal and corruptive-Toulouse lists "tricks" right beside murder and thievery in his catalogue of street-crimes - the space of the brothel, despite its participation in a criminal act, is produced and operated under the illusion that it mitigates the negative consequences linked to prostitution, such as disease and moral corruption. This is in fact how nineteenth-century French bureaucrat Alexandre Parent-Duchtelet viewed the brothel, favoring a regulatory system for prostitution under which the state could maintain surveillance. Elizabeth Wilson observes, however, that ParentDuchtelet's "writings articulate a contradictory ideology of prostitution" (60). Within this ideology "the prostitute's body is putrefying, and infects the social body with corruption and death, yet at the same time it is a drain which siphons off that which would otherwise corrupt the whole of society. In order to effect this, bourgeois surveillance and regulation were to bring the brothel within a utilitarian regime of control" (60). If nothing else, the nineteenth-century brothel was used then to keep the sexualized woman's body out of the street, the space of criminality and corruption that threatens to spill over into the space of bourgeois morality. 
Thus perceiving the brothel as a rigid container of criminality, a space that can be neatly bounded, Poirot naturally assumes that in the space of the brothel he can indeed solve murders, as opposed to those murders in the Montmartre streets. However, as Acker's juxtaposition and superimposition of the spaces of the brothel and the street with and onto one another reveals, the brothel is far from a unified space nor is it hermetically sealed as Poirot's map might lead us to believe. Michel Foucault, in his now famous essay "Of Other Spaces," lists the brothel, as well as the prison and the boarding school, among the sites he labels as heterotopias. ${ }^{3}$ Foucault describes heterotopias as "real places—places that do exist and are formed in the very founding of society" which function as "counter-sites, a kind of effectively enacted utopia in which the real sites, all the other real sites that can be found within the culture, are simultaneously represented, contested, and inverted" (24). According to Foucault, the "heterotopia is capable of juxtaposing in a single real place several spaces, several sites that are in themselves incompatible" (25). As a heterotopian space, the brothel is not a space that can be easily mapped or contained, but is rather a space fraught with conflict.

We see this spatial tension played out in Acker's fiction. From the beginning of the narrative, the anarchy of the street has already infiltrated the space of the brothel in the form of a murder, and this rupture is far from anomalous. While the brothel manages to create the illusion of being a space free from urban decay and disease in which one might enjoy pleasure without consequence, in Acker's version this illusion is not entirely sustainable. At the end of the night the prostitutes are left with "weary bodies" (226), that is with material consequences as real as those in the street. Although, as Toulouse explains, they "try to forget" their "weary bodies by telling each other bedtime stories" (226), which include everything from creation narratives to supermarket romances, even a good story cannot mask 
the material results of prostitution, the "weary bodies." Significantly, our experience of reading the portion of the narrative that includes these stories mirrors their purpose. Once the prostitutes' stories begin, we too can quite easily forget our ontological point of departure and get lost inside the maze of stories that follows, that is until close to twenty pages later when Norvins breaks into Toulouse's supermarket-style romance with, "O, cut the shit" (244), which is to say, cut the illusion that masks the material reality, the tired bodies.

Furthermore, while the brothel was purportedly designed to insulate its visitors, and the outside world from the contagion and filth of the slum prostitute, in Acker's version the disease has clearly seeped into the brothel. Far from isolated, the prostitutes in Norvins' brothel frequently complain about the "claustrophobic filth city" (210). One prostitute notes, "I'm walking down the filthy street to work, and I think I'm going crazy. The skin on my head starts swelling. My fingers, hands, shoulders, legs, feet. My sinuses are pounding" (210). The disease, then, freely travels both in and out of the street with the prostitutes. This would have been no small matter in terms of the nineteenth-century perception of the city. Peter Stallybrass and Allon White contend that the "urban geography" of the nineteenth-century city was in fact constructed out of what they term "the bourgeois Imaginary," which "produced new forms of regulation and prohibition governing their own bodies" as well as "the body of the Other-of the city's scum" (126), which the bourgeois presumed to be ridden with disease. Stallybrass and White explain that Victorian reformers believed that "like crime, disease could be policed" (133). Obviously, one way to police disease was to simply separate it out from the middleclass body, hence the division of the city into the slums and those spaces more suited for the middleclass. Given that "the syphilitic prostitute" (133) was viewed as a central figure in the reformer's efforts 
to rid the city of disease, as Parent-Duchtelet's comments indicate, the brothel itself offered a quarantined space inside which the contagious prostitute could be isolated. Stallybrass and White suggest, however, that "cultural categories of high and low, social and aesthetic," including "those of the physical body and geographical space" which Victorian reformers sought so ardently to keep separate were in fact "never entirely separable" (2). High and low, bourgeois and scum, were, and are, rather, "interrelating and dependant," the high being frequently transgressed by the low and vice-versa. Along these same lines, Acker's fiction implies that the brothel is not free of the filth and disease of the city any more than the outside city is free from the disease supposedly contained within the brothel's walls. Norvins' prostitutes must still walk through the "filth city," the slums, to get to work, bringing with them the contagion, as their complaints of sickness suggest. And, of course, the brothel catered to the bourgeois male, who upon leaving this illusory space, took with him the filth so widely feared by the middle-class body politic. This explains why the bourgeois of the nineteenth-century city constantly feared that the "“contamination' of the prostitute" had "seeped into the respectable home" (Stallybrass and White 137), for once middle-class men entered the space of the brothel—blurring the distinction between worlds - they could not be certain that the contagion associated with the space of the brothel would not in turn penetrate the sacrosanct domestic space to which they retreated from the city at large. Acker's depiction of the brothel suggests, then, that although produced within a rationalized spatial logic, it embodies multiple social and spatial contradictions. It functions simultaneously as a site of comfort for the un-homed male in the city as well as a space in which one might be exposed to the diseases attributed to the city's outcasts, a potential space of resistance to bourgeois morality - a sexually liberated space — as well as a site of strict social regulation. No wonder Poirot's efforts to 
order this space fail to solve the "crime"; ultimately, this conflicted, heterotopian space cannot be fully rationalized. It not only unites in one space "several sites that are in themselves incompatible"; it is born out of the tension and transgression created by this assemblage. Thus, it fails to provide the spatial resolution Parent-Duchtelet imagined, placing the entire city again at risk. The very need for Poirot, or a detective to police its boundaries exposes an ongoing threat to the ideology of the rationally ordered city; although city planners, or bureaucrats, construct sites of containment—such as the brothel or the slum — spatial logic alone cannot insure social order. One still requires the services of the detective to maintain the illusion of urban order (the original notion of the "police," in fact, had less to do with crime per se then it did with the general maintenance of urban space). But unlike the classic detective who adeptly navigates and regulates the space of the city, Acker's Poirot wanders inside a case and space that resist resolution. The detective's attempts to bound and patrol the space of the brothel are thwarted right along with the totalizing logic he employs.

\section{Sexing the City}

By placing the detective's efforts to solve the crime within the confines of the brothel, Acker calls our attention to yet another point of tension inherent to the modern city, that is the friction created by the fact that the city adhered to strict gender divisions, divisions, not coincidently, that were both articulated and problematized in the person of the prostitute and her male counterpart the flâneur, a figure with whom the detective has much in common. As we have seen, within the ideology of the nineteenth-century city the prostitute represents something like the archetypal site of bourgeois regulation of the body, particularly the female body, and it is the detective's job "to control ...

unrestrained desire — through objective techniques of surveillance, tracking (mapping the city) and 
deduction" (Willet 134). This means that for the prostitute Poirot's attempt to control desire—-to secure it inside the brothel's walls — amounts to an attempt to control physical bodies, female bodies, through spatial delineations. It is important to note that although both bureaucrats and policing agents placed a great deal of emphasis on the figure of the prostitute, efforts at spatial regulation in the city were far from limited to prostitutes. As Wilson explains, because the rising metropolises of the late nineteenth-century created a growing population of "public women," the attempt to control prostitutes "could all too easily shade over into the regulation of all—or at least working-class —-women" (61). One of the major anxieties concerning prostitutes stemmed from the belief that many women who chose to become prostitutes only did so for a time, and subsequently returned to more mainstream occupations (like factory work); thus, there was a fear that prostitutes could go undetected. Or as Wilson suggests, the "prostitute was a 'public woman', but the problem in nineteenth-century urban life was whether every woman in the new, disordered world of the city ... was not a public woman and thus a prostitute" (61). Parent-Duchtelet's depiction of the prostitute's body as corruptible as well as a source of corruption was, in fact, readily transferrable to the bodies of all women, necessitating the organization of the city along gender lines so as to keep "respectable" women, and the men with whom they would come in contact, free of the taint of prostitution. But while the figure of the prostitute/public woman was the focal point of the middle-class male's horror at and attempts to regulate the bourgeoning city, she was simultaneously the site of male desire and fascination (Stallybrass and White 137). The prostitute's, and by extension the public woman's ability to inflame desire made it all the more important to the bourgeois male to police the city, at the very least isolating middle-class women from its entrapments. Thus, the male ruling class increased its efforts to restrict the mobility of middle- 
class women in the city, reinforcing the domestic sphere as the woman's place.

In contrast to women, bourgeois men "were free to explore urban zones of pleasure such as_-in Paris especially — the Folies Bergères, the restaurant, the theatre, the cafe, and the brothel" (Wilson 61) — the very sites that Toulouse-Lautrec reproduces in his paintings. As both Baudelaire and Walter Benjamin documented, the leisure among men to wander the city gave birth to a new urban creature, the flâneur. ${ }^{4}$ Just as the prostitute represents the object under surveillance, the flâneur is the one who surveys and assesses. Again, the flâneur bears more than a passing resemblance to our detective Poirot. According to Willett, the flâneur of nineteenth-century literature, particularly French literature, "provides a surrogate for the watchful (male) detective of popular fiction, one who listens, searches and above all, like the private 'eye', sees and deciphers the signifiers of that labyrinth of populated spaces and buildings which forms the modern metropolis" (3). Poirot fits right into the mold of the flâneur, possessing the leisure to wander the city in search of clues. Thus, by invoking nineteenth-century Paris, the detective, and the prostitute, Acker's fiction highlights for us both the regulated female and the male wandering "eye," who does not consume so much as he conducts the surveillance of public bodies and desires as they are inscribed upon the body. By invoking these two key figures, Acker focuses on an oppositional tension within the nineteenth-century city, as well as contemporary cities, that is marked by a spatial tension between those open spaces, spaces freely enjoyed or consumed by men, and those closed, contained spaces inside which women are kept-including the domestic sphere as well as its apparent opposite the brothel, and even the space of the body itself.

It would appear that the city was, once again, "rationally" divided, not simply along class lines 
but along gender lines as well. However, as Acker's fiction suggests in the instance of the heterotopian brothel—which given the fact that it brings together a variety of competing forces can be seen as a microcosm of the larger city - the city is in fact produced not only out of spatial divisions but equally out of the transgression of such divisions. As Wilson contends, while "urban space is structured at some fundamental level by gender difference ... such constructions are contradictory and shifting" (69). Ironically, the expansion of the city, purported to open up new sites of pleasure for men, spaces prohibited to women, actually created an environment in which the mobility of women would only increase, particularly since with the city came factory jobs available to women. The growing number of public women in the city threatened not only the spaces formerly restricted to men, but also the claims of the male ruling class to spatial and social dominance. Wilson suggests that the "very presence of unattended — unowned — women constituted a threat ... to male power" (61). Outside of the domestic sphere, the public woman could not be controlled under former means, hence the attention to regulating prostitutes. By threatening masculine identity, the growing female presence in the city, consequently problematized the overall urban order, which was produced in part out of such gender specific identifications. That is to say, while the nineteenth-century city, especially Haussmann's Paris, was supposed to operate within a rigorous logic, for each thing a place, in actuality it created a scene in which women might leave the home, their assigned place, and roam the streets from which they were forbidden. The public woman, therefore, disrupted the symbolic economy out of which the city was formed, in the process calling the city's founding divisions into question. As with the brothel prostitute, the bodies of public women in the city also could not be strictly isolated, contained, or protected. The prostitute/public woman also presented a threat to the city's economic logic. Because 
"generally understood to be barren," the prostitute as well as the unowned woman "was seen as an 'unproductive commodity'; without value and eroding value" (Swanson 83). While the modern city was generally imagined in correlation with an increase in productivity —again, part of Haussmann's plan was to speed up commerce and by extension production—central to its psychic and symbolic economy stands the unproductive prostitute or in effect the un-reproductive working woman. The latter may aid production by working in a factory, but this comes at a cost to her former role as reproducer of offspring, or future consumers and workers. The prostitute in particular symbolizes the waste at the heart of an urban environment designed to eliminate all waste (updated sewers and plumbing were crucial to Haussmann's designs for a new Paris). But just as Haussmann did not completely eliminate the poor from the heart of Paris by demolishing their homes, neither Victorian reformers nor agents of capitalism could remove the "waste"-both in a reproductive and an economic sense—-that remained prominent in the urban landscape. Furthermore, even though male bureaucrats perceived the brothel as a site of containment that they would oversee, it presents the possibility of undermining the male dominated economic structure of the nineteenth-century capitalist city, especially since in the brothel prostitutes generally work for a female madame, as opposed to the street in which they typically work for a male pimp. Not only is the prostitute "unproductive" in terms of not contributing to the industrial machine, inside the brothel at least, she can also be seen as threatening to take control of profiting from the means of production, as well as reproduction. By making this point, it is not my intention to romanticize prostitution, which as Acker's novel makes clear takes its toll on physical bodies. Rather, I am merely suggesting that the economic relations within the brothel offered yet another potential disruption to the city's spatial, social, and economic order. The heterotopic nature of the brothel 
reminds us that the city is in effect constructed out of such social and spatial points of tension, a point Acker further highlights by bringing the detective/flâneur onto the scene.

Much like the prostitute/public woman, the flâneur, the detective's surrogate, was a highly problematic character at the heart of the modern city. While on one hand the flâneur embodies the supposedly empowered male gaze and its use by the ruling class to rationalize and divide, on the other hand the flâneur transgresses the very power relations he would seem to enforce. The flâneur cannot succeed as the guardian of the city's rationalized spatial logic because as John Lechte argues, he himself operates within the logic of "the transitory and the contingent" (103). "The flâneur's trajectory leads nowhere and comes from nowhere. It is a trajectory without fixed spatial coordinates" (Lechte 103). The flâneur is, in fact, defined by a lack of home, of origin as well as destination. Thus, he not only cannot uphold, but he actually transgresses the very spatial logic he daily navigates, much like Auster's Quinn who follows a route that cannot itself be deciphered. As with the metaphysical detectives seen in earlier chapters, the flâneur's lack of a home makes him a liminal figure both in terms of space and class. As Benjamin himself noted: "The flâneur is still on the threshold, of the metropolis as of the bourgeois class. Neither has him in its power. In neither is he at home" (10). Wilson extends Benjamin's commentary, suggesting that while the flâneur was a "gentleman," he was also "subtly déclassé" (63), in part because even though to be a flâneur required considerable financial resources, the flâneur's disregard for productivity created a good deal of anxiety and even "financial insecurity" that "often lead to poverty and obscurity" (72).

Acker's version of Poirot provides an interesting parallel to the flâneur's class indeterminacy. When Poirot first enters the narrative, he occupies primarily two spaces, the brothel and his apartment, 
a "small flat on the Rue de Ganglia in Paris." (198), where, as Toulouse mentions, "Only one man servant, George, attends the flat" (198). In both cases, since Poirot employs a servant and since the brothel is purportedly a safe environment, attracting a bourgeois clientele, our detective initially appears to be securely situated in the world of the middle class. However, once Poirot enters the street, his class status becomes far less certain. While his presence in the slum obviously is not intended in any way to alter the chaos of the street-he is there, rather, to re-contain its contagion so as to protect the space of the bourgeoisie —once he leaves the safety of his middle-class environs, we never in fact see him re-enter his apartment again. At the point that Acker drops the murder mystery, he is still wandering the streets in search of clues, like the flâneur, trapped in the city with no home, no place he truly belongs. (One might argue that the flâneur, like the in-between subjects in DeLillo and McElroy, also prefigures the state of capital in the postmodern world, that is, everywhere but nowhere, having access to all spaces, yet occupying no particular place.) And, as we have seen, the brothel hardly provides a safe haven from the encroachment of the slum. Finally, Poirot's ability to wander all parts of the city, to transverse its spatial and social divisions, suggests that indeed he himself lacks class specificity. Notably, the historic Toulouse was himself a flâneur of sorts, for while he hailed from a wealthy, aristocratic family he lived a life of "superficial bohemianism” (Frey 216), slumming it along with many other artists in the cabarets and brothels of Montmartre, where he gazed at a new kind of spectacle. According to Frey, Toulouse actually kept a studio/apartment in Montmartre — at one time on the Rue Cailancourt, the very street he and Poirot have to "rush down" in Acker's story-but, of course, unlike the economically deprived he frequently returned to the financially secure world of his parents. A flâneur whose gaze and artistic reproduction of the gaze-again, Toulouse frequently 
painted the nightlife of Montmartre — would seemingly reinforce the social delineations by which the city was structured, actually, then, presented another potential threat to the city's social coding as artists like Toulouse risked their own spatially designated social position while also bringing back with them into the world of the middle-class the "contaminants" of the slum.

Although being a flâneur was a position restricted to males, ironically, the flâneur much like the public woman, also posed a significant threat to the masculine identity and its claims to power. As Wilson contends, lacking economic or spatial stability, "The flâneur represented not the triumph of masculine power, but its attenuation" (74). An endless wanderer, he comes to symbolize the "deferral of satisfaction," synonymous with the commodified, phantasmagoric city (74). In the labyrinthine city, "the flâneur effaces himself, becomes passive, feminine" (75). Similarly, Poirot's failure to find the truth or solve the crime certainly represents a "deferral of satisfaction," both for the detective and the reader. In search of a truth he never finds, Poirot's, the flâneur's desire is intrigued but never satisfied in or by the city. Like the un-homed, disempowered flâneur, Acker's Poirot wanders inside a case that has no end in sight, no resolution, nor implications for the control of future murders - the street remains full of them. In the end, as Toulouse puts it, "Poirot's stumped" (200); that is, his rationality, historically seen as masculine, has been thwarted, leaving him metaphorically castrated. Thus, the male detective who would use his gift of ratiocination to re-order both the city's spaces, and the bodies that inhabit those spaces, is revealed to have lost or to never have possessed the ability to do either. The bodies in Acker's narrative are, in fact, strikingly out of control, frequently shifting from male to female identities, right under Poirot's watchful eyes no less. Even Toulouse, a flâneuresque male who spends much of his time gazing at women's bodies and then reproducing that gaze in his artwork, cannot 
maintain his own designated body; Acker frequently shifts his/her gender identity. As a cripple in real life and feminized in Acker's fiction, Toulouse represents yet another example of the "stumped" male in the city who has lost both control of the spaces he so carefully divided and patrols as well as the means of defining and regulating the bodies in those spaces. Furthermore, once gender identity is thrown into question, so are the city's spaces which are based on those gender divisions, particularly those spaces prohibited to women. If women can become men and vice versa, or better yet uncategorizable in terms of gender, how then can the male ruling class claim to divide and police the city according to anything remotely resembling categorical reason? Acker's invocation of such late-twentieth-century cities as San Francisco and Hollywood, where former gender and spatial boundaries have more clearly undergone erosion— though such boundaries have certainly not been completely eradicated—further reinforces the point that the gender and spatial lines once thought permanent and stable could not and have not held.

Admittedly, we can locate many of these same tensions, regarding both economics and gender, in the classic detective story; however, the classic detective's ability to solve the crime along with the genre's privileging of clear-cut endings, or closed structures in general, works to mask such ideological fissures. In contrast to his more conventional namesake, Acker's detective clearly fails, causing us to recognize that the flâneur was in reality not so much a controlling force as a symbol of a loss of control on the part of the mobile male. Instead of marking his place in the world or ordering the space in which he lives, the flâneur finds himself and his city torn lose from spatial parameters That is to say, rather than realizing the rational order of the modernist dream, the flâneur, a forerunner to the metaphysical detective, shuffles along an indeterminate path, his very (ontologically shifting) presence calling into 
question the notion of a rationally ordered urban space. Not only does flâneur symbolize crisis within the nineteenth-century city, with which he is typically associated, but his ambiguous ontological status also mirrors, or at least prefigures, the shifting spaces and markets of late capitalism.

It is worth noting that unlike the previous, male, novelists we have addressed in the first three chapters, Acker does not invoke the home as a site of loss for the detective. A flâneuresque figure, Poirot appears wholly ambivalent in regard to finding his "place" in the world. Although clearly uncomfortable in the slums of Montmartre, Poirot exhibits no anxiety over whether or not his home awaits him. What is the reason for this disparity between Acker's metaphysical detective story and those of her male counterparts? One possible answer is that while the home has provided stability, both physically and in terms of identity, for both men and women, for women in particular it has also represented immobility, both in terms of physical movement and in relation to the construction of female identity. As Massey contends, for men losing the home as locus of place and identity means a loss of control: "Those who today worry about a sense of disorientation and a loss of control must once have felt they knew exactly where they were, and that they had control" (165). Historically, the majority of women have been denied such power and cannot, therefore, mourn its loss. Furthermore, the disruption of the "home" in postmodern culture brings with it not only the loss of stability, for both men and women, but also, particularly for those once strictly confined by its parameters, the opportunity to explore new spaces and new identities. This would explain then why Acker focuses on the already homeless of the city, the flâneur, the prostitute, etc . . , for they both represent the transgression of the restrictive, alternately comforting, spaces Acker's fiction revels in disrupting as well as symbolize the destabilized spaces and markets of our present postmodern culture. 
To summarize, by invoking the heterotopic brothel along with the social and spatial tensions that lie between and within the figures of the flâneur/detective and the prostitute, Acker's mystery suggests that the nineteenth-century city is born and operates not out of rational order, but out of contradiction, conflict, and transgression. By exposing these rifts within the urban order, Acker's fiction indicates that the history of urban space is not so much one of natural order and domination, as Enlightenment thinking might have it, but, rather, a history of physical as well as cognitive, detective-like attempts to police boundaries that constantly undergo erosion, a history of spatial crisis.

\section{A Geographical History Lesson}

Of course, spatial crisis is not unique to the cities of the past, a point Acker emphasizes by juxtaposing and superimposing a variety of other geographical spaces and historical moments alongside and onto the Paris of her murder mystery, creating a narrative kaleidoscope that links the ideology of detection to capitalism's history of geographical expansion. By taking us beyond nineteenth-century Paris, Acker's novel suggests that it is not just male subjectivity nor merely the modern city that is at stake in Poirot's failure. More broadly, the driving force of capitalism also becomes suspect once the ability to rationalize and control space is called into question. Acker extends the implications of her murder mystery by inserting into it a treatise on political economy, in which she offers an overtly geographical account of the rise of capitalism: "Capitalism as a world system had its origins in the late fifteenth and sixteenth centuries when Europeans, mastering the art of long-distance navigation, broke out of their little corner of the globe and roamed the seven seas, conquering and trading" (275). Since the growth of capitalism has always been tied to an ability to navigate or control space, it is no surprise that laissez-faire capitalism would later take up the imperialist project out of the economically based 
need for geographical expansion. Acker refers to Hobson on this point: "In Imperialism Hobson claimed that capitalism faced an internal and insoluble difficulty and that it was forced to turn to imperialism, not out of pure lust for conquest, but as a means of ensuring its own economic survival" (276). The "insoluble difficulty" Hobson speaks of arises from the fact that "neither rich nor poor could consume enough goods. The poor don't have any money. The rich lack the capacity for that much consumption" (277).

As Harvey argues, this is capitalism's inherent dilemma, "overaccumulation," which "can never be eliminated under capitalism" (181). Or as Acker puts it, the "developed nations ... need new markets" (277). According to Harvey, this problem can at least temporarily be contained, most effectively through what he terms a "spatial fix." He explains that this " spatial fix' . . to the overaccumulation problem entails the production of new spaces within which capitalist production can proceed" (183). But even this "fix" fails to provide a permanent solution, for "to the degree that the progressive implantation of capitalism across the face of the earth extends the space within which the overaccumulation problem can arise, so geographical expansion can at best be a short-run solution" (183). While such conflict would appear to forebode the death of capitalism - how can it survive such internal contradiction? - according to Slavoj đi@̀k such "contradiction" is actually "contained in its [capitalism] very concept" (52). đi@̀k explains, "The 'normal' state of capitalism is the permanent revolutionizing of its own conditions of existence: from the very beginning capitalism 'putrifies', it is branded by a crippling contradiction, discord, by an immanent want of balance: this is exactly why it changes, develops incessantly_incessant development is the only way for it to resolve again and again, ... its own fundamental constitutive imbalance, "contradiction"” (52). In this respect, capitalism's 
survival depends on enacting short-run solutions only, thus maintaining the conflict through which it perpetuates itself.

We witness capitalism's uncanny ability to survive in Acker's text, which reveals both a dilemma inherent to capitalism, that is overaccumulation, and the way in which this dilemma actually facilitates capitalism's expansion and survival, which in her version take on a spatial dimension; if the problem is not spatial in nature, the answer, or fix, certainly is. Acker concludes her history of capitalism by bringing us up to the late twentieth-century, the 1970's to be exact, or the point at which capitalism outgrows specific national boundaries and becomes a more thoroughly global force with the increase of multinational corporations. As Acker notes, "At this point many of the largest American corporations are located, at least in part, outside the USA" (278). However, as Harvey indicates, global expansion, appropriating more space, has not eradicated capitalism's constitutive contradiction, nor will it, but rather creates yet more dilemmas. Acker explains that within the global milieu of late capitalism, "There are the dominant exploiting countries and a much larger number of dominated and exploited countries ... The principle contradiction in the system, at least in the present historical period, is not within the developed part but between the developed and the underdeveloped parts. The relations of one to the other . . are fundamentally exploitive: they perpetuate and deepen the development/ underdevelopment pattern" (286). Thus, capitalism's geographic expansion, itself an effort to resolve its inherent conflict, has produced only more discord, which, according to Harvey, results inevitably in heightened competition for limited spaces of production and consumption, a competition — generally between the developed and the underdeveloped — that often necessitates violence or all-out war. 
Acker appears to make a similar prediction, though far more cryptically, by ending her novel with the story of businessman/gangster Johnny Rocco, who claims, 'I'm the real bourgeoisie cause I'm one of the people who makes the paths everyone in society follows" (308). Like other gangsters, and businessmen, he frequently engages in territorial disputes. Rocco claims, "no one and no family's ever crossed me and won. My territory works and remains untouched because I know how to deal with the world" (309). In other words, he knows how to defend and expand his territory through violence. Like the corporate giants of capitalism, he knows how to go to war. Thus, Rocco mirrors the spatial hegemony of multinational capitalism, for as Acker's novel suggests, after imperialism exhausts its spatial possibilities, "warfare" becomes "a means used by each leading capitalist power to maximize its economic "living space"' (283). Ironically, this is the legacy of Poirot, that is the legacy of the Enlightenment's notion that Western man might rationally control space, a concept capitalism has appropriated in an attempt to ensure its development. The manner in which late capitalism conceives of and produces space continues to rely on the assumption that space can be navigated and ordered so as to ensure power over it. Just as Poirot attempts to contain the social contagion, the murder, by constructing a fixed map of the brothel, capitalism produces space(s) appropriate to its own efforts at social control and economic expansion. Late capitalism's assumption that space can be rationally navigated and ordered remains despite the obvious contradiction that any "spatial fix" must be accompanied by the kind of violence that Acker portrays as synonymous with that of the American gangster. In this respect, Poirot's failed attempt to control space or prevent murders through ratiocination reflects a broader failure on the part of Western metaphysics to "fix" space so as to control its parameters—a failure ironically masked by military action, or more killing; significantly, 
Acker's novel ends with Rocco trying to dispose of dead bodies, to "clean up this mess" as he puts it (310). We are back in the space of the Montmartre slum, the space Poirot can neither explain nor control.

Of course, this conflict between rationality and violence is hardly out of place within the global space of late capitalism, but is rather constitutive of this space. As Lefebvre notes, "one of its contradictions is that between the appearance of security and the constant threat, and indeed the occasional eruption, of violence" (57). By collapsing the worlds of the American gangster, early imperialist efforts at economic expansion, and the nineteenth-century urban detective, Acker's fiction suggests that this contradiction is not unique to the globalized networks we witness today, but was in fact built into the very logic out of which the supposedly rationalized space of the Enlightenment/modern city was produced. Lefebvre argues that in terms of the production of space, rationality and violence in fact go hand in hand, as violence is often "cloaked in rationality, and a rationality of unification is used to justify violence" (282). If Acker's version of the detective story brings anything to light, then, it is this, that the positivistic detective and the rationalized city he polices are not immune to the "illogical" violence that Poirot wishes to solve; rather, the detective comes into being as a result of such illogic, and as we have seen the city itself is constructed both out of the separation of the disorderly from the orderly as well as the transgression of such boundaries: whether they be constructed along class, gender, or any other lines. According to Acker, this, then, is the history of western space, not a tale of rational planning and subsequent order, but rather of an ongoing struggle to contain, detective style, that which repeatedly resists efforts at both intellectual and physical domination. 


\section{NOTES}

1. Admittedly, there is a danger in singling out one narrative fragment within Acker's larger text in that this operation removes the given fragment from its context, making it appear far less radical. Although I trace what I can find of a plot to this murder mystery, it is important to note that "The Case of the Murdered Twerp" is as chaotic as Acker's other narrative spaces. Not only is this story interspersed with other narrative threads, including for instance a summary of Dean's Rebel Without a Cause, but inside this story characters, particularly Toulouse, take on more than one identity. Recognizing this, my goal is not to naturalize what appears to be a highly "un-natural" text, but rather by explicating one of the scraps of material from which Acker works, I hope to locate the specific systems of thought, including spatial imaginings, that Acker's fiction seeks to disrupt, in part through its employment of a violently conflicted narrative structure.

2. Berman notes some spatial conflicts produced by Haussmann's projects which I will not address specifically. For instance, though designed to increase efficiency the boulevards in speeding up traffic actually created a "moving chaos." Berman explains that the "chaos here lies not in the movers themselves - the individual walkers or drivers, each of whom may be pursuing the most efficient route for himself - but in their interaction, in the totality of their movements in a common space" (159). He goes on to suggest, "This makes the boulevard a perfect symbol of capitalism's inner contradictions: rationality in each individual capitalist unit, leading to anarchic irrationality in the social system that brings all these units together" (159). Also, as Benjamin notes, Haussmann's efforts to rid the city of its poor by destroying their homes, ironically, created a greater population of homeless (12).

3. For an in-depth discussion of Foucault's contribution to spatial theory, in particular his notion of the heterotopia see Edward Soja's Postmodern Geographies, in which he coins the term heterotopiology, as well as Benjamin Genocchio's essay “Discourse, Discontinuity, Difference: The Question of 'Other' Spaces."

4. Susan Buck-Morss provides a thorough account of Benjamin's discussion of the flaneur as well as his arcades project in The Dialectics of Seeing. 


\section{CHAPTER 5}

\section{Crossing Western Space: Ishmael Reed's Mumbo Jumbo}

Like the other works of metaphysical detective fiction I have addressed thus far, Ishmael Reed's Mumbo Jumbo looks nothing like a conventional detective novel. A “composite narrative composed of subtexts, pretexts, post-texts, and narratives-within-narratives" (Gates 220), Mumbo Jumbo even includes such oddities as pictures, footnotes, and a bibliography. Mumbo Jumbo is a "composite narrative" in another sense as well in that it presents the reader multiple narrators who speak from a variety of temporal and ontological positions (as in the fiction of Acker and Pynchon, temporal and ontological boundaries are repeatedly transgressed). Furthermore, in keeping with Reed's "Neo-Hoodoo Aesthetic," Mumbo Jumbo combines a variety of literary styles—from African oral tales to the detective genre — as well as a variety of cultural and textual influences: history, film, jazz, Voodoo ceremonies, etc ...

Nonetheless, despite the novel's obvious breaks with convention, after its publication in 1972, Ishmael Reed proclaimed Mumbo Jumbo "the best mystery novel of the year" (qtd. Carter 265). Indeed, the central narrative, among the novel's various intra-texts, is a detective story that involves the classic search for both a murderer as well as a missing text, reminiscent of Poe's "Purloined Letter." But, as we might now suspect, Reed's protagonist, $\mathrm{PaPa}$ LaBas, is no conventional detective. Unlike his literary forerunners who relied on ratiocination, LaBas is described as "a jacklegged detective of the metaphysical” (212), "a private eye practicing ... Neo-HooDoo therapy" (211). In an obvious transgression of the detective genre, LaBas does not depend solely on scientific reason or concrete evidence to explain away mystery; to the contrary, he preaches turning "to mystery, to wonderment," or in the Voodoo tradition, to the loas. ${ }^{1}$ LaBas' very name, in fact, is taken from the African deity Legba 
and his Haitian incarnation PaPa Legba, a trickster figure who mediates between spiritual and material worlds. $^{2}$ Moreover, Reed's novel never offers a solution in the traditional sense. Although we do learn who the guilty parties are, this knowledge does not have the cumulative effect it does in a classic work of detection, for as we will see, more threatening forces than an isolated murderer are pressing in on Western culture.

But while Mumbo Jumbo exhibits all the traits of a metaphysical detective novel, having much in common with the works of Auster, Pynchon, Acker, DeLillo and McElroy, Helen Lock suggests that Mumbo Jumbo also belongs to the category of what she defines as "Afrocentric" detective fiction. By "Afrocentric" Lock means those works that "derive from and incorporate .. . African culture and behaviour"' (ix). She clarifies that it "is not that the 'American' in African-American is being rejected but that the 'African' is being revitalized, and a new and energetic dialectic re-established between the two" (ix). With its inclusion of African tales and Voodoo ceremonies, Reed's novel certainly participates in the "revitalization" of African heritage. But as Lock's comments would indicate, Reed's novel does not simply replace the Western detective story with an Afrocentric version; rather, as in the fiction of DeLillo and McElroy, Mumbo Jumbo concentrates on the space in-between. The difference is that in the case of Mumbo Jumbo, the primary focus is on a specific cultural boundary, between African — or other cultures alien to the West - and Euro-American "civilization." This explains why Reed chooses as his detective LaBas (Legba), a mediating figure who presides over the crossroads for the space he wishes to interrogate is that of the cultural crossroads. As we will see, while Reed places the two cultures in opposition, his work is not so much interested in overturning the binary hierarchies as it is in interrogating and making use, artistic or otherwise, of the ways in which these cultures and their 
forms communicate, mix, clash, or disrupt one another.

This attention to cultural mixing is crucial to Reed's definition of the Neo-Hoodoo aesthetic. He explains, "Voodoo is the perfect metaphor for the multicultural. Voodoo comes out of the fact that all these different tribes and cultures were brought from Africa and Haiti. All of their mythologies, knowledges, and herbal medicines, their folklores, jelled. It's an amalgamation like this country." (Shrovetide 232-33). The very title of Reed's novel exemplifies this amalgamation. While in the English language mumbo jumbo is equated with nonsense, Reed's novel provides an etymology for the term that indicates that it is derived from a Mandingo word referring to one "who makes the troubled spirits of ancestors go away" (7). According to Robert Fox, "Ironically, at the same time that the words lost their original meaning, they took on a meaning which troubled the spirits of whites, invoking the fearful, atavistic vision of the 'dark continent' that Africa inspired in the West, which Vachel Lindsay summed up in his poem The Congo (1914): "Mumbo-Jumbo will hoo-doo you" (52). Thus, by highlighting the term "mumbo jumbo," Reed not only reintroduces a piece of African culture but also invokes an entire history of conflicting meanings produced by cultural amalgamation. It is this “amalgamation" that Reed's novel brings into focus, an amalgamation of cultural logic and forms which, pertinent to our discussion of space, includes the intermingling of differing, culturally inflected spatial perceptions and constructions. As we will see, Мumbo Jumbo ultimately indicates that the meeting points between what are traditionally seen as opposing notions of space deserve special attention because out of such amalgamations comes the potential birth of new spatial forms, new combinations that in their very production upset the spatial order of the West, the spatial logic upon which the detective relies. 


\section{A Jes Grew Mystery}

As Ishmael Reed's Mumbo Jumbo opens, "a psychic epidemic" known as Jes Grew is “creeping" across 1920's America. Although Reed takes the term Jes Grew from James Weldon Johnson who wrote, “'The earliest Ragtime songs, like Topsy, 'jes' grew”" (qtd. in $M J 11$ ), ${ }^{3}$ he traces it as far back as an ancient Egyptian dance craze that reemerges in New Orleans in the 1890's, a "flairup" which authorities thought they had neutralized by fumigating the Place Congo. But they misunderstood the nature of Jes Grew—which western science cannot even "bring into focus or categorize" (40)—and now it is back again, sparking the Harlem Renaissance, and has its carriers, or J.G.C.s, literally dancing in the streets. Alarmed by these developments, Jes Grew's enemies the Atonists call out their military wing the Wallflower Order to "defend the cherished traditions of the West" (15). Jes Grew is spreading for a reason: "Jes Grew is seeking its words. Its text" (6). "It must find its Speaking or strangle on its own ineloquence" (34); however, where and what exactly this "Text" is remains a mystery, the central mystery of the novel.

Ironically, the Text Jes Grew seeks has come to America in the hands of an Atonist, Hinckle Von Vampton, or H.V.V.- - a cartoonish version of Harlem Renaissance patron Carl van Vechten—who decides to send "it out as a chain book" to "14 J.G.C. individuals scattered throughout Harlem"(69). Unknown to H.V.V., one of the 14 J.G.C.s collects and gives the anthology to the black Muslim Egyptologist Abdul Hamid to translate. Anticipating the completion of Abdul's work, Jes Grew is on its way to New York where it will "cohabit" with its Text, that is unless the Atonists get to the Text first; as the Atonists see it, the only way to stop J.G. is to destroy the Text that it seeks. Consequently, H.V.V. and his partner Hubert Safecracker Gould pay a visit to Abdul, demanding he surrender the 
Text, and when Abdul refuses, they murder him. As fate, or convention would have it, LaBas discovers the body along with a clue, a cryptic note from Abdul that LaBas has "the nagging suspicion . . has something to do with the missing anthology" (131), which reads, "Stringy lumpy; Bales dancing / Beneath this center / Lies the Bird" (98). Clues in hand, LaBas, thus, begins his classic search for both the murderer as well as the location of the missing Text.

\section{Interrogating the Detective}

Notably, unlike most metaphysical detective stories, LaBas does actually discover the identity of the murderers, and even thinks he has located the Text, all of which he reveals at a party held at the Villa Lewaro, fittingly, a country-house reminiscent of those in Agatha Christie mysteries. ${ }^{4}$ But while LaBas' explication of the murder mirrors that of Poirot, it hardly mirrors Poirot's ability to close the book on all mystery. With black artists and intellectuals as well as wealthy white patrons, and, of course, the murderers themselves in attendance, LaBas and his fellow "Jacklegged detective of the metaphysical" Black Herman crash the party and confront the guilty parties, but before LaBas can apprehend the two men, "Hank Rollings the Guianese art critic" insists, "We won't yield these gentlemen until you explain rationally and soberly what they are guilty of" (160). But while LaBas agrees to explain, what he actually provides is far from the typical, tidy summary of how the clues lead to and incriminate the murderers. Rather, LaBas begins his summation, "Well if you must know, it all began 1000s of years ago in Egypt" (160) and proceeds to provide a history of Jes Grew that takes so long to convey — it is some thirty pages before we get back to the question of guilt— that once absorbed by this "subtext" the reader can easily forget the "present" scene, the Villa Lewaro, as well as the query to which the partygoers are waiting for an answer. The length of LaBas' narrative is not the only 
problem it presents; it is also full of anachronisms and at times it appears that another voice supplants that of LaBas, which might be attributed to Reed himself but can also be thought of as the mediating voice of a loa. At another point in the novel LaBas believes he is listening to Haitian emissary Benoit Battraville speaking on the history of The Work, but as Battraville explains to LaBas, "You actually have been talking to a seminar ... Agwe God of the Sea took over when I found it difficult to explain things" (138). Similarly, unlike the classic detective who has the definitive last word on the matter, LaBas offers an explanation of the crime that is actually the product of a supernatural, collaborative effort, a fact that is obviously disruptive to the illusion of the detective's authority.

Despite the hyper-prolonged suspense, LaBas eventually gets around to naming H.V.V. and Gould as Abdul's murderers. The problem, however, is that LaBas has yet to show proof of the Text's existence let alone its transmission, and, as the art critic hastens to note, without the book, there is no “empirical evidence" (195), at least not from an Atonist perspective, of either LaBas' version of history or his conclusions regarding Abdul's murder. When called on to produce the book, LaBas again concedes with the intention to reveal the mystery of Jes Grew's missing Text, which after deciphering Abdul's note, he believes he has recovered from "beneath the center of the Cotton Club's dance floor" (190). However, what LaBas has found is only a box, which may at one time have housed the missing Text but now turns out to be "empty!!" (196). Abdul has actually burned the anthology, and "Jes Grew is dissolved" (195), at least temporarily. It would seem, then, that the Atonists have won, but this is not exactly the case since they have no more understanding of Jes Grew than they did during its earlier outbreaks; Jes Grew remains a mystery and, therefore, a threat, even if temporarily a dormant one. At the very moment we expect closure, the case (or box) literally remains open, empty at the center. 
Of course, the fact that LaBas and Herman do get their men would normally indicate closure, but here it does not help much because as far as the reader is concerned there is no mystery surrounding the identity of the guilty parties in the first place. Moreover, LaBas succeeds in bringing the murderers to justice not because of his ability to convince what might be loosely thought of as a jury of their peers of their guilt, but, rather, because at the very moment LaBas's explanation is being called into question, the party is invaded by a group of women and children who accuse H.V.V. and Gould of yet another crime, of stealing black culture from school children, meaning the detectives never do satisfy the Western need for empirical evidence. Of course, this matters little to LaBas and Herman, who make it clear that they intended to see the murderers receive justice with or without the blessing of those who adhere to the Western notion of "proof." As LaBas explains to his captives, "we're jacklegged detectives and don't have a license from New York authorities, but we do have jurisdiction in Haiti though. We are delivering you to Other Authorities" (197 my emphasis). Literally, LaBas means that they intend to deliver the guilty men to Battraville, who will take them on "a little excursion" to Haiti, but we can also read LaBas' appeal to "Other Authorities" as a refusal of the Western notion of proof and faith in concrete evidence. Instead of adhering to white America's sense of justice, LaBas looks outside the parameters, or the jurisdiction of the Atonist mind, to "Other Authorities," and in the process calls into question the entire notion of Atonism (the one way) as well as the idea of the master detective (the sole authority).

Furthermore, while the classic detective's goal is to repair the social order, the white middleclass order, which has been disrupted by a crime, LaBas is actually out to undermine that order, to infiltrate the Atonist, or single-minded tendencies of white America with an alien cultural form. 
According to LaBas, the real plague is Atonism itself, as Reed's description of the headquarters of the Wallflower Order suggests: "You have nothing real up here. Everything is polyurethane, Polystyrene, Lucite, Plexiglas, acrylate, Mylar, Teflon, phenolic, polycarbonate ... The aesthetic is thin flat turgid dull grey bland like a yawn. Neat. Clean, accurate, and precise but 1 big Yawn" (62). Inside this physical and ideological structure, "Plastic will prevail over flesh and bones. Death will have taken over" (62). Ironically, the same neat, clean social order that the classic detective protects, here, leads to death, the very thing the detective is to circumvent. It is no wonder, then, that LaBas and Herman appeal to "Other Authorities."

\section{The Afrocentric Detective}

As I noted above, like his detective, Reed also looks outside the parameters of the West to other cultural models, including alternate models for the detective story. According to Lock, while the Oedipus tale underpins the Western tradition of detective fiction, there is another, "Afrocentric" tradition of detection whose model can be found in the "nonWestern narrative . . of the Egyptian god/man Osiris" (27), the very tale LaBas includes in his history of the Text. While there are many versions - a traditionally oral tale, it has no one chronicler — the basic story goes that Osiris, under whose rule Egypt prospers, is deceived by his jealous brother Set into entering a coffin; in Reed's version Osiris is actually buried as a test of his divine powers and oneness with nature. Once Osiris is inside, Set and his co-conspirators seal the coffin, suffocating Osiris, and then later chop his body into fourteen parts (the same number of parts into which H.V.V. divides the anthology) which they throw into the Nile. However, through the collective effort of Osiris's wife Isis and their son Horus—who gather more than clues; they actually gather the parts of the victim's body—and the god Thoth, who 
knows the "secret 'words of power'," Osiris is resurrected and elevated to the level of godhead as a "symbol of the cycle of the life force, of creation and regeneration" (Lock 27-8).

As Lock suggests, while in the Oedipus model the objective is to "reconstruct" the "past in order to find the truth about the crime," (viii)—a task accomplished by a lone detective or authority—in the Osiris model "the reconstruction is of the victim himself, through a communal effort" (viii). The "detectives" literally reconstruct the victim, meaning "it is the crime which is nullified rather than the mystery. The mystery itself—how death is transformed into life" remains a mystery (Lock 34), just as Jes Grew and its Text remain a mystery. And just as the purpose of the Osiris story, "is not to reveal the circumstances of the crime, which are common knowledge, but to explore the means of undoing the crime" (Lock viii), Reed's detective story does not focus on the whodunit—we know from the start who killed Abdul — but rather takes aim at the history of racial oppression, exploring the possibility of "undoing" this crime and revitalizing those who have suffered.

\section{"Time is a pendulum"}

Of course, this tradition of revitalization and regeneration conflicts sharply with a number of suppositions of Western detective fiction, including those regarding time. In its classic form the detective novel requires a concept of time/history in which past events can be frozen in order for the detective to reconstruct those events into a teleologically-driven narrative thread, leading from a mystery-laden crime to a resolution. In Reed's version of the detective story, however, at the moment when LaBas ought to petrify the past by narrating, or textualizing it, he actually makes the past come alive through narration by revising history to include both the present and future (relative to the 1920s). In LaBas's history the past is not re-constructed so as to stabilize it in the hopes of locating its one 
"Truth"; rather, it is re-constructed in the sense that it is made part of the present. History, Reed suggests, need not be locked away within the rigid determination, but rather, like Osiris, can be resurrected through infinite, communal versions. Mumbo Jumbo further disrupts the temporal schema of the Western detective story by closing not with the incarceration of Von Vampton and Gould, but rather with an appended "Epilogue" that flashes forward to LaBas lecturing on a college campus in the early 1970s on the history of Jes Grew (he continues to keep the past present). This final scene presents an obvious problem from the Western standpoint in that $\mathrm{PaPa} \mathrm{LaBas}$, who is described as a middle-aged man in the 1920s, appears not to have aged. To further complicate matters, Reed closes his novel by in effect reversing the chronology of the text, which begins in the 20 s and ends some fifty years later, by summarizing LaBas' history in reverse, starting with his activities during the 60s and counting backward to the 20s, which the novel claims "were back again" (218). In short, "Time is a pendulum. Not a river. More akin to what goes around comes around" (218). Such temporal circularity undermines both the logic of the detective story as well as the entire Western notion of time and history, upon which the Atonist claim to "Truth" relies.

\section{The Missing Text at the Center}

By evoking the Osirian model and its resistance to rigidity and stagnation, Mumbo Jumbo not only questions the temporal and epistemological suppositions of the classic detective story, but also mounts a not-so-subtle attack on the Western view of textuality. As far back as Oedipus, the Western detective has succeeded in large part because of his ability to locate missing texts as well as to decipher cryptic texts by providing The authoritative interpretation. In Mumbo Jumbo, however, the Text remains not only missing but unreadable as well. The Text's absence does more than question LaBas' 
ability as a reader; rather, as LaBas' history of the Book of Thoth indicates, the Text's absence questions the entire notion of textuality held by the West. According to LaBas, the Book comes into being when, following multiple Jes Grew “outbreaks” throughout Egypt, Thoth goes to Osiris and suggests that "if Osiris would execute these dance steps" for him "he would illustrate them" (164). Importantly, Thoth's intention is not to restrict Jes Grew's future forms; rather, he envisions a "Book of Litanies to which people ... could add their own variations" (164). As Lock recognizes, "Thoth's book uses the inscribed image illustratively rather than deterministically. It is also clear that the Book is to be regarded as an indeterminate process rather than a determinate product" (56-7). The indeterminate nature of the Book makes little sense to the Atonists who demand definitive interpretations. Thus, while the Atonists recognize that Jes Grew cannot be contained through traditional means, they still assume that it can be defined by its Text, locked into its Logos.

LaBas's history of the book of Thoth actually includes an anecdotal warning against such a misreading. In his version of the story of Moses, LaBas tells of Moses' quest for the Text as a means of gaining power in Egypt. Upon visiting the temple of Osiris and Isis in Koptos, Moses actually does gain access to the Text, or a version of it, and leaves feeling that he has "gotten it all down. All down. Had it down pat" (182). However, when Moses later performs the "words of the Book of Thoth" for the people of Egypt, instead of bringing life to the crowd or inspiring the Egyptian masses to worship him, the songs actually cause their ears to bleed. The work, which previously sparked life, in this instance turns destructive. This results not only because Moses misuses the Text for his own, power-hungry ends, but equally because Moses has mistakenly assumed that such a Text can be gotten "down pat" in the first place. He approaches the Text as if there exists but one determinate reading, or signification. 
By contrast, the Neo-Hoodoo perspective views the Book as a work in progress, like the Osiris tale, kept alive through variation and improvisation. Notably, the music of the Osirians who attend Moses' concert, though they "didn't know The Work that Moses knew," has the effect Moses seeks, that is causes the people to break out in dance (185). The text itself, then, is not as crucial as the Atonists, or the detective might presume, for Jes Grew seeks its expression, not its confinement within a definitive reading.

PaPa LaBas' own quest for the Text, in fact, places too much emphasis on the object itself and even seems counter-intuitive because, according to the Atonists, to control the text means the death of Jes Grew. LaBas' one flaw is that he is "a bit too rigid" (130). Herman advises LaBas to "Improvise some. Open up, PaPa. Stretch on out with It" (130). Herman recognizes that Jes Grew is not seeking to define its parameters through its Text, but rather to stretch the limits of the Atonist culture it disrupts. Buddy Jackson, a Harlem gangster and Grand Master of the African Lodge \#1, suggests that the Text itself, in its empirically evident form at least, is ultimately of little significance. While Jackson and his men learned of H.V.V.'s possession of "a Black sacred Book" (194)_Jackson is the anonymous J.G.C. who collects and gives the anthology to Abdul—unlike those who ardently hunt the Text, they claim they "didn't care" about the Text. Jackson explains, "We had invented our own texts and slang" (194). This would indicate that the Text's absence does not close the book on signification, so to speak, but actually opens a space in which Jes Grew can continue to signify indefinitely. Jes Grew dissolves, then, not because Abdul burns the anthology but because those who seek it, whether to embrace or destroy it, mistakenly derive "their understanding of the nature of this Text from the dominant culture" (Lock 58), which assumes the text's ability to foreclose signification. The final irony 
is that Jes Grew's “dissolution" allows it to live on, to remain unbound, open to future manifestations and interpretations.

Indeed, Jes Grew does not meet its final demise at the close of the Harlem Renaissance. As LaBas recognizes, "Jes Grew has no end and no beginning ... They will try to depress Jes Grew but it will only spring back and prosper. We will make our own future Text. A future generation of young artists will accomplish this" (204). Mumbo Jumbo itself can, in fact, be seen as Reed's contribution to this "future Text" and a product of Jes Grew: "the manic in the artist who would rather do glossalalia [sic] than be "neat clean and lucid" (211). That is to say, against the backdrop of the "neat clean and lucid" detective novel and its adherence to rational explanation and definitive closure, Reed's open-ended, multi-textual, polyvocal "glossalalia" calls attention to its own un-solvablity.

While Mumbo Jumbo resists the Western impulse to solve mysteries, determine meanings, and discover truths, this does not mean that Reed's detective novel does not concern itself with attaining knowledge. As Fox notes, “A derivation of ‘mumbo jumbo’ from a Swahili expression suggested by Henry Louis Gates, Jr., and 'loosely' translated as 'What's Happening?' is . . instructive, for the answer is supplied by various strategies of trickery and redress, of fending and proving" (52). It is not that there is no answer, then, but that the answer supplied by "Western rationalism . . is countered by Neo-Hoodooism, which provides an old new twist to the braided strands of Western reality" (Fox 52). Thus, the knowledge that the Neo-HooDoo detective and the reader gains "is a different kind of knowledge from that acquired by the traditional detective" (Lock 35), a knowledge presumably aimed at undoing the "crime" perpetrated by the Atonists. The difference is that Mumbo Jumbo does not reveal an immutable truth that explains and firmly establishes the events of the past; rather, it exposes as 
always suspect the grounds upon which such knowledge is founded. Furthermore, it introduces the reader to an entirely different concept of knowledge in which mystery signals not so much a lack of knowledge as a willingness to open—or "stretch"—one's mind to a different kind of knowledge: a knowledge that remains alive, a knowledge that is repeatedly renegotiated through a willingness to improvise.

\section{Double-Crossings}

By asking us to resist the Western impulse to definitively solve mysteries, determine truths, and interpret texts, and to instead turn to mystery, Mumbo Jumbo appears to be an "anti-detective" novel in the truest sense. That is, it might appear to merely reverse binaries: dominant Western logic is suppressed in favor of now validated "alien" cultural forms. A closer examination of the novel suggests, however, that this is not exactly what Reed is up to, for Mumbo Jumbo does not actually present the battle between mystery and science or rationality as a clear-cut opposition in which we must choose one or the other. Mumbo Jumbo does, of course, play off the notion that mystery and Western detective, or scientific logic act as opposing forces. (On one side we have those, who like the Guianese art critic remain steadfast in their "devotion to empirical method" (215) and on the other we have those who like LaBas, according to the art critic, "always abandon reason and fall back upon Mumbo Jumbo" (195)). But while LaBas clearly wishes to introduce the world of mystery into the sterile order of the Atonist West, this does not mean that he gives up on reason altogether. In fact, LaBas depends heavily upon his ability to deduce and reason, detective-style, to sort through a string of clues as well as to interpret Abdul's cryptic note. At one point, in fact, LaBas appears to be relying too heavily on his ability to reason. He is so preoccupied with attempting to piece together clues inside his own mind that 
he misses an important piece of information. Upon hearing Abdul's epigram, Herman tells LaBas of a "vision" he has received of a dancer at the center of a "night club floor" (131). Had LaBas listened to Herman's vision, to the metaphysical, he would have better understood Abdul's cryptic text. LaBas misses this because he is not in tune, so to speak; he is too busy playing detective. ${ }^{5}$

As Herman instructs, "Doing The Work is not like taking inventory" (130); it cannot be boiled down to tidy lists that account for all the missing pieces. Rather, the Hoodoo detective, as LaBas learns, needs to rely equally on the metaphysical or on his contact with the loas. What Reed's novel attacks is not so much scientific logic as Atonism, that is one-mindedness or the cultural restraints that allow for only one way of thinking or proceeding. Mumbo Jumbo does not disparage all science, but rather a particular narrow-minded devotion to what Deleuze and Guattari term the "imperial sciences" or "State science" which holds to "a set of strictly limited formulas" (362), as does the science of detection. Deleuze and Guattari distinguish this "State science" from "nomad science," which by definition is "difficult to classify" (361); as with Jes Grew its "history is even difficult to follow" (361). Unlike State science, nomad science resists rigidly confined parameters, including textual parameters. We might even say that like the Hoodoo detective, the nomad scientist is willing to "stretch on out with It," to bypass restrictive formulas in favor of "deformations, transmutations, passages to the limit" (Deleuze and Guattari 362). Significantly, what most interests Deleuze and Guattari are these "limits," or the "borderline phenomena in which nomad science exerts pressure on State science, and, conversely, State science appropriates and transforms the elements of nomad science" (362). Similarly, Reed's novel both focuses our attention on "borderline phenomena," the points of interaction between Western science or Western cultural logic and Afrocentric culture and tradition, and also 
suggests that the place where "The Work" is most alive is at the cultural crossroads. As the poet Nathan Brown, Reed's version of Countee Cullen, tells H.V.V., one can "use the advantages of both" cultures (117). Or as Battraville suggests, Americans have come upon the "new thang" because they have "synthesized the HooDoo of Voodoo," or have made use of borderline phenomena unique to the new world (152). Cultural synthesis seems, in fact, to be the aim of Mumbo Jumbo itself: a textual crossroads that in its sheer poly-vocality as well as its multi-textuality questions both the adherence to a singular truth espoused by the Western detective story as well as the more general one-minded, univocalism of Atonism.

As Reed's description of the Neo-Hoodoo as a multicultural "amalgamation" like America itself would suggest, the borderline or crossroads is integral to the Voodoo tradition upon which he draws. Again, LaBas is the new world incarnation of the deity Legba who mediates between realms. Fox explains further, 'Legba, who reigns over the crossroads which is 'the meeting point of opposites,' is met there by his own opposite, Loko Carrefour, who represents youth, night, and the moon, just as Legba stands for age, day, and the sun" (52). But while in the Western tradition, opposition mandates a choice which in effect ends the opposition —one side of any opposition must be suppressed so that the other, the "correct" side can rise to prominence — in the Voodoo tradition "[o]pposition is associated with vitality. Unity created by removing conflicting or opposing elements is a hollow and meaningless unity" (52). This is the kind of unity that the Atonists establish and protect by militantly repressing all opposition to their cultural logic or aesthetic. The very existence of a cultural crossroads threatens the Atonist way, the one way, and, therefore, must be eradicated. For the Neo-HooDoo-ist, however, opposites are desirable in that they produce a "rupture of plane" (Fox 48) out of which new 
life arises, meaning, opposites are crucial to the ongoing regeneration of the "new thang." The rigid, and dead, "right way" is replaced, then, by a crossroads at which such opposites as mystery and science do not so much act as binaries jockeying for position as they explode the very lines that divide them, reconstituting the structures by which we know our world. ${ }^{7}$

The crossroads is, in fact, that point at which Reed's novel leaves its readers; at its close we see LaBas driving his Locomobile Town Coupe across the bridge back into Manhattan, back where the story begins and ends. At the final "Freeze frame," LaBas is suspended in-between, symbolizing his ability to bridge disparate cultures as well as disparate realms, including "real and spiritual worlds" (Shadle 65). The final moment in the novel can also be viewed as a bridging, or rupture, of the dividing line between fiction and reality. In the penultimate line, "Skyscrapers gleam like magic trees" (218), in which case "the fictive world is both real and fiction" (Shadle 66); I would add that the "real" world in this instance is also both real and fictional, simultaneously both concrete and steel as well as the stuff of "magic." Reed suspends his reader, not on a side—as does Atonism—nor at an end point—as does the science of detection — but at a multi-directional, multi-cultural crossroads where the lines that define history and reality are ruptured, regenerated, and revised. 


\section{Crossing Social Space(s)}

The Neo-Hoodoo emphasis on the crossroads has compelling implications for spatial analysis, regarding both how space is imagined and produced. By working toward a rupture of plane, a rupture of spatial boundaries, the Neo-Hoodoo produces a "kind of 'exploded space"'(McGee 82), which obviously threatens the spatial logic through which the Atonists maintain their social order. The Atonist vision of Western space is synonymous with what Deleuze and Guattari term a "striated space," or the space of State science, which they suggest is both "limited and limiting" (382). The space of the nomad, on the other hand, is a "Smooth space," an open space yet to be plotted, fenced, or demarcated by Western spatial practices. Smooth spaces, such as, for instance, Pynchon's “The Zone," pose an obvious threat to the striated spaces to which the Atonist mind subscribes; the very existence of such spaces, in fact, disrupts the Atonist spatial "order." Accordingly,

One of the fundamental tasks of the State is to striate the space over which it reigns ... It is a vital concern of every state not only to vanquish nomadism but to control migrations and, more generally, to establish a zone of rights over an entire "exterior," over all of the flows traversing the ecumenon. If it can help it, the State does not dissociate itself from a process of capture of flows of all kinds, populations, commodities or commerce, money or capital, etc. There is still a need for fixed paths in well-defined directions, which restrict speed, regulate circulation, relativize movement, and measure in detail the relative movements of subjects and objects. (Deleuze and Guattari 385-86)

Deleuze and Guattari explain further that "each time there is an operation against the Stateinsubordination, rioting, guerrilla warfare, or revolution as act—it can be said . . that a new nomadic 
potential has appeared, accompanied by the reconstitution of a smooth space or a manner of being in space as though it were smooth ... It is in this sense that the response of the State against all that threatens to move beyond it is to striate space" (386).

Jes Grew, a "Creeping Thing," embodies this "nomadic potential" in its resistance to the striating logic of Western science and conventional detection. When the Mayor of New Orleans asks one of the doctors treating Jes Grew Carriers, "But can't you put it under 1 of them microscopes? Lock it in?" the doctor explains, "It's nothing we can bring into focus or categorize; once we call it 1 thing it forms into something else" (4). Jes Grew is the migration, the flow that cannot be controlled nor restricted; it creeps across the supposedly variegated American landscape, defying all boundaries; it "knows no class no race no consciousness" (5). In other words, it disregards all Atonist social demarcations regarding both the subject and the space the subject inhabits. As we have seen, Jes Grew refuses to be placed in a box or in a determinative Text. Rather, Jes Grew moves as if in a smooth space, challenging the categorizing limits that the State wishes to impose. As Deleuze and Guattari's comments would suggest, Jes Grew's transgression of the clearly demarcated space of the State is met with swift and militant efforts to re-produce a more limited space that would restrict future flows. But the Atonists have set out to "capture" what ultimately cannot be captured. The solution the Atonists assume is to replace the "manic" (smooth) with the "lucid" (striated) by confining Jes Grew to its Text, or to the Atonist version of textuality which does not open up meaning but restricts it to one reading, in effect killing it by preempting future signification. Jes Grew, however, lives on beyond the Text, or outside the striating lines of Atonist (classic detective) spatial production.

Mumbo Jumbo provides another example of this interaction between smooth and striated 
space, between delimiting boundaries and nomadic flows, in its dramatization of the efforts on the part of the Mu'tafikah to recover Eastern art from the American and European Museums. As one of the multiple narrative voices in the novel reports, in a news radio parody, "Compounding" the "Jes Grew crisis," "Black Yellow and Red Mu'tafikah were looting the museums shipping the plunder back to where it came from" (15). While this group of art-nappers works to liberate the aesthetic forms of nonWestern cultures, the Atonists "believe that art should be placed in intellectual cells to hinder people from being moved by it" (Carter 269). Significantly, Reed depicts museums as "Centers of Art Detention," aesthetic prisons inside which America looks to "guard the 'fetishes' of civilization" (15). In fact, the Curator of the Center of Art Detention just happens to be former corrupt Police Commissioner Biff Musclewhite, who the novel makes clear has been hired not because of any knowledge of art but because of his experience in policing the striated space within which the Atonist order has confined the nomad art that threatens to move its beholders beyond the State's established "zone of rights." In retaliation, as McGee puts it, the Mu'tafikah are attempting "to extract the art of the third world from the space of the norm and return it to the realm of the incommensurable" (97), to the smooth, undefined, de-historicized space of the nomad.

Musclewhite's connection to the police force reminds us that the conventional detective himself participates in this effort to striate space by containing both the crime and its repercussions as well as the criminal, or, in effect, all that threatens to disrupt the boundaries by which the State defines itself and its claims to power. Even the very "mental space" of the detective is subject to and reinforces the striating impulse of the State, for the detective can think only one way, can deduce only one truth, one history, one cause and one effect. LaBas, however, is no conventional detective. His movement away 
from rigidity suggests that he is learning to move and think as if in a smooth space, or in keeping with his position in Voodoo tradition, as if at the crossroads between the striated and the smooth, where the rupture of plane occurs.

While Deleuze and Guattari set up the opposition between striated and smooth space, they also point out that this is no "simple opposition"; rather, "the two spaces in fact exist only in mixture: smooth space is constantly being translated, transversed into a striated space; striated space is constantly being reversed, returned to a smooth space" (474). They explain, "What interests us in operations of striation and smoothing are precisely the passages or combinations: how the forces at work within space continually striate it, and how in the course of its striation it develops other forces and emits new smooth spaces" (500). Deleuze and Guattari go so far as to suggest that smooth space is not preferable in and of itself. They directly instruct us, "Never believe that a smooth space will suffice to save us" (500), for "smooth spaces are not in themselves liberatory. But the struggle is changed or displaced in them, and life reconstitutes its stakes, confronts new obstacles, invents new spaces, switches adversaries" (500). In other words, the objective is not to capture a smooth space, which would ultimately mean its striation, but rather to interrogate the oppositional confluence at which the two types of space meet, the "constantly shifting borderline" (367) through which both types of space are constituted, and out of which Western spatial logic is challenged and at times exploded into a multi-directional space, into a "new thang."

Mumbo Jumbo further illustrates this ongoing tension between smooth space on one hand and striated space on the other at both physical and metaphysical levels. Obviously, the access the loas have to this world as well as the access that human beings have to the loas constitutes a breach in the 
striated space of Atonism. While the Judeo-Christian tradition also speaks of another realm, it preaches strict adherence to one God and one path, the only way to the "other side." As Battraville notes, the Atonists have a "fetish about highways," clearly marked paths which it appears they wish to extend across the ontological divide. This adherence to the one way stands in sharp contrast to the Voodoo notion of multiple gods transgressing seemingly impervious ontological barriers. In this respect, LaBas' interaction with the loas, an operation that opens up or stretches out the space of the quotidian, directly conflicts with the Atonist desire to convert the incommensurable space of the metaphysical into a striated space that can be policed and categorized.

And it is not merely the space of the "other world" that is causing problems for or threatening the Atonist spatial order. Mumbo Jumbo dramatizes the tension between smooth and striated space at a more concrete level as well, most notably within the space of the city, or more precisely the space of Harlem. As Deleuze and Guattari suggest, the "city is the striated space par excellence" (481). Even the criminal element of the city follow its striated logic, as evidenced by the turf wars between rival gangs that we witness in Reed's novel. At the same time, however, "Even the most striated city gives rise to smooth spaces ... Movements, speed and slowness, are sometimes enough to reconstruct a smooth space" (Deleuze and Guattari 500). The movement of Jes Grew threatens to do just that. In anticipation of its arrival "Wall Street is tense" (21); a bout of Jes Grew has left another city, New Orleans, "a mess" (17), a mess that the striating logic of the Atonists seeks to quickly tidy up. Interestingly enough, Reed's novel indicates that the threat to the striated space of the Atonist city is indeed the result of a fluctuation in the speed of movement. As one of the quotations Reed includes in Mumbo Jumbo suggests, "Jazz did a number of things to popular music as well as to metropolitan life. 
It sped up the tempo of things ... Once the new musical spirit had come, it rapidly spread into dailyand nightly_activities" (115 my emphasis). Jazz, a Jes Grew phenomenon, in effect, changes the flows of 1920s New York City, particularly of Harlem, altering its migrations as well as the circulation of commodities within the city: white consumers are circulating through Harlem commercial and cultural sites; more money is being distributed throughout ghetto spaces, and black culture is being distributed among white consumers and carried outside Harlem. One might argue that jazz itself belongs to and produces a smooth space. Deleuze and Guattari, in fact, propose a musical model to aid our understanding of the difference between smooth and striated spaces, in which they argue that the "smooth is the continuous variation, continuous development of form" (478) - this is, of course, an apt description of Jazz. It is important to note that despite its "continuous variation," Jazz begins in or develops out of striation, out of the common melody upon which it improvises. In this respect, Jazz rises out of an amalgamation of forms. It is a nomad art which speeds up the quotidian, reconstituting a smooth space, a space both within the striated, logic bound city as well as somehow beyond it.

As Mumbo Jumbo reminds us, the logic, or il-logic, of Jazz and its potential nomadic challenge to the striated space of the city, particularly to the space of Harlem, was met with the infiltration of the Harlem nightclub scene-which facilitates the spread of Jes Grew, and subsequently the spread of smooth space — by the guardians of striated space. Most notably in the novel, we find Biff Musclewhite, who makes a profession of imprisoning art forms, frequenting Harlem cabarets such as The Cotton Club. While these visits to the spatial and cultural crossroads expose him to the contagion, his trips to Harlem also allow him to keep an eye on, to police the development of this smooth space within the otherwise striated city. We witness an even more overt attempt to infiltrate and re-contain 
the space produced by Jes Grew in the Atonist contingency plan —in case they cannot locate Jes Grew's Text—-"to groom a Talking Android who will work within the Negro ... to drive it [Jes Grew] out, categorize it analyze it expell it slay it blot it out" (17). H.V.V. astutely recognizes that because the white Atonists control the media, "J.G.C.s have no control over who speaks for them" (69). The Talking Android is, then, to speak for Jes Grew and in the process to "tell it that it is derivative" (69). The Android will keep J.G. from its "Speaking" by imitating the latter, or at least that's the plan. But this can be accomplished only from "within" the space of the nomad, or the alien cultural form. While initially H.V.V. and Gould seek an African-American spokesman for this job, interviewing a number of black writers as possible candidates, eventually Safecracker Gould himself takes the position. Gould is qualified because he has been stealing African-American culture by infiltrating Harlem cabarets, the space in question. During one of his many visits to a Harlem nightclub, Gould concentrates on "writing down the 'nigger mumbo jumbo words' he is hearing from the surrounding tables" (101). He even attempts to capture the dances, which he admits are "difficult to write down" (103). Gould is, in effect, writing his own Text, or script for Jes Grew, but his is not the Text which will enliven the epidemic, but a text intended to "categorize" and kill, that is, to arrest Jes Grew by placing the "mumbo jumbo" he has copied down within the striated space of the Western Logos, inside which Jes Grew cannot survive. Through both Musclewhite and Gould, the State works from within the potentially smooth space of the Harlem nightclub, drawing the smooth space of the J.G.C.s back in to the striated space of the modernist city.

Much to the dismay of the Atonists, the plan to implement the Talking Android is ultimately ineffective in capturing a rampaging Jes Grew. While H.V.V. is correct in his observation that the white 
Atonists control the media, and, therefore, have the potential to either influence the voice of the J.G.C.s or to simply overwhelm them with Atonist propaganda, their notion that they might imitate the voice of Jes Grew is based on the false assumption that all J.G.C.s speak alike. Here again, they presume the ability to contain the language of Jes Grew within the bounds of a striated space. African-American poet Major Young, who is modeled on Langston Hughes, questions this Atonist assumption that all African-American artists share a common, striated voice. Young asks H.V.V., "Is it necessary for us to write the same way?" (102). Young answers his own question: "I am not Wallace Thurman, Thurman is not Fauset and Fauset is not Claude McKay, McKay isn't Horne. We all have unique styles" (102). The voice of Jes Grew, of the "new thang" does not belong to the homogenized space that Atonism produces - the space inside which the detective can solve all crime — but is, rather, like jazz "a continuous variation of form," a perpetual becoming that as Reed's Neo-HooDoo mystery novel remains open-ended.

Reed depicts Harlem, then, as a space of contention inside which two competing productions of space mix and compete. Ironically, while Atonists focus their efforts on striating this space, these efforts, unintentionally, produce a cultural crossroads out of which "new combinations," cultural and spatial, have the potential to grow. Like we saw in our discussion of Acker, marginalized spaces within the city inevitably constitute a contested space in that such spaces are simultaneously both part of the prototypical striating logic of the city, as well as equally outside the flows—economically and socially —of the city. In the case of Harlem in particular, we find in Reed's novel that due to racial oppression and economic deprivation, the space of Harlem breeds nomadic potential that threatens to disrupt the striating logic of the Atonist dream. Just as the caging of Eastern art within Western 
institutions ignites the Mu'tafikah to action, to attempt to free the nomadic art from such spaces of striation, so the Atonist efforts to contain African-Americans and their culture within the striating space of the city—boxed in the parameters of the metropolis—-where its boundaries and potential permutations can be policed, ultimately inspire the J.G.C.s to look for "new combinations" that defy the Western notions of space and culture. Following Deleuze and Guattari, one might argue that not only are the Atonist efforts to striate all space unable to contain Jes Grew, but that, ultimately, the effort at striation in this case has the reverse effect and actually "emits new smooth spaces" (500), or at the very least those spaces at the crossroads that defy the one-way logic the Atonists wish to impose on all peoples and places.

As Deleuze and Guattari point out, the battle between the mutual-constitutive spaces of the smooth and the striated continues on indefinitely; that is to say, while the smooth space of Jes Grew challenges the neat lines drawn by Atonism, there are also forces at work within the State that continually striate all space. In fact, as Deleuze and Guattari might predict, the dissolution of Jes Grew and the Harlem Renaissance results from the Atonists' ability to capture flows, or more specifically to "regulate circulation." In Mumbo Jumbo Jes Grew's relapse into dormancy is attributed to a conspiracy on the part of wealthy Atonists to spark the depression. An insightful Walter Mellon, the mastermind of this plan, explains to the Hierophant 1, "The liquidity of Jes Grew has resulted in a hyperinflated situation, all you hear is more, more, increase growth ... Suppose we shut down a few temples ... I mean banks, take money out of circulation, how would people be able to support the appendages of Jes Grew" (154). It seems that the speed-up of the Jazz Age has produced a speed-up in economic circulation, and while this would appear to be desirable to Atonist capitalists, it threatens to 
move beyond their control, to overflow the striating networks of circulation they have constructed. Deleuze and Guattari explain that while capitalism has taken striation to "an unequaled point of perfection, circulating capital necessarily recreated, reconstituted, a sort of smooth space in which the destiny of human beings is recast" (492). This becomes readily apparent in the age of global capitalism, for as they suggest, "Striation ... relates primarily to the state pole of capitalism, in other words, to the role of the modern State apparatuses in the organization of capital" (492), the very apparatuses the Atonists in Mumbo Jumbo manipulate. However, once capitalism expands to a global level, "a new smooth space is produced in which capital reaches its 'absolute' speed ... The multinationals fabricate a kind of deterritorialized smooth space in which points of occupation as well as poles of exchange become quite independent of the classical paths to striation" (492). While these comments may not seem applicable to Mumbo Jumbo, in that Mellon's plan to control circulation takes place in the 1920s, prior to the age of "global capitalism," we should remember that Reed writes from a postmodern perspective, in the midst of the phase of multinational capitalism, which, in keeping with his view of history, he projects back onto the state capitalism during the interwar years. Reed depicts the Atonist capitalists of the 1920 s as having already tapped into global networks. Furthermore, Jes Grew is threatening to go "pandemic"; that is, its speed and logic threaten to alter flows world wide.

Ironically, by conspiring outside the state pole, or in manipulating state apparatuses from outside the state, the private capitalism of Mellon and his cohorts, as Deleuze and Guattari would suggest, has opened the way for the striated space of state capitalism to be recast. But as Mellon recognizes, if the circulation of capital is restricted, drawn back within the domain of the striating State apparatuses, Jes Grew cannot be supported. The growing global networks of circulation that Jes Grew 
would travel, appropriate, and alter will be striated to the point of restricting its flow entirely.

Circulation will be shut down.

In addition to the space of the city and the space of global capitalism, Mumbo Jumbo also suggests that the body, in particular the racialized body, can be viewed as a surface subject to Atonist mapping, for under the Atonist regime the body itself is striated, racially classified and categorized. The Atonist notion of constructing a Talking Android that can imitate blackness is, obviously, predicated on the notion that blackness is itself a definable, categorizable essence. This sentiment underlies H.V.V.'s suggestion to Major Young that presumably all black artists think and write alike because they belong to the same racial category, a category constructed by the Atonists. Again, though, Young counters Von Vampton by suggesting, "We all have our unique styles" (102). In his reading of this passage, McGee suggests that Von Vampton's assumptions, and those of others like him, “can be dangerous insofar as they identify African-American writing with a homogeneous concept of ethnicity" (100). McGee argues, "A 'unique' style breaks away from such a norm" (100). Furthermore, a "unique style" potentially "subverts the ends, or instrumental functions, of race in late capitalist culture by disrupting the process of racial identification through the articulation of the incommensurable" (100). In other words, while Atonist cultural logic striates racial and ethnic categories, the unique, or that which does not fit already fixed categories disrupts the striating assumptions that subtend racial categories because it exceeds such limits; it moves as if within a smooth space. Ironically, Gould's "passing” as black itself questions the very racial categories the Atonists wish to secure by suggesting the possibility of racial nomadism that defies strict striation.

We should not, of course, take Reed's invocation of the metaphysical as solely a metaphor for 
what occurs in the material world (though the supernatural in the Voodoo tradition is always pertinent to the material). As Reed himself makes clear, "When I say I use the Voodoo aesthetic I'm not just kidding around" (Shrovetide 233). My point is that Reed is quite serious about his use of Voodoo, as we see in Mumbo Jumbo's repeated invocation of the loas and the most unknowable of spaces, that of the "other world." The unknowability of this other world is precisely what makes it so appealing to Reed's project, for by invoking the supernatural he draws it into this world, or into the striated vision of this world, causing the two planes to collide and, quite possibly, to explode one another. Mumbo Jumbo leaves us in a state of suspense at the end, or at the crossroads, for a reason, for the crossroads is where the opposites meet—black and white, East and West, science and mystery, smooth and striated—and potentially create new "combinations." While the classic detective seeks the certain path, the one right way, LaBas the Neo-Hoodoo detective is learning to live in a spatial amalgamation on the borderline, for it is only in this space that Reed's vision of multiculturalism can be realized and difference embraced (rather than repressed or dismissed as "pathological"). Atonism is not, then, defeated by the instantiation of a different "right way," but rather by the obliteration of the either/or, that is by the rupture of planes that occurs at the crossroads where the smooth and striated interact, compete, and potentially explode. 


\section{NOTES}

1. For a more in-depth discussion of loas see Maya Deren's Divine Horseman-a source Reed includes in Mumbo Jumbo's bibliography—or Zora Neale Hurston's Tell My Horse, to which Reed has contributed an introduction.

2. Mumbo Jumbo is not the only example of a metaphysical detective novel that introduces the world of the supernatural into the human or material world of the detective. In Peter Ackroyd's Hawksmoor, an eighteenth- century architect, Nicholas Dyer, taps into occult or other-worldly powers by presenting a human sacrifice at each of seven churches he has been commissioned to build. These powers allow him to transcend time and space, evidently catapulting himself, or some version of himself, into the twentieth century, where he lives as a tramp and a murderer, killing at the very churches he designed. Hawksmoor, a conventional detective facing a highly unconventional case, not only cannot locate Dyer, the tramp-murderer, at the end of the novel, through supernatural causes, Dyer and Hawksmoor collapse into one another, as if Dyer has become Hawksmoor and vice versa. In John Fowles $A$ Maggot we are presented with the mysterious disappearance of an $18^{\text {th }}$-century nobleman, who, depending on which account we believe, either has been abducted by the devil during an occult ritual or has been transported off this planet in an alien craft.

3. In Uncle Tom's Cabin, Topsy's mistress, Miss Ophelia, questions her about her father and mother — Topsy claims she never had any — and then about her belief in God: "Do you know who made you?" "Nobody as I knows on," Topsy answers. "I spect I grow'd. Don't think nobody never made me" (210). Later, in the many theatrical versions of Uncle Tom's Cabin "I grow'd" became "I jes grew," and ultimately became proverbial: "Like Topsy, it jes grew," meaning something happened spontaneously, without planning.

4. The Villa Lewaro is actually modeled on a real Harlem-Renaissance-era country house, Madame C.J. Walker's (the cosmetic queen) place at Irvington-on-Hudson.

5. There is a parallel motif in Umberto Eco's The Name of the Rose in which the monk detective, William of Baskerville, resists using "irrational" means to solve the crime, only later to discover that his efforts to discover a "pattern that ... underlie all the crimes" has caused him to miss the "accidental" or irrational nature of the crimes he seeks to solve (599).

6. Fox takes the notion of "rupture of plane" from Mircea Eliade who suggests that it allows for the "rediscovery of the primordial spontaneity" (271-72).

7. Reed's attention to the crossroads reminds us both of the "in-between" spaces in DeLillo and McElroy as well as of the fact that in Pynchon's Gravity's Rainbow Slothrop actually becomes himself a crossroads; or the ruptured plane itself. 


\section{CHAPTER 6}

\section{Cinema and the Crime of Social (Spatial) Reality}

To conclude my discussion of metaphysical detection and space, I wish to steer a somewhat different course and address two recent films, Alex Proyas' Dark City and Josef Rusnak's The Thirteenth Floor (based on Daniel F. Galouye's Simulacron 3), both of which might be thought of as variations on the metaphysical detective story. While the two films differ from one another in some respects, they display a number of interesting parallels. Both begin with a mysterious murder for which the protagonist, who in both plots is transformed into an amateur detective, is the primary suspect. As detective/mystery films, the two films borrow heavily from the tradition of film noir - the city is an almost entirely dark space in both films. Furthermore, both films include elements of science fiction. In Dark City the detective's search leads to a confrontation with an underground group of aliens inhabiting human "vessels" who it turns out are not only running the city but are its creators. And in The Thirteenth Floor the detective's investigation draws him into cyberspace. As with the novels we have discussed, then, the search for the answer to a murder mystery ultimately extends to an exploration into the nature of the spaces that the various characters inhabit or experience, which in these films means an inquiry into the constitution of futuristic, technologically produced spaces or computer simulated spaces.

While I claim that both of these films can be thought of as metaphysical detective stories, I am not suggesting that either disrupts the logic of the detective and its "rational" underpinnings in quite the same way as the novels of writers such as Auster or Pynchon. Rather, Dark City and The Thirteenth Floor are in effect popularized versions of the more radical metaphysical detective fictions I have dealt with in preceding chapters. As one might expect, both films conclude with fairly stock Hollywood endings: the mystery is solved, the good guy wins out over the forces of evil and, of course, gets the girl. 
However, despite their attempts to tidy things up at the end, both films along the way offer considerable challenges to the detective's ability to explain away the mystery through science or reason. As I discussed in the introduction, the force of metaphysical detective story does not lie simply in its refusal to solve a crime that emerges within its pages; rather, its impact is felt in its suggestion that the real crime is "contingent existence" (Spanos 167), leaving the metaphysical detective as well as the reader (us) to grapple with a variety of existential questions that surround the mysteries of an ultimately unknowable universe. I include Dark City and The Thirteenth Floor as variations on the metaphysical detective story precisely because they too implicate "contingent existence" as the culprit—in both plots the solving of "murders" becomes of little consequence in the face of broader epistemological and ontological concerns. More interestingly, for my purposes, in both films the detective's discovery of the nature of his "contingent existence" manifests itself clearly through his discovery of his contingent spatial existence; the moment of "truth" so to speak for these two detectives arrives when they become aware that the space they imagined themselves to inhabit is not at all what they had presumed it to be. In both cases questions regarding the nature of "reality" center on explorations into the nature of social space—which, as is the sci-fi tradition, has been radically impacted, or even constructed by "technological progress." Dark City and The Thirteenth Floor are of interest, then, because their detective narratives suggest a link between the production of social space and the construction of our lived "reality" while revealing, more specifically, the role of "advanced technologies" in the representation and production of social space under late capitalism. ${ }^{1}$ 


\section{The City at Night}

In the opening scene of Dark City John Murdoch (Rufus Sewell) awakens in a strange hotel room to discover the lifeless body of a murdered prostitute; uncannily, he has no memory either of who she is or how he came to be in this place. Suffering from complete amnesia, Murdoch cannot even recall his own name, which he "knows" only from the identification cards in his wallet, and while his wallet includes a picture of his "wife" Emma (Jennifer Connelly), Murdoch does not even recognize her. Uncertain of his identity and his involvement in the prostitute's demise, Murdoch, therefore, turns amateur sleuth roaming a metropolis that is literally always dark, and truly creepy, in an attempt to discover if he is indeed the murderer. Or as another character, the psychiatrist Dr. Schreber (Keifer Sutherland), suggests, Murdoch begins "searching for himself." Also searching for the murderer is a professional police detective, Inspector Daniel Bumstead (William Hurt) — a classic detective figure "consumed by details" - from whom we learn that the city has experienced a series of call girl murders, for which John Murdoch is now the primary suspect. But this is no ordinary case, nor is the city in which these two detectives search an ordinary urban space. As Dr. Schreber informs us during the opening credits, the city is actually controlled by a group of aliens known as "The Strangers" (which we might view as physical manifestations, or allegorical figures for the generally unnameable forces explored in metaphysical detective fiction and its dramatization of the "global paranoia" Jameson associates with late capitalism) who possess the "ultimate technology"; they can "alter physical reality by will alone." We later learn that these aliens are facing extinction, for some unspecified reason, and have come to believe that the human mind or consciousness holds the key to their future survival. Taking human bodies as their vessels will not suffice; The Strangers "must learn what it means to be 
human."

To this end, with the help of Dr. Schreber, The Strangers conduct experiments with the city's population by "imprinting" each individual with a template of new memories. Using what The Strangers call "Tuning," every "night" at 12:00 they cause the humans to "sleep," at which time The Strangers alter the city — buildings and other structures literally change shape — while Schreber injects specific subjects with a new set of memories. When the humans wake, they do not notice the changes nor do they seem to have any memory of the past beyond the memories with which they have been imprinted. In one of the most striking scenes, for example, we watch as The Strangers transform a working-class couple into a wealthy, upperclass one and their tenement building into a mansion.

As with any valid experiment, The Strangers' inquiry into the nature of humanity requires a controlled environment, and, unbeknownst to the humans, their city is just that. As Murdoch ultimately discovers, there is no outside to the metropolis. Rather, the city is a technologically produced "planet" unto itself, afloat in outer space. As one of The Strangers explains, "The city is ours. We made it ... Each night we revise it. Refine it." During one of these revisions, Murdoch was to be given the memories of a serial killer-The Strangers being the actual killers — but Murdoch inexplicably resisted imprinting. According to Schreber, in the hotel room Murdoch somehow woke up too soon, before his new memories were fully formed, and as a result became immune to The Strangers' command to sleep. But what makes Murdoch of such interest to The Strangers is that he has himself acquired the ability to "tune" - again this seems somehow connected to waking too soon-which leads them to believe that if they gain access to Murdoch's mind or "soul" they might ensure their own survival. Thus, while Murdoch searches for clues to both the murder mystery as well as his identity, The Strangers search for 
Murdoch, as does Detective Bumstead, who continues believing he is investigating a routine murder for which a single human is responsible. Bumstead has actually taken over the case from a Detective Walenski who has apparently been driven insane by his involvement in the investigation. As it turns out, however, Walenski has, in fact, discovered the truth concerning The Strangers and their city, from which he recognizes there is "no way out." Walenski, consequently, explains to Bumstead, "There is no case. There never was." It's all a ruse, or at least the killer cannot be found among the human population. As a result, much as in the works of Auster, the initial "case" soon fades into the background as the investigation turns instead to questions involving the nature of identity and reality. Eventually, even Bumstead, who holds that there must be an "explanation" for the city's oddities, is forced to confront the "truth." In what is the beginning of the end so to speak, Bumstead and Murdoch, or the two detectives, together break through the walls of the city to find themselves standing on the edge of space. Notably, while Murdoch literally retains his grip on the world, Bumstead, the classic detective, falls off the edge of the city and is sucked out into space, as if to suggest that the classic detective and his reliance on "facts" can no longer survive in such an environment; rational explanations simply do not hold here. If there is such a thing as a resolution in this world, it will have to come from a new breed of superhuman detective, i.e., Murdoch.

Still, as I mentioned above, despite its questioning of "reality," Dark City does not end with the horrifying discovery that, as Walenski puts it, these humans are "just dreaming this life." Rather, the film climaxes in what can only be described as a tuning showdown between Murdoch and The Strangers, which of course Murdoch wins (though he requires help from Schreber who imprints Murdoch with inside knowledge of The Strangers and the machinery they use to control the city.) And after defeating 
The Strangers? In a gesture of pure platonic idealism, Murdoch simply "imagines a new world," that is, he tunes into being a world of light that extends outward from the dreary urban center.

\section{The Future is Now}

While it is obvious enough that Dark City has much to say about spatial production and spatial practices, as with most science-fiction we might tend to discount this film as unrelated to our own present (spatial) condition in that the film imagines an alien, or futuristic space that may not appear to reflect the social space we presently produce and experience. It is Jameson's contention, however, that science fiction does not simply provide a "representation of the future (although its various forms use such representations)." Rather, science fiction allows the reader/viewer to perceive "the present as history: that is, as a relationship to the present which somehow defamiliarizes it and allows us that distance from immediacy which is at length characterized as a historical perspective" (284). ${ }^{2}$ The inclusion of the detective figure in these films serves as a reminder of this point in that we recognize the detective, in his conventional forms, as belonging to our world and our time. The question Jameson's point raises, then, is what exactly does Dark City — and the same will be asked of The Thirteenth Floor-have to say to us about our present cultural moment? Or more to the point, in what way does this film portray the production of social space under late capitalism?

One way to answer this question is to argue that, at least prior to uncovering the city's secret, Murdoch's physical and psychological disorientation within the city as well as the structure of the city itself reflect the "mutations in space" that Jameson contends have resulted in "postmodern hyperspace," a space that has "finally succeeded in transcending the capacities of the individual human body to locate itself, to organize its immediate surroundings perceptually, and cognitively to map its position in a 
mappable external world" (44). Much like the subject caught within the "great global multinational and decentered communicational network" (44) that characterizes late capitalism, neither Murdoch nor his fellow urbanites can map the city nor their position within the city—all experience continual reterritorialization - and while they imagine an outside, or extra-urban position, they cannot seemingly locate such a place, at least not without the equivalent of supernatural intervention. In this respect, we might view Dark City as a surrealistic allegory of the postmodern urban space in which the subject struggles to locate either himself or his position within an overwhelming techno-capitalist network. ${ }^{3}$ In Dark City this sense of being lost within the techno-spatial rhizome is further complicated by the collective amnesia of the city's inhabitants, who remain unaware of their predicament; experiencing a truly "false consciousness," they continue to act as if there is an outside to the city, as if they are not at all entangled within the ongoing technological modifications made by The Strangers. This loss of memory is maintained in part through The Strangers' construction of the city which they have "fashioned . . on stolen memories. Different eras. Different pasts all rolled into one." The city combines a 1940's cultural backdrop with futuristic elements and objects, as well as objects from the more distant past: syringes that appear Victorian, an art-deco clock, and an underground world that combines the medieval with sci-fi. The overall effect of this eclectic mix of objects and images is not only dizzying but also forestalls any temporal, and consequently spatial, point of reference.

Of course, The Strangers' fashioning of a city out of a hodgepodge of past forms is not really the stuff of science fiction; rather, such appropriation and incorporation has become the model for the postmodern city which is characterized by postmodern architecture's penchant for "citing" or combining forms identified with different historical periods in a single object. In this way, the postmodern city has 
created "a 'palimpsest' of past forms superimposed upon each other, and a 'collage' of current uses, many of which may be ephemeral" (Harvey 66). As Jameson observes, this interweaving of historical forms not only acts as "a symbol and analogon" of the subject's inability to navigate "the great global multinational and decentered communicational network in which we find ourselves caught as individual subjects" (44), but also aggravates the subject's disorientation, which he suggests results in part from a loss of historicity, or a loss of the historical referent, which has been replaced by "simulacra of that history, which itself remains forever out of reach" (25). That is to say, in the "collage city," in place of the "historical referent," we are confronted only by copies, citations that offer us a "series of pure and unrelated presents in time" that now make up the city (Jameson 27). Dark City offers, then, a heightened form of the late-twentieth-century urban condition. And while the subjects in the film literally have no memory of a "real" past, or only a fabricated memory, Jameson's remarks suggest that something similar may be said of the postmodern subject, who also experiences history as simulacra, as a copy for which the original has gone missing.

The significance of the city's present role as locus of this loss of memory within the postmodern city becomes more apparent once we recognize that the city itself has long acted as a memorial to social and political history. As Anthony Vidler explains, "the traditional city, antique, medieval, or Renaissance" provided an "image of the city that enabled the citizen to identify with its past and present as a political, cultural, and social entity; it was neither the 'reality' of the city nor the purely imaginary 'utopia' but rather the complex mental map of significance by which the city might be recognized as 'home' as something not foreign, and as constituting a (more or less) moral and protected environment for actual daily life." (177) The city acted, then, as a "memory map" or monument to the social 
structure, which in turn provided a certain level of comfort to those who would call it home. Modernist planners, however, attempted to "forget the old city, its old monuments, its traditional significance, which were all seen as being too implicated with the economic, social, political, and medical problems of the old world to justify retention" (Vidler 179). This does not mean that the modernist city no longer offered a "memory map," but rather that it attempted to negate the memory of the old city and replace it with a new vision grounded in its present moment. Thus, according to Vidler, the "old city, doubly negated, presents itself to the postmodernist as a haunting absence, not a haunting presence" (183). That is to say, the repressed has returned in the collage city of postmodernism but what appears to be a "presence is neither the absence of the modern nor the presence of the past," but is rather a "third negation" (183). While the city once again provides images from throughout the history of the city and its social underpinnings, those images no longer construct a cohesive narrative that would enable the citizen to identify with the city's past and present as a political, cultural, and social entity. Rather, as in Dark City the postmodern city presents us with what Jameson calls "heaps of fragments" that simultaneously call us to construct out of them a cohesive "home" and also resist such a construction in that the historical referent is only a haunting absence, a simulacrum that remains just out of reach. Or in the case of the city The Strangers have produced, while their city incorporates all of the objects through which one might map the culture's memory, these objects have been removed from their context, literally taken to another world, so as to turn them into something more akin to an unsettling puzzle than a reassuring map. This is, of course, the very unsettling discovery that we have come to equate with the postmodern or metaphysical detective, who as a figure linked to the rationalized city of the past would seem to invite us to re-map a secure urban environment, to recreate our memory of the urban "home" 
so to speak, yet as it turns out, actually dramatizes the unraveling of our ability to "identify" with the city or perceive it as a source of security.

\section{They Know not what they Do}

While Dark City reflects certain aspects of postmodern hyperspace as well as its effect on the subject, its commentary —as is the case with all metaphysical detective stories—reaches back even beyond our present in that it also provides an urban history lesson of sorts that connects the state of the postmodern city to the dreams of its predecessors, modernist or even Enlightenment thinkers. Although I have noted ways in which The Strangers' urban creation reflects a postmodern aesthetic, they themselves are actually more representative of a modernist vision or a modernist desire to control space and unify power around the logic of the city. By turning the city into a literal machine, that runs on clockwork no less, and sealing that machine/space off from the rest of the universe, The Strangers create a clearly alien and alienating world - a place no viewer would ever want to experience. Yet, modernist urban designers envisioned just such a city; in their "machine architecture" they themselves imagined and represented buildings as symbols of technological modernity or cogs in a rationally designed urban machine, whose logic was to penetrate and govern all space. As Lefebvre explains, however, the call for urban logic "to be total" comes with a cost in that to preserve the modernist fantasy, urban rationality must either absorb or expel that which appears to operate according to a different logic, mandating an element of violence that he suggests is "inherent in space itself" (332), or is inherent to the production of space. But while the production of space necessitates violence, that "violence is cloaked in rationality and a rationality of unification is used to justify violence" (282). That is to say, the very spatial logic — a rationally organized space — that produces violence also hides or 
justifies that violence. Interestingly enough, this uncanny mixture of violence and rationality is represented in the person of the hard-boiled detective, who in many respects is the quintessential subject of the modernist city. While the classic detective acts as a symbol of pure rationality, the antithesis of or antidote to violence - he comes in contact with violence, but only to eradicate it from an otherwise ordered environment— the hard-boiled detective (Philip Marlowe, Sam Spade, Mike Hammer), while still attempting to achieve a rational conclusion to his respective case, regularly and unapologetically employs violence; the rational conclusion, in fact, justifies the violence he employs just as the violence inherent to the production of space is justified by the representation of a rationally ordered space. One might argue that our fascination with as well as our dis-ease with the hard-boiled figure can be explained by his ability to unmask for us the very violence that is inherent to the production of the modernist city. In similar fashion, Murdoch's investigation uncovers the violence hidden beneath the "rationality" that unifies and justifies a city that is the only spatial logic its subjects know. But in the case of Dark City, this violence manifests itself more overtly in the production of the city space itself, which is repeatedly, violently re-fashioned. While the city's inhabitants are oblivious to the inner workings of the city's power structure, they are daily, or rather nightly, subjected to extreme forms of colonization that invade even the deepest recesses of their minds in order to absorb these subjects into a totalizing urban design.

Of course, while The Strangers may control space, the city they have built is not exactly that which the modernists imagined. Under modernism, the logic of the city was to become total in large part because of its equation with progressive or enhanced forms of production, hence the envisioning of the city as a machine. The city in the film, on the other hand, is a clearly dystopic zone that could hardly 
be equated with production. As we know, however, this has been exactly the fate of numerous thisworld cities that, in the wake of modernism, have had to deal with unsightly post-industrial wastelands. Why have dreams of endless production turned to dystopic nightmare? Precisely because of the drive toward more efficient or accelerated production, which leads to overaccumulation, which brings circulation to a standstill. ${ }^{4}$ The Strangers' city, bearing all the earmarks of this problem, is inundated with the signs of accelerated production — both in the form of commodities and the call to consume those commodities, i.e., advertisements; nothing, and no one, is going anywhere, but all have rather become locked inside stagnant networks that continue circulation for the sake of circulation. Bumstead's investigation itself, which according to the tenets of classic detection ought to be going somewhere, ought to result in an end product, reflects this stagnation of production. While he goes through the motions, circulating among the city population asking all the right questions, The Strangers' plan has him merely traveling in circles, investigating a case that in effect does not exist and, therefore, has no rational conclusion. He epitomizes the aftermath of a rationalized city that once imagined it was getting somewhere, yet now must face the nightmarish possibility of being "nowhere." In short, there is no production here, only reproduction; The Strangers have not in fact produced anything new, but rather have simulated and recombined that which they gathered elsewhere.

As Harvey points out, once such techno-economic problems cast their shadow over the city, urban space requires a spatial fix, which, ironically, generally calls for a search beyond the very spatial logic, that of the city, which still aspires to be total. This is one of the contradictions inherent in the totalizing impulse of the city—which under late capitalism is now imagined as a multinational entity — namely, that it can never in fact be total, because of both the potential for overaccumulation as 
well as the need for an "other" space or "extra-urban" space relative to which the rationalized city establishes its psycho-social dominance. As Dark City reveals, even when there is no outside, there is an outside. The success of a totalizing urban logic and its alignment with production actually depends on the idea of an outside; this is a point not lost on The Strangers, who are careful to build into the city the signs of an exterior space. The representative of a peripheral or qualitatively other space in this instance takes the form of Shell Beach, a sunny resort town that haunts the urban darkness, producing a nostalgia for a space that has ostensibly been lost. In fact, one of the crucial clues that leads Murdoch to a discovery of his supposed "identity," or rather his imprinted identity, is a postcard he finds among his effects which shows a picture of Shell Beach, the place where Murdoch supposedly spent his childhood. Later, he encounters a billboard advertising this Shell Beach, complete with an eroticized woman waving as if to beckon all to come visit this sunny utopia. When Murdoch attempts to locate this place, however, he finds that no one in the city actually knows how to get there. Even a cab driver who claims to have spent his honeymoon at Shell Beach, and carries a souvenir from his trip on his dashboard, finds while trying to give Murdoch directions that he cannot in fact remember the way. And while the subway map indicates that it has a stop in Shell Beach, Murdoch cannot board the right train because, of course, Shell Beach does not exist, at least not in this world. As Murdoch eventually discovers, there is no outside to the city, at least not an outside occupying the same planetary space. The subway merely goes in circles, never venturing outside the urban walls. Thus, Murdoch's clue leads him to a destination that is no destination at all; signs lead to only other signs, leaving him another metaphysical detective wandering an indecipherable city with no end to the case in sight. ${ }^{5}$

Yet, despite the fact that Shell Beach is purely a fiction, the city's inhabitants, with the exception 
of Walenski, assume that Shell Beach does exist and conduct their lives accordingly. Their lives are in fact built around the illusion that such a place is out there awaiting them. In this respect, they exhibit what ði@̀k terms the "ideological fantasy." According to ठi@̀k, "The fundamental level of ideology . . . is not an illusion masking the real state of things but that of an (unconscious) fantasy structuring our social reality itself" (33), the same "social reality" that the detective serves to protect. đi@̀k argues that what subjects "overlook, what they misrecognize, is not the reality, but the illusion that is structuring their reality, their real social activity. They know very well how things really are, but still they are doing it as if they did not know. The illusion is, therefore, double: it consists in overlooking the illusion which is structuring our real, effective relationship to reality. And this overlooked unconscious illusion is what may be called the ideological fantasy" (33). While the cab driver cannot give directions to Shell Beach, meaning he recognizes at least for the moment the reality of his inability to reach such a place, he continues to act as if the illusion, Shell Beach, were a reality, even fastening a souvenir, or reminder to his dash board. Or to give another example, when Murdoch asks Bumstead if he can remember the last time it was day, Bumstead answers that in fact he cannot, as if he recognized this reality all along; yet Bumstead insists that there "has to be an explanation," meaning he continues to act as if day exists even though he "knows very well" that it does not.

The crucial point here is that this not knowing does not simply act as a smokescreen for the "real" but is rather formative in the production of social reality, "which is possible only on condition that the individuals partaking in it are not aware of its proper logic" (21). That is to say, the success of The Strangers' experimental social reality is predicated on the lack of awareness on the part of its subjects, who must continue to overlook the illusion regardless of the reality it structures. As đi@̀k insists, social 
reality's “very ontological consistency implies a certain non-knowledge of its participants-if we come to 'know too much', to pierce the true functioning of social reality, this reality would dissolve itself” (21). This might explain Walenski's “insanity," for in uncovering the "truth" regarding his memories and the structure of the city, Walenski does not so much locate "reality" as he dissolves it. Unable to locate a hard and fast "real" beneath the false consciousness to which he and the others have been subjected, Walenski is left to conclude that he must be "just dreaming this life." The horror Walenski, and later Murdoch, unearths is that there is no "real Walenski" beneath the ideological illusion. His very identity is a simulacrum; the original is nowhere to be found. Or as đi@̀k puts it, 'Ideological' is not the 'false consciousness' of a (social) being but this being itself in so far as it is supported by 'false consciousness"” (21). But once this "false consciousness" is exposed or known, the "social being" dissolves, which might explain why Walenski chooses to throw himself in front of a train rather than continue as a non-reality. Walenski's fate points to a crucial difference between classic detective fiction and its postmodern, metaphysical counterpart. In the former, the detective continues to act as if there is a rational solution even in the face of a mystery, e.g., the locked room, which seems to indicate just the opposite; that is to say, the classic detective acts — as does the reader-as if the case can be solved until this "fantasy" becomes a social reality, which in classic detective fiction it inevitably does. In believing that the inexplicable will be explained, Bumstead, then, merely stays in character so to speak. In the metaphysical detective story, on the other hand, the detective, despite any initial belief in rationality, finds himself, like Walenski and eventually Bumstead, confronting the possibility that there is no "solution," nor "real" that exists outside the ideological fantasy. The metaphysical detective does not so much discover the "real" beneath the false illusion, 
beneath the misleading mysterious clues, as he-Quinn, Slothrop, Axton—discovers that the fiction is his reality, which when exposed as such dissolves before his eyes. (This would certainly explain why Quinn appears to enter a new work of fiction at the end of City of Glass; we might think of his reinvention as the postmodern alternative to killing oneself.)

The particular relevance of Dark City on this point is not only that it dramatizes the inner workings of the "ideological fantasy," but more importantly that it highlights the role that space or the production of space plays within the ideological. In a more traditional notion of ideology, space might be equated with the "concrete reality" or "real state of things" that lies beneath the miasma that blocks our ability to see reality for what it is - this view would present space as essentially stagnant and equate it with pre-socialized nature or pure use value. The problem with this view is not only that such a space does not exist, being rather a representation of space, but also, as Shell Beach exemplifies, that social space can be very much part of the "social reality itself" while ultimately not existing at all. Furthermore, while Murdoch strips away the facade, uncovering a "spatial reality" beneath the false consciousness, this "spatial reality" is in fact a copy of some other reality—where presumably Murdoch's "real place" and "real identity" exist - that remains forever out of reach. What Murdoch finds beneath the surface is not the "concrete reality" he desires, which as with a space of "pure nature" is always already irretrievably missing or covered over, but rather an ever-changing reproduction of some other space. Using Ji@̀k's notion of the "ideological fantasy," we might alternatively view space as part of the "social reality itself" which is structured by the "(unconscious) fantasy." As we have seen, while not a "real" place, Shell Beach is very much a part of the city's lived experience, or social reality. At the same time, however, space can also be thought of as a structuring element within the "fantasy" that in 
turn structures that social reality, meaning that social space then is split, at one and the same time part of the "social reality itself" structured by the "(unconscious) fantasy" and a structuring element of that "fantasy." While on one hand "social reality itself' is in part a spatial reality, which is structured by the ideological fantasy, on the other hand, as Lefebvre suggests, the "abstract space" of late capitalism is also "the locus and medium of the generation (or production) of false consciousness" (310). Shell Beach, then, provides the medium for the production of the fantasy that structures the reality of the urban experience; it is the form taken by the dream of an extra-urban space (a dream that is shattered at the moment Murdoch breaks through the wall to find rather than a sunny utopia, only more darkness). More generally, Lefebvre's remarks would explain why space has played such a crucial role in detective fiction, for in order to sustain the ideological fantasy, one must also maintain the production of a rationalized space, that is, one must unlock the mysteriously locked room.

\section{The End of Enlightenment}

As I mentioned, Dark City is not content to leave its viewers to grapple with ontological or epistemological uncertainties for long, nor with the horrors of dissolving social reality that we experience when Murdoch knocks down the walls of the city, opening the way for Detective Bumstead, our last hope for a rational explanation, to fall off the face of the "planet." Rather, the film provides a means through which Murdoch can accomplish the impossible, so to speak, can reach a space, Shell Beach, that never was, and in so doing seemingly offers the kind of resolution that the metaphysical detective story eviscerates. Having defeated The Strangers and claimed the city, Murdoch, using his superhuman powers, simply "imagines a new world" of sun, sea, and sand extending out from the city walls. In the final scene, Murdoch stands squinting in this sunlight next to his "wife" — who no longer remembers him 
because she has undergone recent imprinting — gazing at the Shell Beach resort town which now lies at a distance. But despite the film's suggestion that the solution, at least the spatial solution, is at hand, this Hollywood resolution is in fact no resolution at all, but rather merely returns us to the Enlightenmentbased desire to master space through the "logic of visualization." To return to de Certeau, we are back atop the World Trade Center occupying the imagined space of the perspectiveless eye (I), or the private eye (I). That is to say, Murdoch does not so much locate a new position of knowledge of or power over space as he returns to the dream of a distantiated position outside/above from which is constructed an imagined transparency; here, space is literally brought from the darkness into the light. As with de Certeau's observer atop the World Trade Center, Murdoch's final position imagines total knowledge and control. As de Certeau argues, however, such a viewpoint provides only "the fiction of knowledge" (92), for the "whole" of social space remains unreadable and unknowable. Furthermore, it is no coincidence that Murdoch employs the same power, or technology that The Strangers use to repress and control through spatial production, for he is not enacting a solution but rather reenacting an old perception of space and spatial production that has been instrumental only in producing more repression and violence. This sunny ending offers an old, modernist dream in a new, sci-fi form.

One might argue on the other hand that Murdoch does not merely return us to the Enlightenment or Cartesian subject, the classic detective, but rather has become some kind of cyborg subject who, to use Jameson's terms, has mastered postmodern hyperspace by growing "new organs" and expanding his "sensorium" and "body to some new, yet unimaginable, perhaps ultimately impossible, dimensions" (39). If so, then we might argue that Murdoch embodies Jameson's soughtafter position from which one can perform cognitive mapping. This would also mean that Murdoch, 
now a super-detective, has attained some kind of "real knowledge," rather than the "fiction of knowledge" of which de Certeau speaks. In a subtle, or unconscious move, the film, however, indicates that Murdoch's knowledge of and power over space may not be as complete as it would appear on the surface. Tellingly, Murdoch never does actually get to Shell Beach. At the end of the film, he is actually standing on a pier that leads from the city to nothing, still imagining the resort from afar. Yes, Shell Beach now "exists," that is, there now exists a geographical or material space to support the fantasy that the city's inhabitants have already collectively believed; however, Murdoch remains at a distance, and while he and his "wife" act as if they are on their way to Shell Beach, it is not quite clear how they are to get there, short of flying. From what the viewer can tell, they would have to reenter the city and exit at some other, unidentified point. In the end Murdoch both reaches the space of his dreams, standing in the sunshine outside the darkened city, and yet that space continues to remain just beyond his reach.

It would seem, then, that even the "ultimate technology" does not provide a true "spatial fix"; the spatial contradictions remain. We should keep in mind, though, that "contradiction" is actually "contained in its [capitalism's] very concept" (ði⿳亠㐅. 52). đi@̀k explains, "The "normal' state of capitalism is the permanent revolutionizing of its own conditions of existence: from the very beginning capitalism 'putrifies', it is branded by a crippling contradiction, discord, by an immanent want of balance: this is exactly why it changes, develops incessantly — incessant development is the only way for it to resolve again and again, ... its own fundamental constitutive imbalance, "contradiction"” (52). Technology aids the growth of capitalism, then, not by resolving its internal contradictions once and for all, but rather by offering a means through which capitalism can repeatedly respond to its "constitutive 
imbalance," spatial and otherwise, can demonstrate, often in dramatic fashion, efforts toward resolution without ever realizing that resolution in full. Like all technology, the "ultimate technology" is merely another in a long line of necessarily temporary resolutions - a list to which classic detective fiction itself belongs - to an ongoing socio-spatial dilemma.

\section{The Thirteenth Floor}

Rusnak's The Thirteenth Floor has much in common with Dark City both visually and in terms of content. As I mentioned, it too incorporates science-fiction and detective motifs, and it also begins with a mysterious murder for which the protagonist, Douglas Hall (Craig Beirko) is the primary suspect, causing Hall to turn amateur detective. Interestingly enough, as with Murdoch, doubts surrounding Hall's innocence stem directly from a loss of memory, though in this case the amnesia is only temporary. Furthermore, like Dark City, The Thirteenth Floor promises to make us "question reality." In this case, however, the epistemological and ontological uncertainties do not result from the presence of alien life forms but rather from the introduction of computer generated virtual realities.

Unquestionably, cyberspace has come to play a significant, if not leading role in how we imagine and produce space at the onset of the twenty-first century. Much of the rhetoric surrounding the development of cyberspace has in fact suggested that in virtual reality we have discovered a new space that transcends the problems of "this-world space." Scholars speaking from a variety of backgrounds and vantage points have promoted cyberspace as the ultimate "spatial fix" to a variety of problems, suggesting that cyberspace operates outside the constraints of our repressive modernist past or, as preposterous as it may now seem, even outside the realm of multinational capitalism. (This latter notion became much harder to believe once web sites began to look like billboards.) The portrayal of 
cyberspace that The Thirteenth Floor offers, however, indicates that virtual reality does not so much break with a former regime as it allows that regime to survive and flourish as never before. David Brande, in his reading of William Gibson's Neuromancer (which I am much indebted to here), goes so far as to suggest that cyberspace "is a dream of late-capitalist ideology," meaning it has come to “constitute, in đi@̀k’s terms, an ideological fantasy of crucial importance to advanced capitalism” (81). My intention in analyzing The Thirteenth Floor is to show not only that cyberspace does indeed stage an "ideological fantasy" through which techno-capitalism retains or even increases its power, but also that this "ideological fantasy" is not grounded upon a fundamentally new space or even a new perception of space. As Robert Markley contends, cyberspace is the product of "repackaged philosophies of space, subjectivity, and culture" (56). ${ }^{6}$ As we will see, cyberspace is not so much a break from as it is an extension of the Enlightenment/Modernist dream - the same ideological dream that produced the detective figure — of a world that could be both known (solved) and controlled.

\section{A Cyber-Mystery}

As The Thirteenth Floor opens a wealthy looking gentleman named Hannon Fuller (Armin Mueller-Stahl) finishes off an evening at the Wilshire Grande Hotel in 1937 Los Angeles, or what appears to be 1937 Los Angeles, by handing a letter to the bartender with the instructions that it be given to Douglas Hall. The catch is that Hall is in 1999 Los Angeles, where Fuller is a computer visionary who has designed a computer generated replica of the city of his youth that he now visits via a simulator. On this night, after exiting the system, Fuller telephones Hall, his right-hand man, saying only that he has "stumbled on to something incredible that changes everything." But before Fuller can explain, a mystery person seduces him into the alley where Fuller is later found murdered. When Hall 
awakens the next morning, he discovers blood on his clothing just prior to learning the news of his boss's demise, yet Hall, uncannily, has no memory of the past night's events. Meanwhile, the lead detective on the case, McBain (Dennis Haysbert) has already identified Hall as a suspect, largely because Hall is named the sole beneficiary of Fuller's two billion dollar enterprise. After enduring some initial questioning from McBain, Hall returns home to find his only clue to the "truth," a message from Fuller on his answering machine explaining that Fuller has left Hall a letter in the system, the same letter Fuller gave to the bartender. To solve the mystery, Hall must enter the system, something he has never done before, and become a virtual detective engaged in a classic search for a missing text which holds the answer to the mystery.

As Hall and the resident tech-expert Whitney (Vincent D'Onofrio) on the thirteenth floor project explain to Detective McBain, Fuller's simulation of 1937 Los Angeles is essentially selfsustaining — as long as no one pulls the plug — meaning this virtual world functions with or without a user; the simulated characters, or units, carry on with their lives even when Fuller is not inside the system. Fuller, Hall, Whitney, or any other user is assigned one of these units, virtual replicas, to "enter" when jacked into the system. Hall's remaining search involves virtual trips back and forth between the 1999 and 1937 Los Angeles, where he meets Fuller's unit, who has been suffering from bouts of amnesia that correspond to Fuller's visits. After a bit of detective work, Hall does cross paths with the bartender Ashton (Whitney's unit) who has opened Fuller's letter and discovered the truth that had so alarmed Fuller in the first place. While, in classic detective story fashion, Hall never does see the letter, during a physical confrontation with an infuriated Ashton, who attempts to kill him, Ashton relays its basic contents. According to Ashton, the letter instructed the reader simply to keep driving. 
As Ashton explains, heeding this message, he drove out of the city and into the desert, only to find that at the point where he should have reached the next city, he had shockingly come to the end of the world, in fact the end of the simulation, beyond which lies only a computerized grid.

The contents of Fuller's letter remain puzzling, however, because it makes no sense for him to leave Hall, the intended addressee, such a message since Hall already knows that Ashton's world is a simulation. While Hall ponders the reasoning behind the letter, another character enters the scene, in the 1999 world, who claims to be Jane Fuller (Gretchen Mol), Hannon Fuller's daughter, and quickly becomes Hall's love interest. Despite the fact that no one else knew that Fuller even had a daughter, she claims both that she is the rightful owner of her father's company and that her father's wishes were that the project be shut down. Later, McBain, who tells Hall, discovers there is no such person as Jane Fuller, which leaves them both with a new mystery whose solution may hold the answer to who killed Fuller. Through a bit of detective work, Hall tracks down the woman who claimed to be Jane Fuller, a Natasha Millinano who works in a supermarket and claims to have no memory of Hall, but does admit to suffering from recent amnesia attacks, much like Fuller's unit, a fact that gives Hall the clue he needs to decipher Fuller's message. The letter did not mean for Hall to "keep driving" inside the 1937 simulation, but rather in the world of 1999 Los Angeles. Hall, then, takes the same drive as did Ashton and, in a moment not unlike that in which Murdoch breaks through the walls of his world, discovers that his own world is a simulation as well (though, ever the strong, silent type, Hall does not appear as unnerved by this as we might expect). Thus, while the detective is successful in following the trail of clues, doing so does not restore the world but rather leads to the dissolution of its very foundation.

Of course, there is still the question of who killed Fuller, the answer to which is eventually 
provided by Jane Fuller, who explains that while Hall did in fact commit the murder, Hall is not actually responsible since he himself is merely a unit inside a simulation. The "real killer" is, in fact, Jane Fuller's husband who has resorted to using the simulation to act on his murderous desires. Jane Fuller, who has presumably jacked in from the "real world," explains further that there are actually thousands of simulations, but that this is the only case in which the units have produced a simulation within a simulation, which she has been sent to shut down. As we might expect, Jane Fuller has in the process fallen in love with Hall, who she says reminds her of what her husband used to be. The problem, of course, is that they belong to two different worlds and while she can cross into his world he cannot, one would expect, make the ontological leap into the real world from which she comes. The film, however, does not leave Hall to deal with the horrors of discovering that he is merely a simulation, at least not for long. Rather, Jane Fuller discovers that if a unit is killed in the virtual world while being inhabited by its user, an ontological breach occurs such that the unit, not the user, returns to the "real world." Suspecting that her husband may now want to kill her, she, therefore, calls McBain just before she knows her husband will be jacking in to the system, setting up a series of events that end with McBain, who has himself discovered the "truth," shooting Hall—or Jane Fuller's husband—which allows the virtual Hall to be transported to Jane Fuller's world. The film ends, not unlike Dark City, with Jane and Douglas united in the "real world," looking out over the ocean of a futuristic 2024 Los Angeles. Like Dark City, then, The Thirteenth Floor questions reality, in the end only to offer yet another Hollywood answer. But, as with Dark City, we sense that the film questions more than it resolves, for along the way to its efforts at closure, The Thirteenth Floor exposes the underlying assumptions, or representations of space, upon which virtual realities have been constructed and, by 
extension, reveals certain spatial contradictions or dilemmas that even after the introduction of virtual reality continue to haunt capitalism.

\section{Contingent (cyber) Existence}

In light of The Thirteenth Floor, it strikes me that cyberspace offers possibly the most fitting spatial representation for the very existential quandaries that the metaphysical detective story evokes. If metaphysical detective fiction implicates "contingent existence" as the real crime/criminal, then we might read cyberspace, as portrayed in this film, as a material, allegorical figure, representing the kinds of ontological dilemmas that the metaphysical detective story has been drawing our attention to all along, for what form of existence is more "contingent" than that of a cyber-existence? The moment at which Hall discovers the edge of the grid stands in, then, for that moment at which the metaphysical detective faces the fact that he can neither fully know nor rationally control the inner workings of the universe as he had presumed. Cyberspace works particularly well as a symbol of the kinds of ontological uncertainties that have come to the forefront in the postmodern moment because it has such a clear, metonymic relationship to late capitalism, which, as Jameson observes, is characterized by the consumption of images. While cyberspace, obviously, is all image, in the film Hall finds that the image has passed itself off as a material reality; the bewildering moment for the detective arrives when, gazing into uninhabitable grid (a figure of the unknown, the unrepresentable, or the postmodern sublime), he must come to terms with the fact that his social reality is comprised entirely of images, of a surface lacking depth, leaving him, or the postmodern subject, unable to map his present position within either history or space. Writing before the mass proliferation of cyberspace, Jameson himself offered John Portman's Westin Bonaventure Hotel, which sits in downtown Los Angeles, as a symbol of 
postmodern hyperspace. In his extended analysis of this building, Jameson remarks primarily on his "bewildering" experience within the space of the hotel, which he finds difficult to navigate for a variety of reasons. One of the design characteristics that leads to this bewilderment is the building's "curiously unmarked" exits/entrances, whose seeming absence creates a sense of inescapability. In light of this design peculiarity, Jameson concludes that "the Bonaventure aspires to being a total space, a complete world, a kind of miniature city" (40). Yet, the exits/entrances do in fact exist, meaning the Bonaventure is at one and the same time insulated from while remaining a part of the larger city-space, a trait Jameson reads as a reflection of multinational communicational networks of late capitalism, within which we find ourselves both cut-off from (isolated) and fully networked (integrated) into the system. I would suggest that cyberspace exemplifies this dilemma even more perfectly. Clearly, the virtual world Hall inhabits "aspires to be total"; exiting this space is much trickier than exiting the Bonaventure, but, of course, like all of cyberspace, it is simultaneously networked to different worlds, both real and simulated; the catch for Hall here is that it is not clear how one is to move beyond the grid, which it turns out is possible but only through unimaginable modes of travel. Thus, in a more concentrated and recognizable fashion even than postmodern architecture, cyberspace in The Thirteenth Floor acts as a “symbol and analogon" of even the detective's, or master logician's inability to navigate the overwhelming networks that comprise late capitalism.

While Hall's confrontation with the ends of his virtual world would appear to be pertinent only to those existing in the age of advanced technology, it is worth noting that his discovery actually has a good deal of relevance for a long line of urban detectives. One of the predominant features of such detectives as Chandler's Marlowe is that they are so completely integrated into the space of the city, 
which is represented as an almost hermetically sealed environment, as if the organizational logic of the modernist city had in fact become total. For all intents and purposes, Marlowe's world is Los Angeles and Los Angeles only. With this in mind, it is my sense that in much the same way as Auster's metafiction literalizes the detective's lack of existence outside the case, Hall's discovery that his world is strictly limited to the (virtual) city makes material the urban detective's spatial condition all along, that of being locked inside an urban environment that imagines itself to be total. By allowing Hall to confront the ends of his world, the film implies that the state of the very figure who patrolled the rationalized modernist city always in fact existed in something like a spatial impossibility which can no longer be sustained. The detective's existence (space), as it turns out, was always contingent.

\section{The Production of Cyberspace}

While cyberspace certainly reflects, or offers a metonymic vision of the larger cultural logic of late capitalism, its dramatization in The Thirteenth Floor suggests that cyberspace also acts as a formative agent within late capitalism, returning us to Brande's suggestion that cyberspace is, in fact, one form taken by the "ideological fantasy" that constitutes advanced capitalism. If this is so, it is primarily because cyberspace allows us to imagine the kind of limitless space that capitalism ultimately demands. Tellingly, when questioned by McBain about Fuller's cyber project, Hall suggests that "Fuller was onto a whole new frontier." Hall's choice of words suggests a link between the virtual space produced by Fuller's simulator and the formerly open space of the western frontier that has played such a crucial role in America's collective consciousness as well as in the spatial fantasy through which capitalism is perpetuated. As Harvey notes, "If continual geographical expansion were a real possibility, there would be a relatively permanent solution to the over-accumulation problem" (183). 
Conversely, the survival of capitalism is guaranteed only so long as there remains the possibility of more space(s) that might be dominated, cultivated, or appropriated. This explains the need for an always-asyet-unchartered territory, represented as "raw nature," to exist outside the urban industrial or technoeconomic center. While at one time the "old frontier" appeared as if it could fulfill this role indefinitely, could underpin the ideological fantasy that capitalism would advance without limitation, the realities of finite geographical and ecological resources have seriously jeopardized the capitalist dream of limitless "natural environments" that would support endless expansion. Fuller offers a "new frontier" then because the old frontier has gone missing, causing a spatial dilemma that The Thirteenth Floor dramatizes most strikingly in its representation of the "real" (future) world in 2024 Los Angeles. In the final scene, we catch one of the few glimpses in the film of a space that extends beyond the city when Hall and Jane Fuller gaze out to sea from the California coast. What is striking about this futuristic world is that there are now high-rise buildings jutting up out of the ocean, meaning the formerly "natural" or "extra-urban" space of the sea has been encroached upon by the expanding city-scape.

Given that this future culture (which is not all that futuristic) has found it necessary to seek new spaces ripe for appropriation, it makes perfect sense that it would also employ computer technology in the creation of thousands of virtual worlds, yet another spatial fix. In response to the spatial crisis that has already necessitated looking beyond conventional geographical limitations or beyond what the physical land can hold, along comes the "new frontier" in the form of thousands of virtual worlds that, represented as having no limit, appear to be the ultimate "spatial fix." In effect, cyberspace provides the stage upon which the subject can once again imagine that space will no longer present an economic, or even a metaphysical deterrent. As Robert Markley suggests, 
The fiction of cyberspace is useful precisely to the extent that it allows its proponents to imagine an androcentric reality in which a threatening, messy, or recalcitrant (and invariably feminized) nature never intrudes. In this respect, cyberspace is consensual primarily in its insistence that technologically mediated experience can transcend the ecological and economic constraints that have shaped and continue to shape human culture. It offers the fantasy that the more technologically sophisticated our society becomes the less it has to worry about the distribution of wealth and resources. (4)

Just as new modes of transportation have sped-up the circulation of things and objects through the circuits of exchange, cyberspace expands these networks of exchange, but seemingly without doing further ecological damage or taking up more space. To extend this argument to The Thirteenth Floor, or L.A. 2024, there is little need to worry about the possible ecological damage done by extending the city into the ocean so long as another world that is supposedly free from such encroachments exists in cyberspace. Thus, while the increasing loss of this-world space supplies the impetus for the creation of thousands of simulated worlds, in turn those virtual spaces mask the ecological and geographical consequences of market expansion. Rather than feeling the pressures of the increasing scarcity of space, the inhabitants of this world are allowed to enter a cyber-fantasy, or reenter a re-circulated fantasy of an endless "frontier," which in turn constructs for them a new "social reality" in which there are, in effect, no spatial dilemmas, or to put this in terms of the detective story, no crimes to solve. Interestingly enough, the loss of beach front that we witness in 2024 - or the loss of the "quality" space of which Murdoch dreams_-suggests that cyberspace has in some sense taken the place of the resort town in that cyberspace, even more so than the resort, promises the subject the 
possibility of escaping his or her present spatial condition. Cyberspace promises more than just quantity; it promises quality as well. As Lefebvre suggests, "desire" ultimately seeks "a space where it has full play: a beach, a place of festivity, the space of the dream" (353), or better yet cyberspace, which offers the possibility of "full play" as never before. In fact, one of Hall's discoveries in his search for Fuller's message is that Fuller was using the simulator as a sexual playground, spending much of his time with showgirls or prostitutes. Furthermore, Jane Fuller's husband David uses the simulator as a playground for killing, a space in which the libido can run wild without social consequence or constraint. While both uses of cyberspace are demonized or at least stigmatized in the film, it nonetheless recognizes that cyberspace provides the very space for which desire calls. This is, of course, what makes cyberspace so attractive to both the consumer and the marketer of products. As Markley contends, "Cyberspace is the ultimate capitalist fantasy because it promises to exploit our own desires as the inexhaustible material of consumption," transforming the self into a "thoroughly efficient desiring machine" (74). In cyberspace even the limitations of the body, or what William Gibson terms the "meat," can seemingly be transcended, freeing desire to consume without limit. Represented as both an infinite space free from the geographical and ecological constraints of "real space" as well as a space inside which desire has full play, cyberspace offers the medium or "ideological fantasy" through which techno-capitalism can perpetuate its promises of endless market expansion.

One of the interesting aspects of the film, in fact, is its representation of cyberspace as intimately affiliated with the corporation. While cyberspace, particularly in its nascent stage, has been imagined as a space outside the grasp of multinational capitalism—a notion that went out the window with the introduction of seemingly endless advertisements on the web-The Thirteenth Floor makes a fairly 
clear connection between virtual reality and the corporate world. The simulated world created in 2024 produces or reproduces a world in which the urban fabric appears to revolve around the logic of the corporation, so much so that it has even taken the place of the conventional home. In another example of the eroding barriers that once demarcated spaces of enclosure-as well as another variation on the detective figure whose office acts as his home- - Hall lives in the same building that houses his corporate office; his home and office are literally the same space. The simulator designed by those in 2024 does not so much free cyberspace from the grasp of multinational capitalism as tightens its grip; inside this simulated reality seemingly all spaces are colonized by late capitalism. For those in 2024, then, cyberspace provides the medium through which the ideological fantasy can perpetuate itself in order to construct a social reality in which the transnational corporation continues toward the colonization of all space. But what if the locus— i.e., cyberspace—of that ideological fantasy were shattered, so that even the detective cannot put it back together? Ultimately, this is the question with which The Thirteenth Floor presents us.

\section{New Fix Same as the Old Fix}

Like other metaphysical detectives, Hall does not so much solve a crime—in fact, no crime has actually been committed since the murdered Fuller is not even a "real" person—as he discovers to his dismay that neither he nor the world he inhabits are what they appear to be. The "truth," or better yet the "crime" here is that there is an end to his world, or to cyberspace, at least at the point at which Ashton and Hall confront the edge of the simulator. And while there remains the possibility of extending this simulated reality, expanding its limits to the point that no user/unit would ever experience such a horrifying moment, Hall's confrontation with the end of his world, which he previously could not even 
imagine, reintroduces, even if only momentarily, the very spatial problem virtual reality is said to resolve, leaving capitalism to confront its greatest fears, that lacking a space inside which it might expand it will wither and die. Here that fear is realized; for Hall, there is an end to space, which means an end to the resources at his disposal. Hall's discovery not only reminds us of the geographical reality that cyberspace works to mask, but if cyberspace is indeed the form of the ideological fantasy through which we construct social reality in "our world," then Hall's discovery both dissolves his own social reality and has the potential to dissolve ours as well. Thus, in ending his own "non-knowledge," a nonknowledge which is obviously required to sustain Hall's social reality, he, in effect, exposes the point at which our own ideological fantasy remains vulnerable.

Like Dark City, however, The Thirteenth Floor muffles much of the impact of Hall's terrifying insight. Providing its own spatial fix, the film does not leave Hall to cope with the knowledge that his world has limitations; rather the film transports Hall, and the viewer, to another world, L.A. 2024, which, we assume, has the distinct advantage of not terminating at the edge of the city. And as a bonus, from his new home space Hall can visit thousands of virtual worlds, not to mention the fact that in this world Hall is now at last "real." In this respect, the film restores the very fiction it calls into question. While Auster's detective remains trapped inside a case that does not exist, or is itself a fiction, here the detective is not only provided a way out of the case he cannot solve, but is afforded the opportunity to act as if the existential dilemmas with which he once grappled had little or no impact on the "real" world he now inhabits. Yet, while on one hand the final scene appears to repair any damage done to the spatial fantasy of late capitalism, on the other hand the same scene simultaneously points to another crack in the fiction that is perpetuated by cyberspace. I am referring here to the notion that the 
production of virtual reality comes at little or no ecological cost. As I pointed out previously, the film's depiction of L.A. 2024 indicates not that cyberspace has solved the problem of a scarcity of space but rather that the problem not only still exists but has been further aggravated, as evidenced by the expansion of the city out over the ocean. We might even argue that the development of thousands of simulated worlds not only does not stop the progressive exhaustion of natural resources, but that it ultimately demands such activity. As Markley points out, "access to the presumptive world behind the screen carries with it an effaced history of labor, of people building machines to design and to build even more sophisticated hardware and software. The imaginary realm of cyberspace —of the reproduction and satisfaction of endless desire — is a fantasy based on the denial of ecology and labor" (77). The increasing scarcity of resources or spaces for expansion and the development of virtual realities have entered into a vicious cycle whereby simulated spaces require computers that require industry and labor that have an ecological impact, which in turn is masked by the development of infinitely expandable simulated spaces. Still, as the final scene of the film suggests, the problem that cyberspace promises to erase remains in plain view.

\section{This Is Not My World (Is It?)}

As we all know, one of the appeals of cyberspace is that its world as well as the experiences the user has inside that world appear of little consequence in the "real" world. If a given virtual world is unsatisfactory, we can choose either to shut it down, Jane Fuller's solution, or we can simply not jack in. Hall, for instance, is far from disturbed by Ashton's confrontation with the ends of space in the 1937 virtual world because Hall already knows that the simulation has limits and he sees those limits as belonging exclusively to that world. So while Hall empathizes with Ashton's disillusionment, he does 
not experience that same disillusionment regarding his own world. However, when Hall discovers that his world is no different than Ashton's, he can no longer ignore the implications and is forced to question the ideological fantasy that has structured his life. The key here is that he begins to rethink the self and his world only after the "dream" that structures his "real" social experience is dissolved. In this respect, Hall's experience with Ashton and Ashton's cyber world mirrors the audience's experience of Hall and Hall's world; his discovery may cause us to empathize, but we can easily remind ourselves that he is not "real" (twice over) nor does his world function according to the same logic as our "real" world. This might, in fact, explain why the film fails at times to impact its audience with the kind of existential dread one might expect as a result of discovering that the world is merely a simulation. But just as Ashton's world tells Hall more about his own world than he initially realizes, we should not miss the ways in which Hall and his simulated world mirrors the postmodern subject and our postmodern social space.

While Hall's discovery that he and the space he inhabits are merely computer generated abstractions dramatizes an extreme scenario, even before the onslaught of cyberspace Lefebvre suggested that late-twentieth-century culture was gravitating toward abstraction and the production of "abstract space" (52). Lefebvre explains that abstract space operates according to the "logic of visualization"; within abstract space "all of social life becomes the mere decipherment of messages by the eyes, the mere reading of texts" (286). The abstract space of late capitalism is not only the space inside which the sign reigns, where the image is the object of consumption, but is itself all sign, or all surface. Lefebvre argues that within this space an "extraordinary-indeed unthinkable, impossible — confusion gradually arises between space and surface, with the latter determining a spatial 
abstraction which it endows with a half-imaginary, half-real physical existence. This abstract space eventually becomes the simulacrum of full space ... Traveling —walking or strolling about—becomes an actually experienced, gestural simulation of the formerly urban activity of encounter, of movement amongst concrete existences" (313). This "space offers itself like a mirror to the thinking 'subject', but, after the manner of Lewis Carroll, the 'subject' passes through the looking-glass and becomes a lived abstraction" (313-14). If we take Lefebvre's portrayal as accurate, our social reality begins to look strikingly like Hall's cyber reality. Thus, cyberspace as well as Hall's condition, that of a "lived abstraction," do not represent so much a new reality as an extension of the ongoing production of space in accordance with the inner workings of advanced capitalism and its march toward abstraction. In this respect, cyberspace is merely the latest form taken by an ongoing process that involves multiple sociosymbolic registers. ${ }^{7}$

The film attempts to mitigate much of this by moving Hall up one level to the "real" world, ostensibly restoring him as a clearly Cartesian subject, where it is assumed he may now begin experiencing a more real version of encounter with his world and other humans. In other words, Hall reemerges from the looking glass. The final scene is striking, however, because it has the quality of being so purely visual. In the scene, L.A. 2024 is actually framed by the glass doors which open onto a deck on which Hall now stands visualizing his new "social reality." It is as if we are looking through yet another screen, gazing upon a city that appears even more abstract than the city inside the simulated world Hall has "escaped." While the urban image Hall consumes allows him to sustain his fantasy—the fantasy of the detective— of having located the "real" beneath the ideological facade, the framing of this scene suggests a much more harrowing "truth" revealed by his cyber-investigation, that, as ði⿳亠k 
suggests, the fantasy, or in terms of late capitalism the image, is the reality. In other words, abstract space does not cover for but is the spatial reality of late capitalism. Furthermore, while Hall's entrance into a new (real) space provides a source of optimism, it is important to note that like Murdoch, Hall, although poised on the verge of entering a sunny new world, does not in fact enter it. The movie ends with Hall imagining the urban reality rather than experiencing it, as if the city remains a simulation. Hall has not stripped away the ideological fantasy (has not solved the crime) in order to experience the real, but has instead found a way to continue believing in the (spatial) fantasy that, despite what he knows, once again structures his social (spatial) reality.

In this respect, The Thirteenth Floor indicates that cyberspace does not in the end offer the advance in spatial production or logic with which it is credited. Rather, it reproduces the space of which capitalism has always fantasized. The irony of Fuller's "new frontier" is that it is not new at all (either materially or symbolically) but merely a reproduction of the simulated world he as a unit already, unknowingly inhabits. While one of cyberspace's selling points, in the "real" world, is that it promises to deliver us into an entirely different space that transcends the problems and limitations of this world, as if it operated according to an entirely new logic, Fuller's new frontier is merely a copy of a copy, an abstract concept produced by an abstract concept. What this indicates, as Markley has argued, is that cyberspace does not represent a break from Western metaphysics so much as it offers the latter a new medium in which it might flourish. The epigraph to The Thirteenth Floor is, in fact, Descartes' famous line, "I think, therefore I am," suggesting that cyberspace merely extends the tradition of Western metaphysics, the same Western metaphysics that has produced both the detective figure as well as the rationalized space he inhabits and protects. Cyberspace arises from the same Enlightenment 
/Modernist thinking that prioritized "the conquest and rational ordering of space" as "an integral part of the modernizing project" (Harvey 249). This does not mean that cyberspace corresponds to the same modes of production which characterized earlier historical periods, or that those of us living in the postmodern moment experience space in the same way as did those living during earlier historical periods; as Pynchon's fiction shows, post-World War II culture has seen a significant transition in both the form of capitalism and the production of space. The link between cyberspace and the tradition of Western metaphysics does suggest, however, a common thread that runs through and connects the history of spatial thought and production and the regeneration of capitalism in its various forms. While cyberspace may present a more abstract form than, say, the western plains, the dream of a space that can be mastered both physically and mentally remains the same. It is no coincidence that just when the perception of space as an object subject to rational control begins to appear less viable, cyberspace arrives on the scene to revive that dream, that is until the detective, the thinking subject par excellence, discovers that cyberspace has its limitations as well. The Thirteenth Floor and Dark City indicate that if anything technology only exacerbates the problem by providing a vehicle through which the subject can once again imagine, possibly more vividly than ever, that space can be produced according to human desire, as if "advanced" technology will allow us all to circumvent or transcend the limitations of the now darkened city and enter the kind of utopian space of which the Enlightenment could only dream. What remains with us from these two films, however, is not so much the sunny utopias with which they end, but rather those "darker" moments when Hall and Murdoch reach the end of the world, or the metaphysical grid to expose the crime that metaphysical detective fiction has been calling our attention to all along, the crime of contingent (spatial) existence. 


\section{NOTES}

1. As much as the metaphysical detective novels break ontological, spatial, and temporal barriers, for the most part the books I have addressed predate cyberspace. These two films are useful, then, in that they allow us to talk about recent technological "advances," which have been purported to have fundamentally altered perception of space.

2. In fact, fiction writers such as Pynchon and Fowles have incorporated science-fiction into their works, just as they use the historical past, in such a way as to illustrate this very point.

3. Jameson suggests that subjects who experience postmodern hyperspace cannot perform cognitive mapping because they "have not kept pace with that evolution [of space]" and, therefore, "do not yet possess the perceptual equipment to match this new hyperspace" (38). In this respect postmodern hyperspace "stands as something like an imperative to grow new organs, to expand our sensorium and our body to some new, yet unimaginable, perhaps ultimately impossible, dimensions" (39). Interestingly enough, Murdoch is able to cognitively map his position, if indeed he does learn to do this successfully, only after experiencing just such an evolution, only after expanding his sensorium to the point of being able to perform the unimaginable.

4. This returns us to Harvey's discussion of capitalism's ongoing need for a "spatial fix," which I discuss in greater detail in Chapter 4.

5. There is an interesting connection here with Derrida's discussion of the message that never arrives in The Postcard. While in Derrida's case the postcard symbolizes the adestination of the message, here it represents the adestination of the subject himself, or a more clearly spatial version of Derrida's theories of writing.

6. It is worth noting that The Thirteenth Floor offers no new insights either into virtual reality, or its role within late capitalism, that were not already present, and probably more effectively conveyed, in Gibson's novel of more than ten years, Neuromancer. The Thirteenth Floor, however, fits more obviously into my overall project and its concentration on the detective story, and while the film may never spark the same discussion that was created by Gibson's novel, it, nonetheless, provides an interesting springboard for a discussion of cyberspace and its function within our culture.

7. For further discussion of this progression toward abstraction under capitalism within the economic and subjective registers, see Jean-Joseph Goux's Symbolic Economies after Marx and Freud. 


\section{Conclusion}

In my introduction, I stated that my project here is twofold: to extend the spatial analysis of detective fiction down to its postmodern version and in the process to illustrate the ways in which metaphysical detective fiction writes, or re-writes the history of Western spatial production. The examples of metaphysical detective fiction that I have provided, as well as the theoretical accounts with which I have placed them in dialogue, indicate that social space indeed has a history—a history in which the detective figure, and the cultural logic he embodies, has played a leading role—and that its production is intricately connected to other areas of cultural production: intellectual, aesthetic, political, economic, technological, etc ... By appropriating the detective figure, these works of metaphysical detection suggest that to apprehend the forms that these cultural products have taken over time, we must return to the very age in which the classic detective is born, that is, to the cultural and spatial logic of the Enlightenment. While Pynchon and such theorists as Deleuze indicate that postmodern space reflects a transition both in the form of its own production as well as in techno-economic modes of production, such spatial historiographies, along with those of Acker and Reed, also indicate that postmodern hyperspace does not so much represent a leap in spatial logic as it provides a response (whether an extension or a counter) to an entire history of spatial production. Significantly, according to de Certeau, this history of spatial production is inexorably tied to the production of knowledge (power) that the classic detective reenforces.

Although these examples of metaphysical detective fiction certainly suggest that we think in terms of a "history" of space, this does not mean that they precipitate a teleologically driven narrative of the advancement of spatial production from the Enlightenment, to modernism, to postmodernism. In fact, these works provide a self-consciously spatialized version of history that collapses what were once 
thought of as distinct eras and the cultural forms supposedly unique to them. Space may have a history, but this history does not unfold in a straight line. For instance, while the works of Pynchon and Acker suggest that postmodern space results from certain changes in cultural production occurring over time, their collapsing of temporal boundaries indicates that postmodern space does not mark some absolute transcendence of Enlightenment or modernist spatial forms or logic. However ineffective, the detective remains on the scene, so to speak, as does his impulse toward totalized, rationally organized spaces. While the metaphysical detective fails - discovering within the abstract space of multinational capitalism that his existence is in fact (spatially) contingent—-the metaphysical detective story suggests, nonetheless, that his empirically driven efforts to control space continue to haunt postmodern culture. Cyberspace, for example, as I show in my analysis of The Thirteenth Floor, both adds to our disorientation within the informational or communicational networks of late capitalism and simultaneously offers a new form through which the dream of organizing space is revived. This means that the same intellectual and economic forces that imagined and produced the modernist city continue to impact the production of space; the repressed continues to return. If, then, postmodern culture is dominated by categories of space, as Jameson contends, this is so not only because of the increasingly abstract, mediated spatial forms that we encounter daily but also because those forms so clearly conflict with this recurring rationalist logic which has in effect led to their production. It is as if the attempts to extend the totalizing impulse of both science and capitalism to "new" spaces has somehow outgrown the very rationalist logic that justified the production of such spaces in the first place. The globalization of late capitalism has, ironically, meant the erasure of the very cartographic boundaries that the Enlightenment once instituted to establish the notion of control over the world, the same spatial ideology 
that capitalism has formerly exploited to ensure its own growth. The mixture of increasing abstraction and the residual impulse toward striation has left us, as Lefebvre notes, with a contradictory space that is both fragmented and homogenous at one and the same time. Our dilemma arises not from only our incapacity to navigate the technological networks that arrive during the late twentieth century, but also our inability to situate these recent modes of production within the Western history of space which has long imagined, detective-style, that all space can be rationally organized.

The compression of historical modes of (spatial) production within the metaphysical detective story, points, then, not only to a crisis in historicity but a spatial crisis as well in which the Western impulse to rationalize all space has failed to master the very spaces it has produced or that have been constructed to counter this tradition. (Either way, we are still contending with the detective.) As I have noted, the surfacing of such conflicts does not, however, mean that capitalism faces its own immanent demise. Rather, as ði@̀k explains, such "contradiction” is actually "contained in its very concept" (52). Again, "The "normal' state of capitalism is the permanent revolutionizing of its own conditions of existence: from the very beginning capitalism 'putrifies', it is branded by a crippling contradiction, discord, by an immanent want of balance: this is exactly why it changes, develops incessantly_incessant development is the only way for it to resolve again and again, ... its own fundamental constitutive imbalance, "contradiction"” (52). My readings of metaphysical detective fiction add to JiQ̀k's insight by indicating that under late capitalism the "constitutive imbalance" has become overtly spatial in nature. This is not to say that capitalism has not always required a "spatial fix," but, rather, that, since World War II, its need for such a fix moves to the forefront, as is indicated by the increasing investment in virtual technology, which has in many respects extended the function of the 
detective through its ability to conduct surveillance and subsequently dominate all space. It is as if, in effect, the male thinking subject has been replaced, through a technological fantasy, by some kind of cyborg thinking subject (still encoded male) or super detective, imagined once again to be capable of maintaining the perspectiveless position of knowledge that the metaphysical detective finds so impossible to attain.

As Pynchon's work indicates, and films such as The Thirteenth Floor corroborate, while technological "advances" and global expansion have extended the reign of late capitalism, they have led simultaneously to the further abstraction of space and subjectivity, leaving the detective in a world he can no longer so easily imagine he can know or control, a world where he must concede that existence is indeed (spatially) contingent. This might have the appearance of fatalism, of yet another dystopian view of postmodern culture, but the fiction of Reed and Acker in particular suggests that this might not in fact be the case. While metaphysical detective fiction is known for its evocation of that moment of existential dread, Acker and Reed locate in the failures of a former regime the possibility for the production of new, less restrictive identities and spaces (new combinations) or in Auster's sense, new fictions. This does not mean that like Murdoch in Dark City, they imagine that we might create utopian spaces that offer a fix to all our socio-economic dilemmas, but, rather, that out of the "passages" and "combinations" formed between the mixture of striated and smooth space, a space might arise that would be somehow less repressive — in terms of race, class, and gender — than that neatly organized space produced under the watchful eye of the classic detective. This indicates not only that space does not behave as the ideological fantasy of the Enlightenment would have imagined, but also that space continues to be produced through those ruptures, the contested points that lie in the conflict 
between emerging modes of production and residual spatial imaginings. It is at such contested points, or crossroads, that the metaphysical detective finds himself, embodying both the classic detective's impulse to solve as well as the recognition that the space he now encounters refuses to submit to such ideological dreams of conquest and order. His story, along with our tale of spatial production, ends, then, not with resolution nor an absolute conclusion, but with the proliferation of yet more mystery, for unlike his predecessor, the metaphysical detective remains inside the case, inside a space that refuses to be fixed. 


\section{Works Cited}

Acker, Kathy. The Adult Life of Toulouse Lautrec by Henri Toulouse Lautrec. 1975. Rpt. in Portrait of an Eye: Three Novels. New York: Grove Press, 1998.

Ackroyd, Peter. Hawksmoor. London: Hamish Hamilton, 1985.

Alford, Steven. "Spaced-Out: Signification and Space in Paul Auster's The New York Trilogy." Contemporary Literature. 36 (1995): 613-32.

Auster, Paul. The New York Trilogy. [1985, 1986, 1986.] New York: Penguin, 1990.

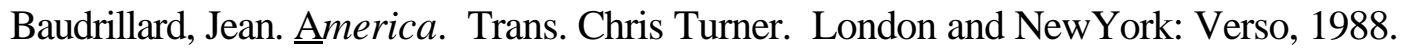

Benjamin, Walter. The Arcades Project. Trans. Howard Eiland and Kevin McLaughlin. Cambridge, MA and London: Belknap, 1999.

Berman, Marshall. All that is Solid Melts into Air: The Experience of Modernity. New York: Simon and Schuster, 1982.

Bernstein, Stephen. “'The Question is the Story itself': Postmodernism and Intertextuality in Auster's New York Trilogy. Merivale and Sweeney. 134-153.

Bryant, Paula. "Discussing the Untellable: Don DeLillo's The Names. Critique. 29 (1987): 16-29.

Brande, David. "The Business of Cyberpunk: Symbolic Economy and Ideology in William Gibson. Virtual Realities and Their Discontents. Ed. Robert Markley. Baltimore and London: Johns Hopkins UP, 1996. 79-106.

Buck-Morss, Susan. The Dialectics of Seeing: Walter Benjamin and the Arcades Project. Cambridge, Mass.: MIT Press, 1989.

Carter, Steven R. "Ishmael Reed's Neo-HooDoo Detection.” Dimensions of Detective Fiction. Ed. 
Larry Landrum, et al. Bowling Green: Popular, 1976. 265-74.

Caillois, Roger. "The Detective Novel as Game." The Poetics of Murder: Detective Fiction and Literary Theory. Eds. Glenn W. Most and William W. Stowe. New York: Harcourt, 1983. $1-12$.

De Certeau, Michel. The Practice of Everyday Life. Trans. Steven Rendall. Berkely: U of California P, 1988.

Deleuze, Gilles. "Postscript on The Societies of Control." Rethinking Architecture: a Reader in Cultural Theory. Ed. Neil Leach. New York: Routledge, 1997.

--- and Felix Guattari. A Thousand Plateaus: Capitalism and Schizophrenia. Trans. Massumi, Brian. Minneapolis: U of Minnesota P, 1987.

Fox, Robert Elliot. "Blacking the Zero: Toward a Semiotics of Neo-Hoodoo." The Critical Response to Ishmael Reed. Ed. Bruce Allen Dick. Westport CT and London: Greenwood, 1999. 46-58.

Gates, Henry Louis, Jr. The Signifying Monkey: A Theory of African American Literary Criticism. New York: Oxford UP, 1988.

DeLillo, Don. The Names. New York: Vintage, 1982.

Deren, Maya. Divine Horseman: The Living Gods of Haiti. London : Thames and Hudson, 1953.

Derrida, Jacques. The Postcard: From Socrates to Freud and Beyond. Trans. Alan Bass. Chicago and London: U of Chicago P, 1987.

Eco, Umberto. The Name of the Rose. Trans. William Weaver. New York: Harcourt, 1980.

---. Postscript to The Name of the Rose. Trans. William Weaver. New York: Harcourt, 1983. 
---. Semiotics and the Philosophy of Language. Bloomington: Indiana UP, 1984.

Eliade, Mircea. Yoga: Immortality and Freedom. Princeton, NJ: Princeton UP, 1970.

Foucault, Michel. “Of Other Spaces.” Diacritics. 16 (1986), 22-27.

---. Power/Knowledge: Select Interviews and Other Writings 1972-1977. Ed. Colin Gordon; trans. Colin Gordon, et al. New York: Pantheon, 1980.

Fowles, John. A Maggot. New York: Plume, 1985.

Frey, Julia. Toulouse- Lautrec: A Life. New York: Viking, 1994.

Genocchio, Benjamin Genocchio’s “Discourse, Discontinuity, Difference: The Question of 'Other' Spaces.” Postmodern Cities and Spaces. Eds. Sophie Watson and Kathy Gibson. Cambridge, Mass.: Blackwell, 1995. 35-46.

Goux, Jean-Joseph. Symbolic Economies after Marx and Freud. Ithaca, N.Y.: Cornell UP, 1990. Gregory, Derek. Geographical Imaginations. Cambridge, Mass.: Blackwell, 1994.

Grosz, Elizabeth. "Woman, Chora, Dwelling." Postmodern Cities and Spaces. Eds. Sophie Watson and Kathy Gibson. Cambridge, Mass.: Blackwell, 1995. 47-58.

Harvey, David. The Condition of Postmodernity: An Enquiry into the Origins of Cultural Change. Cambridge, Mass.: Blackwell, 1989.

Holquist, Michael. "Whodunit and Other Questions: Metaphysical Detective Stories in Post-War Fiction.” New Literary History. 3 (1971-72): 135-56.

Hurston, Zora Neale. Tell My Horse. New York: Lippincott, 1938.

Hutcheon, Linda. A Poetics of Postmodernism: History, Theory, Fiction. New York and London: Routledge. 1988. 
Hume, Kathryn. "Views from above, Views from Below: The Perspectival Subtext in Gravity's Rainbow." American Literature. 60 (1988): 625-42.

Jameson, Fredric. Postmodernism, or, The Cultural Logic of Late Capitalism. Durham: Duke UP, 1991.

Jarvis, Brian. Postmodern Cartographies: The Geographical Imagination in Contemporary American Culture. New York: St. Martin's, 1998.

Jencks, Charles. What is Post-Modernism? Fourth edition. London: Academy Editions, 1996.

Keesey, Douglas. "The Ideology of Detection in Pynchon and DeLillo." Pynchon Notes. 32-33 (1993): 44-59.

Lechte, John. “(Not) Belonging in Postmodern Space.” Postmodern Cities and Spaces. Eds. Sophie Watson and Kathy Gibson. Cambridge, Mass.: Blackwell, 1995. 99-111.

Lefebvre, Henri. The Production of Space. Trans. Donald Nicholsan-Smith. Oxford and Cambridge, Mass: Blackwell, 1991.

Lock, Helen. A Case of Mis-Taken Identity: Detective Undercurrents in Recent African American Fiction. New York: Peter Lang, 1994.

MacCannell, Dean. Empty Meeting Grounds: The Tourist Papers. London and New York: Routledge, 1992.

---. The Tourist: A New Theory of the Leisure Class. New York: Schocken, 1976.

Maltby, Paul. “The Romantic Metaphysics of Don DeLillo.” Contemporary Literature. 37 (1996): $258-277$.

Markley, Robert. "Boundaries: Mathematics, Alienation, and the Metaphysics of Cyberspace." 
Virtual Realities and Their Discontents. Ed. Robert Markley. Baltimore and London: Johns Hopkins UP, 1996. 55-77.

Massey, Doreen. Space, Place, and Gender. Minneapolis: U of Minnesota P, 1994.

McElroy, Joseph. Lookout Cartridge. New York: Knopf, 1974.

McGee, Patrick. Ishmael Reed and the Ends of Race. New York: St. Martin's, 1997.

McHale, Brian. Constructing Postmodernism. London: Routledge, 1992.

Merivale, Patricia and Susan Elizabeth Sweeney, eds. Detecting Texts: The Metaphysical Detective Story from Poe to Postmodernism. Philadelphia: U of Pennsylvania P, 1999.

Noya, José Liste. 'Mapping the 'Unmappable': Inhabiting the Fantastic Interface of Gravity's Rainbow." Studies in the Novel. 29.4 (1997): 512-537.

Pynchon, Thomas. Gravity’s Rainbow. New York: Penguin, 1973.

Reed, Ishmael. Mumbo Jumbo (1972); rpt. New York: Antheneum, 1988.

---. Shrovetide in New Orleans. Garden City: Double Day, 1978.

Relph, Edward. The Placelessness of Place. London: Pion, 1976.

Russell, Alison. "Deconstructing The New York Trilogy: Paul Auster's Anti-Detective Fiction." Critique. 31.2 (1990): 71-84.

Shadle, Mark. “A Bird's Eye View: Ishmael Reed's Unsettling of the Score by Munching and Mooching on the Mumbo Jumbo Work of History." The Critical Response to Ishmael Reed. Ed. Bruce Allen Dick. Westport CT and London: Greenwood, 1999.

Soja, Edward. Postmodern Geographies: The Reassertion of Space in Critical Social Theory. London: Verso, 1989. 
Spanos, William V. "The Detective and the Boundary: Some Notes on the Postmodern Literary Imagination." Casebook on Existentialism 2. Ed. William V. Spanos. New York:

Crowell, 1976. 163-89.

Stallybrass, Peter and Allon White. The Politics and Poetics of Transgression. Ithaca: Cornell UP, 1986.

Stowe, Harriet Beecher. Uncle Tom's Cabin. A Norton Critical Edition. Ed. Elizabeth Ammons. New York: Norton, 1994.

Swanson, Gillian. “"Drunk with the Glitter': Consuming Spaces and Sexual Geographies.” Postmodern Cities and Spaces. Eds. Sophie Watson and Kathy Gibson. Cambridge, Mass.: Blackwell, 1995. 80-98.

Swope, Richard. “Approaching the Threshold(s) in Postmodern Detective Fiction: Hawthorne's 'Wakefield' and Other Missing Persons.” Critique. 39.3 (1998): 207-227.

Vidler, Anthony. The Architectural Uncanny: Essays in the Modern Unhomely. Cambridge Mass: MIT, 1992.

Willett, Ralph. The Naked City: Urban Crime Fiction in the USA. Manchester, Manchester UP, 1996.

Wilson, Elizabeth. "The Invisible Flâneur." Postmodern Cities and Spaces. Eds. Sophie Watson and Kathy Gibson. Cambridge, Mass.: Blackwell, 1995. 59-79.

Woods, Robin. "'His Appearance is Against Him"': The Emergence of the Detective." Eds. Walker, Ronald, and June M. Frazer, eds. The Cunning Craft: Original Essays on Detective Fiction and Contemporary Literary Theory. Macomb: Southern Illinois UP, 
1990: 15-24.

đi@̀k, Slavoj. The Sublime Object of Ideology. London and New York: Verso, 1989. 